\title{
NBSIR 80-1637
}

\section{HELIUM RESEARCH IN SUPPORT OF SUPERCONDUCTING POWER TRANSHISSION}

\section{ANNUAL REPORT}

October 1978 - September 1979

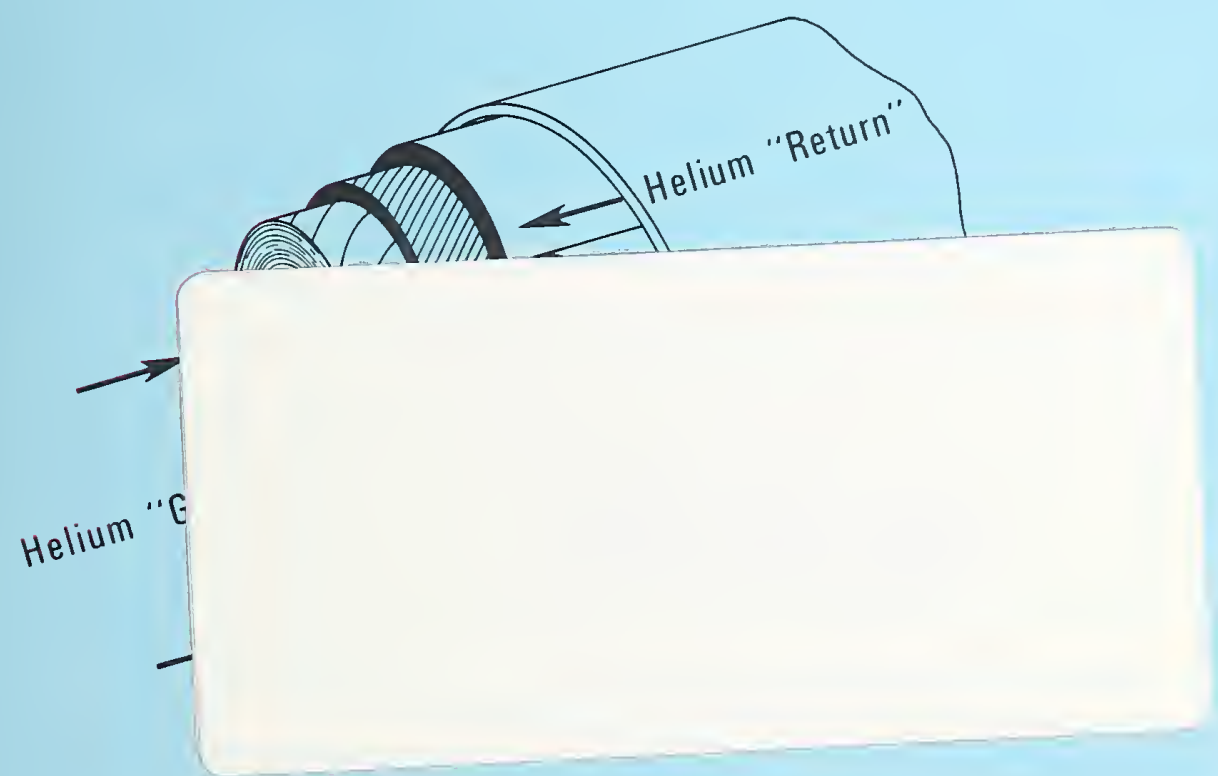

Prepared by

THERMOPHYSICAL PROPERTIES DIVISION NATIONAL BUREAU OF STANDARDS BOULDER, COLORADO 80303
Prepared for

BROOKHAVEN NATIONAL LABORATORY POWER TRANSMISSION PROJECT UPTON, NEW YORK 11973 



\title{
HELIUM RESEARCH IN SUPPORT OF SUPERCONDUCTING POWER TRANSMISSION
}

\section{Annual Report for the Period October 1, 1978 - September 30, 1979}

\author{
Prepared by \\ Thermophysical Properties Division \\ Center for Continuous Process Technology \\ National Bureau of Standards \\ Boulder, Colorado 80303
}

D.E. Daney, Editor

Contract No. 433475-S

\author{
Prepared for \\ Brookhaven National Laboratory \\ Power Transmission Project \\ Upton, New York 11973
}

U.S. DEPARTMENT OF COMMERCE, Philip M. Klutznick, Secretary Jordan J Baruch, Assistant Secretary for Productivity, Technology and Innovation 



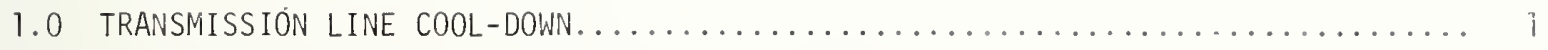

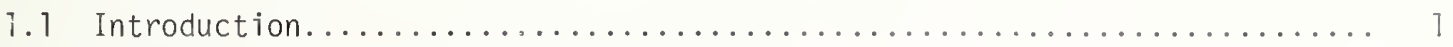

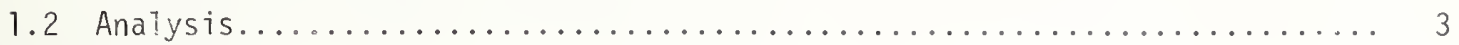

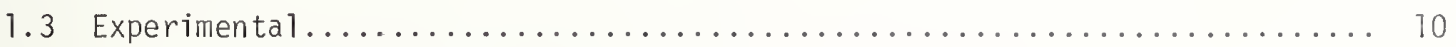

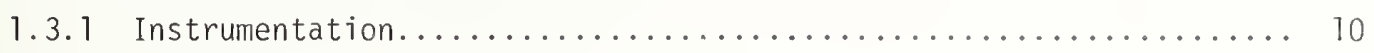

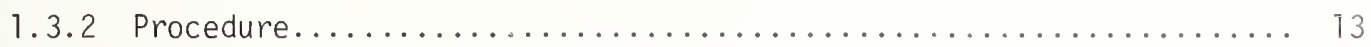

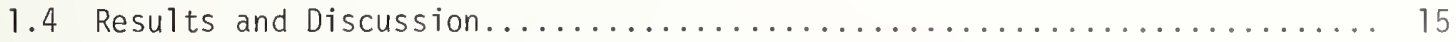

1.5 Detailed Computer Program for the Calculation of Cool-down - Comparison

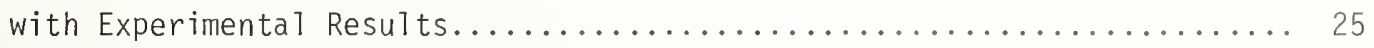

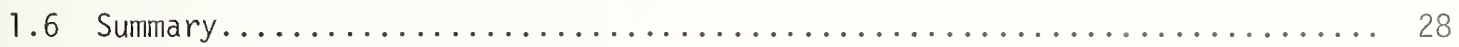

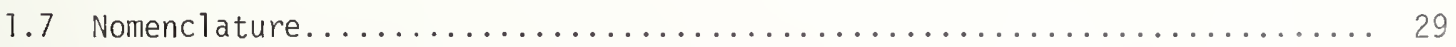

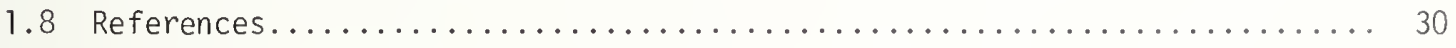

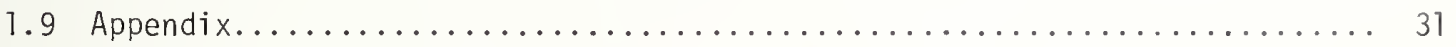

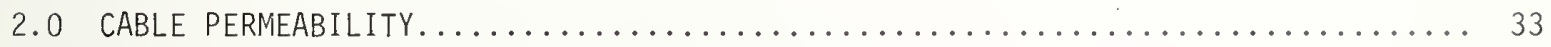

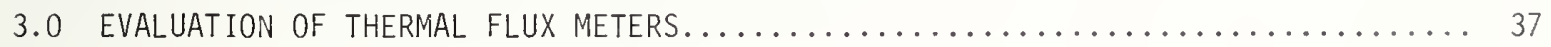

3.1 Introduction. . . . . . . . . . . . . . 37

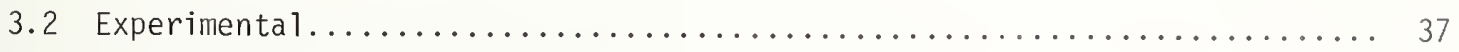

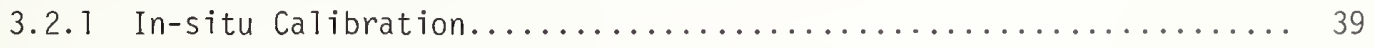

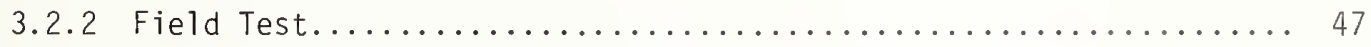


During FY 79, the NBS Thermophysical Properties Division program of research for superconducting power transmission line (SPTL) development focused on three tasks:

1) Analytical, numerical, and experimental modeling of counter-flow SPTL cool-down.

2) Measurement of radial permeability of a SPTL cable to gas flow.

3) Experimental evaluation of thermal flux meters as a possible technique for determining enclosure heat leak.

We have completed the first phase of our investigation of SPTL cool-down in which the aim was to develop a fundamental understanding of the counter-flow method of cool-down. The excellent agreement of our analytical, numerical, and experimental results gives us confidence that we can accurately model the cool-down of full scale SPTL's.

The cable permeability measurements indicate that any significant rupture of the lead gas barrier of the cable will lead to an unacceptably high leak rate from the pressurized core.

Evaluation of thermal flux meters continues, but preliminary results indicate large effects due to seasonal variations in the soil heat flux and percolation water through the soil.

During FY 80 we shall concentrate on developing cool-down strategies for full scale SPTL's using the detailed computer code previously developed at NBS. Field evaluation of thermal flux meters will also continue.

KEY words: Cable cool-down, cable permeability, counter-flow cool-down, heat flux meters, liquid helium, permeability of composites, superconducting power transmission. 


\subsection{TRANSMISSION LINE COOL-DOWN}

(D. E. Daney, P. R. Ludtke and M. C. Jones)

\subsection{Introduction}

The time required to cool down a superconducting (or cryoresistive) power transmission line is critical to the success of these lines since excessive cool-down and warm-up times would result in unacceptably long interruptions of service when repairs are required. For example, Jones [1] has calculated a cool-down time of 20 days for a $15 \mathrm{~km} 1$ ine cooled by a two stream counterflow method (thermally-coupled return). Since the warm-up process is simply the inverse of the cool-down process (at least for the constant property case), a service interruption of six weeks or more could be expected each time internal repair or maintenance is required for a SPTL of this configuration.

If we understand the exact nature of the cool-down process, then we may alter the design or operating conditions to give acceptable cool-down times. For example, one solution to excessive cool-down times is to reduce the length between refrigeration stations since, as we demonstrate in this report, the cool-down time is proportional to the square (constant mass flow rate) or cube (constant pressure drop) of the distance between refrigeration stations for counter flow cooling. As is often the case in engineering designs, the design of the SPTL cooling configuration may be governed by transient rather than steady-state considerations.

Two arrangements have been proposed for cooling cryogenic power transmission lines. The more usual arrangement, Fig. 1b, has the return stream thermally isolated from the go stream (thermally-uncoupled return). Because this method requires an expensive vacuuminsulated return line, Dean and Jensen [2] proposed a system with thermal contact between the go and return streams, Fig. la, (thermally-coupled return) for the Brookhaven National Laboratory (BNL) line. This same general scheme has also been adopted in the Los Alamos Scientific Laboratory (LASL) proposal.

In this latter arrangement supercritical helium flows down the hollow core of the cable, is expanded to a lower pressure (and temperature) at the far end, and then is returned in the space outside the cable within the enclosure. The wrapped dielectric provides weak local thermal contact between go and return streams. Integrated over a length of $10 \mathrm{~km}$ or $15 \mathrm{~km}$, however, this configuration produces a rather good counterflow heat exchanger, $\mathrm{N}_{\mathrm{tu}} \approx 40$.

The cool-down characteristics of these two arrangements are markedly different as indicated in Figure 1. In the case of the thermally-uncoupled return, a cool-down wave propagates along the length of the line, and cool-down is complete when this wave has passed the far end. In contrast, in the thermally-coupled case (counterflow) a cool-down (temperature) wave developes along the whole length of the line, and cool-down is not complete until the amplitude of this wave decays to zero. The rate of decay is proportional to the temperature difference between the go and return streams (i.e., to the rate of refrigeration) which in turn is proportional to the thermal resistance between the go and return streams. 

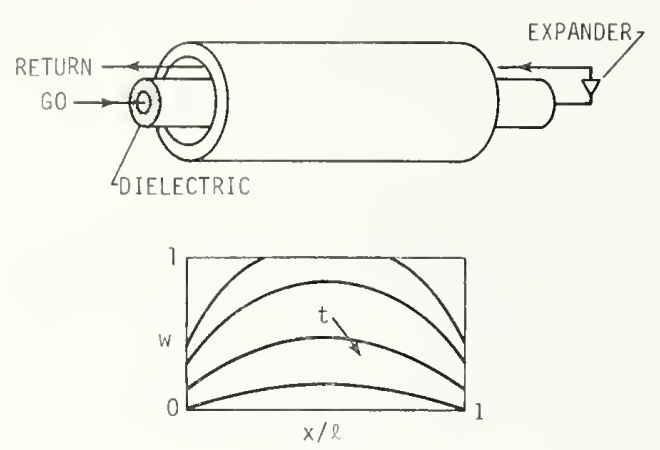

a) Thermal1y-coupled return both ends cooled
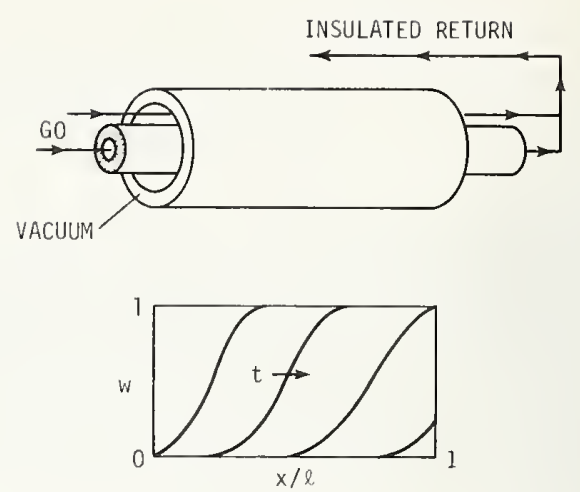

Figure 1.1 Configuration and cool-down characteristics of cooling schemes.

Prior to the proposal of Dean and Jensen [2] for the BNL 1ine, Wilkinson [3], Garwin and Matisoo [4], and Norris and Swift [5] discussed the thermally-coupled return arrangement. Flemming [6], Edney, et al. [7] and Morgan and Jensen [8] analyzed the steady state operating behavior of this arrangement. For constant properties and symmetry in the heat transfer and boundary conditions, a parabolic temperature distribution results. When the thermal contact is good between the go and return helium streams, a large temperature maximum will occur at the midpoint of the line. This occurs because as the thermal contact between streams increases, the net enthalpy flux of coolant across a section of the line decreases. The same phenomena occurs during cool-down, except in this case, the heat load consists primarily of the line heat capacity.

The object of this study has been to investigate the cool-down behavior of superconducting power transmission lines which use the thermally-coupled return arrangement. Our original comnission was for detailed numerical modeling of cool-down of the BNL and LASL lines (reported previously by Jones [1]) followed by experimental modeling of this thermallycoupled return arrangement. We have expanded the scope of our investigation somewhat so the second phase of the work, which is reported here, includes:

1) An approximate analytical solution in terms of dimensionless variables for the constant property, constant mass flow rate case.

2) Numerical solution in terms of dimensionless variables for the constant property, constant mass flow rate case.

3) Experimental study of the thermally-coupled return arrangement for:
a) cool-down to $76 \mathrm{~K}$
b) cool-down to $6 \mathrm{~K}$
c) warm-up from $76 \mathrm{~K}$ and $6 \mathrm{~K}$

4) Detailed numerical modeling of the experiments for experimental confirmation of the computer program developed by Jones for modeling of the BNL and LASL 1ines.

The experimental, analytical, and numerical results agree well, so that we may now predict transmission 1 ine cool-down times with good accuracy. 


\subsection{Analysis}

For analysis of the thermally-coupled return (counterflow) arrangement, we choose the simple, one-dimensional model shown in figure 1.2 .

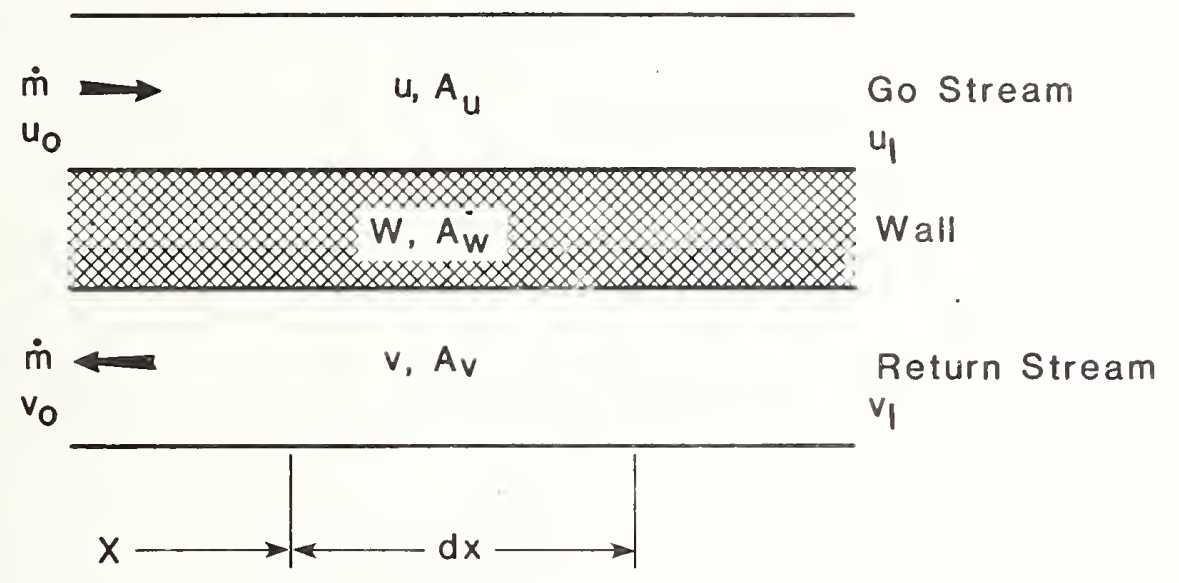

Figure 1.2 simple model of transmission line.

The solid is lumped into a single wall separating the go and return stream, and constant properties and mass flow rate are assumed. The thermal resistance is concentrated at the wall-fluid interface.

The time dependent energy equations for the problem (obtained from the first law and continuity equation in the standard manner and neglecting axial conduction and any time dependence of the pressure) are:

for the go stream

$$
\frac{\partial T_{u}}{\partial t}\left(C_{p} \rho A\right)_{u} d x=-\dot{m} C_{p} \frac{\partial T_{u}}{\partial x} d x-(h P)_{u} d x\left(T_{u}-T_{w}\right)
$$

for the return stream

$$
\frac{\partial T_{v}}{\partial t}\left(C_{p} \rho A\right)_{v} d x=\dot{m} C_{p} \frac{\partial T_{v}}{\partial x} d x-(h P)_{v} d x\left(T_{v}-T_{w}\right)
$$

and for the wall

$$
\frac{\partial T_{w}}{\partial t}(\rho A C)_{w} d x=(h P)_{u} d x\left(T_{u}-T_{w}\right)-(h P)_{v} d x\left(T_{\dot{w}}-T_{u}\right)
$$

If we set $(h P)_{v}=(h P)_{u}$ and $A_{v}=A_{u}$, then equations 1.1 through 1.3 , expressed in terms of dimensionless variables (defined in Section 1.7 ), become 


$$
\begin{aligned}
& \frac{1}{b} \frac{\partial u}{\partial \tau}=-\frac{\partial u}{\partial y}+w-u \\
& \frac{1}{b} \frac{\partial v}{\partial \tau}=\frac{\partial v}{\partial y}+w-v \\
& \frac{\partial w}{\partial \tau}=u+v-2 w
\end{aligned}
$$

with initial conditions:

$$
u=v=w=1 \text { for all y at } \tau=0
$$

and boundary conditions:

$$
\begin{aligned}
& u=0 \text { at } y=0 \text { for } \tau>0 \\
& u=v \text { at } y=L \text {. }
\end{aligned}
$$

Thus, we consider the response of a transmission line, initially at uniform temperature, to a step change in the coolant inlet temperature at the near end.

The second boundary condition is for cooling from one end only (single-ended cooldown). In this case the coolant streams are short circuited at the far end $(x=\ell)$ so that the go stream is connected directly to the return stream, resulting in $T_{v}=T_{u}$ at $x=\ell$. If both ends are cooled ( $i . e ., T_{v}=v=0$ at $y=L$ ) the temperature distribution is symmetrical about the midpoint, and the solution for a half length of this double-ended cool-down corresponds to the solution for single-ended cool-down. Thus we need only obtain the solution for single-ended cool-down and the following analysis applies to this case. At the conclusion of the analysis, transformations for double-ended cooling are given.

Numerical integration of equations (1.4) through (1.8) was accomplished using the computer program PDECOL developed by Madsen and Sincovec [9].

We are unaware of an analytical solution to this problem. We obtain an approximate solution by neglecting the time dependent terms in equations (1.4) and (1.5) as has been done in analysis of the regenerator problem [10]. That is, we assume that $b$ (the heat capacity of the solid relative to the heat capacity of the gas) is 1 arge. At ambient temperature this is a good approximation; at helium temperature it is not. However, we are able to reintroduce the dependence on $b$ to give cool-down solutions good for a wide range of heat capacity ratios.

Before giving the details of the solution we will first outline the method. We begin by assuming a solution of the form

$$
u=F(\tau) \cdot G(y)
$$

Based on our experimental and numerical results, we further assume a sinusoidal form for $G(y)$ so that equations 1.4 thru 1.8 may then be solved to give 


$$
\begin{aligned}
& v=F(\tau) \cdot H(y) \\
& w=F(\tau) \cdot I(y)
\end{aligned}
$$

where $H(y)$ and $I(y)$ are known and $F(\tau)$ remains to be determined. With the spatial temperature distrubutions known as functions of the assumed spatial distribution $G(y)$, we may now integrate the first law of thermodynamics for steady flow

$$
\dot{m} C_{p}\left(v_{0}-u_{0}\right) d t=-(\rho A C)_{w}\left(1+\frac{2}{b}\right) \int_{0}^{l}[w(x, t+d t)-w(x, t)] d x
$$

to obtain the time-dependent part of the solution $F(\tau)$. The term $2 / \mathrm{b}$ accounts for the heat capacity of the two gas streams. The key to the method is to obtain an expression for $v_{0}-u_{0}$ (which gives the rate of refrigeration) for use in equation 1.12 .

From our experimental and numerical work, we observe that counterflow cool-down progresses in two stages. During the first and relatively brief stage, a cool-down wave propagates towards the far end $(y=L)$ with $u_{\ell}$ undiminished, figure 1.3.

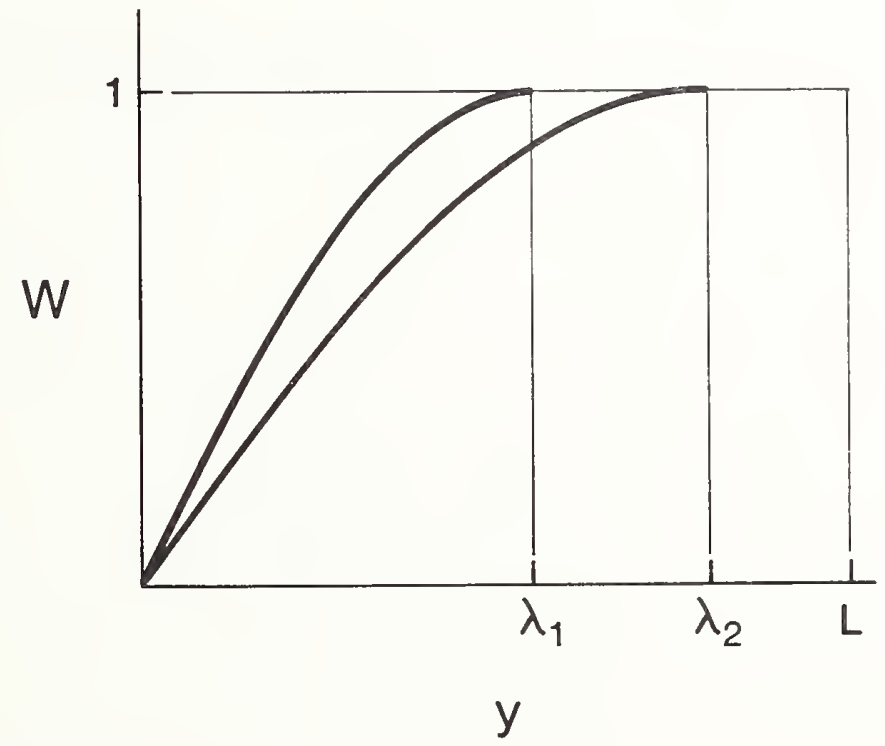

Figure 1.3 Assumed temperature profile during first stage of cool-down.

During the second and longer stage, the cool-down wave extends the full length of the line and the amplitude of the wave undergoes an exponential decay, figure 1.4. The instantaneous rate of decay depends on the rate of refrigeration which is proportional to the near end fluid temperature difference, $v_{0}-u_{0}$. 


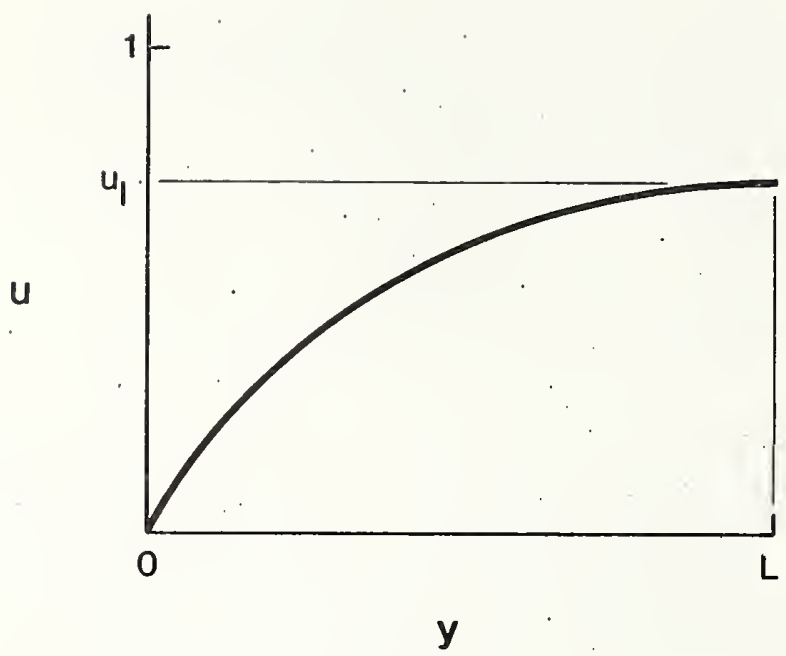

Figure 1.4 Assumed temperature profile during second stage of cool-down.

Returning now to the details of the solution, we approximate the go-stream temperature distribution by:

$$
u=u_{\ell} \sin \frac{\pi}{2} \underline{y}
$$

where $u=u(t)$. Eq (1.4) gives:

$$
w=u_{\ell}\left(\sin \frac{\pi}{2} \frac{y}{L}+\frac{\pi}{2 L} \cos \frac{\pi}{2} \frac{y}{L}\right)
$$

Intergration of equation 1.5 gives:

$$
v=\frac{2 u_{\ell}}{1+\left(\frac{\pi}{2 L}\right)^{2}}\left(\frac{\pi}{2 L}\right)^{2} \exp (y-L)+\frac{1}{2} \cdot 1-\left(\frac{\pi}{2 L}\right)^{2} \quad \sin \frac{\pi}{2} \frac{y}{L}+\frac{\pi}{2 L} \cos \frac{\pi}{2} \frac{y}{L}
$$

Evaluating $v$ at $y=0$, we obtain:

$$
v_{0}=\frac{\pi}{L} u_{l} \quad \frac{1+\frac{\pi}{2 L} \exp (-L)}{1+\left(\frac{\pi}{2 L}\right)^{2}}
$$


which, noting that $u_{0} \equiv 0$, is the normalized temperature difference $\left(v_{0}-u_{0}\right)$ between the go and return streams at the cooled end of the transmission line. For large $L$, equation (1.16) reduces to:

$$
v_{0}=\frac{\pi}{L} u_{\ell}
$$

We will now use this result in equation 1.12 to obtain the time-dependent part of the solution. During the first stage of cool-down, we assume the cool-down wave progresses towards the end of the line, as shown in figure 1.3 , such that:

$$
w=\sin \frac{\pi}{2} \frac{y}{\lambda} \quad \text { for } y \leq \lambda
$$

and

$$
w=1 \text { for } \lambda<y \leq L
$$

where $\lambda=\lambda(t)$ is the position of the cool-down wave front.

Although (1.18) does not strictly agree with (1.13); its use simplifies evaluation of the integral in (1.12). The error in the total cool-down time introduced by this approximation is small because the duration of the first stage is short compared to that of the second stage.

Substituting (1.17) and (1.18) into equation (1.12) and noting that $\mathrm{u}_{\ell}=1$ during the first stage gives

$$
\dot{m} C_{p} \frac{\pi}{L} d \tau=\left(1+\frac{2}{b}\right)\left[\int_{0}^{\lambda_{2}} \sin \frac{\pi}{2} \frac{y}{\lambda_{2}} d y+\left(L-\lambda_{2}\right)-\int_{0}^{\lambda_{1}} \sin \frac{\pi}{2} \frac{y}{\lambda_{1}} d y-\left(L-\lambda_{1}\right)\right]
$$

or

$$
\frac{\pi}{\lambda} d \tau=\left(1-\frac{2}{\pi}\right)\left(1+\frac{2}{b}\right) d \lambda
$$

and finally,

$$
\tau_{1}=\frac{1}{2 \pi}\left(1-\frac{2}{\pi}\right)\left(1+\frac{2}{b}\right) L^{2}
$$

as the dimensionless time for the first phase of the cool-down.

The second stage cool-down time is obtained in an analogous fashion. The first law (including the heat leak $Q$ and the heat capacity of the gas) gives:

$$
\left(-\frac{Q}{\left(T_{i}-T_{f}\right)_{0}}+\dot{m} C_{p} v_{0}\right) d t=-(\rho A C)_{w}\left(1+\frac{2}{b}\right) \int_{0}^{2}[w(x, t+d t)-w(x, t)] d x
$$


Replacing $w$ and $v_{0}$ by equations (1.14) and (1.17) and transforming to dimensionless variables gives:

$$
\left(-\frac{Q}{\dot{m} C_{p}\left(T_{i}-T_{f}\right)}+\frac{\pi}{L} u_{\ell}\right) d \tau_{2}=-d u_{\ell}\left(1+\frac{2}{b}\right) \int_{0}^{L}\left(\sin \frac{\pi}{2} \frac{y}{L}+\frac{\pi}{2 L} \cos \frac{\pi}{2} \frac{y}{L}\right) d y
$$

Evaluating the integral and rearrangement yields:

$$
\frac{d u_{\ell}}{d \tau_{2}}+\left[\frac{\pi^{2}}{2 L^{2}\left(1+\frac{\pi}{2 L}\right)\left(1+\frac{2}{b}\right)}\right] u_{\ell}=\frac{Q}{m C_{p} L\left(T_{i}-T_{f}\right)_{\ell}}\left[\frac{\pi}{2\left(1+\frac{\pi}{2 L}\right)\left(1+\frac{2}{b}\right)}\right]
$$

which has the solution:

$$
u_{\ell}=\left[1-\frac{Q L}{\pi m C_{p}\left(T_{i}-T_{f}\right)_{\ell}}\right] \exp \left[-\frac{\pi^{2} \tau_{2}}{2 L^{2}\left(1+\frac{\pi}{2 L}\right)\left(1+\frac{2}{b}\right)}\right]+\frac{Q L}{\pi \dot{m} C_{p}\left(T_{i}-T_{f}\right)_{\ell}}
$$

for the second stage of cool-down.

To summarize the cool-down behavior of the thermally-coupled arrangement, we find that following an initial lag given by (1.22), the normalized end temperature $u_{\ell}$ (note that $\left.\mathrm{w}_{\ell}=\mathrm{u}_{\ell}=\mathrm{v}_{\ell}\right)$ undergoes an exponential decay from $\mathrm{u}_{\ell}=1$ to $\mathrm{u}_{\ell}=\mathrm{QL} / \pi \dot{\mathrm{m} C} \mathrm{p}_{\mathrm{p}}\left(\mathrm{T}_{\mathrm{i}}-\mathrm{T}_{\mathrm{f}}\right)_{0}$. The term $Q L / \pi m C_{p}$ is the rise in the final steady state temperature of the end of the line due to heat input. It is the maximum temperature in the line and, it has a value $L / \pi$ times the temperature rise that would occur with no thermal coupling between the two streams (i.e., the temperature rise for the go stream only - single ended cooling).

We may compare this estimate of the maximum steady state temperature with the exact soiution for the steady state constant property case with heat leak [7], which is

$$
\frac{\left(T_{0}-T_{\ell}\right)_{u}}{\left(\frac{O}{m_{p}}\right)}=\frac{(1+L)^{2}}{4 L}
$$

for $L>1$ with equal heat inputs to the go and return streams. Evaluating the expressions, we obtain:

$\begin{array}{rcc}L & \frac{(1+L)^{2}}{4 L} & \frac{L}{\pi} \\ & & \\ 1 & 1.00 & 0.32 \\ \Pi & 1.36 & 1.00 \\ 10 & 3.03 & 3.18 \\ 20 & 5.51 & 6.37 \\ 50 & 13.01 & 15.90 \\ \infty & L / 4 & L / \Pi\end{array}$

The agreement of the sinusoidal approximation with the exact solution is adequate for our purposes, because in most cases of practical interest, the temperature rise due to heat leak will be small. Our numerical results indicate that the sinusoidal approximation should be limited to cases where $L>5$. 
The cool-down constant time given by $(1.26)$ is:

$$
\tau_{2}=N \frac{2}{\pi 2}\left(1+\frac{\pi}{2 L}\right)\left(1+\frac{2}{b}\right) L^{2}
$$

for the second stage of cool down. The constant $N$ is 2.3 for 90 percent cool-down and 4.6 for 99 percent cool-down (i.e., 90 or 99 percent of $u_{\ell}-Q L / \pi m C_{p}$ ).

The preceeding results apply to cooling from one end (single-ended cooling). They may also be applied to cooling from both ends (double-ended cooling) by noting that the appropriate length in the preceeding is $\frac{1}{2}$ the total length because of the symmetry of the solution about the mid-point.

When considering an actual line or experimental measurements, it is more convenient to use the overall heat transfer coefficient $U$. The corresponding dimensionless length is then the number of heat exchanger transfer units $N_{t u}$, where $N_{t u}=U A / m C_{p}$. Noting that $\mathrm{U}=\mathrm{h} / 2$, the following transformations apply:

$\begin{array}{llcc} & & \text { one end cooled } & \text { both ends cooled } \\ \tau^{\prime} & = & 1 / 2 \tau & 1 / 2 \mathrm{~T} \\ \mathrm{~N}_{\mathrm{tu}} & 1 / 2 \mathrm{~L} & \mathrm{~L} \\ \tau^{1} / \mathrm{N}_{\mathrm{tu}}^{2} & = & 2 \mathrm{\tau} / \mathrm{L}^{2} & 1 / 2 \mathrm{\tau} / \mathrm{L}^{2}\end{array}$

The total cool-down time obtained adding (1.22) and (1.28) becomes

$$
\tau_{\text {cd }}^{\prime}=1.048 \mathrm{~N}_{\text {tu }}^{2}\left(1+\frac{.70}{N_{t u}}\right)\left(1+\frac{2}{b}\right)
$$

for single-ended cool-down, and:

$$
\tau_{\text {cd }}^{\prime}=0.262 \mathrm{~N}_{\text {tu }}^{2}\left(1+\frac{1.40}{N_{t u}}\right)\left(1+\frac{2}{b}\right)
$$

for doubled-ended cool-down (90 percent-cool down for both cases i.e., w=0.1).

We note from 1.29 and 1.30 that for large $N_{t u}$ (say $N_{t u}$ greater than 10) the parameter $\tau_{c d}^{\prime} / N_{t u}^{2}$ is nearly constant. If we choose $\tau^{\prime} / N_{t u}^{2}$ as a correlating parameter, then a plot of $w$ vs. $\tau^{\prime} / N_{t u}$ should coalesce the results to a narrow band of curves having only a weak dependence on $\mathrm{N}_{\text {tu }}$.

The first order dependence of the cool-down time on transmission line length follows directly from 1.29 or 1.30 . For large $\mathrm{N}_{\text {tu }}$

$$
t_{c d^{\sim}} U\left(\frac{l}{i}\right)^{2}
$$

For cases where the total pressure drop across the transmission line is fixed, we obtain

$$
\tau_{c d} \sim \frac{U \ell^{3}}{\bar{p} \Delta p}
$$

for an ideal gas coolant. Expression 1.32 may be obtained directly from 1.31 by noting that $\dot{\mathrm{m}}^{2} \sim \overline{\mathrm{p}} \Delta \mathrm{p} / \ell$ for an ideal gas. Because 1.31 was derived for constant $\dot{\mathrm{m}}$, however, a rigorous proof of 1.32 requires integration of 1.12 with $\dot{m}=m(t)$. This proof is given in the appendix (section 1.9). 


\subsection{Experimental}

The analysis shows that an experimental model of a counterflow (thermally-coupled return) cooled SPTL should be scaled so as to have the same values of $\mathrm{N}_{\text {tu }}$ and b (ratio of cable to coolant heat capacity) as the full scale line. Typical ranges of these parameters for a SPTL are 10 to $100 \mathrm{~N}_{\text {tu }}$ with $b$ on the order of $10^{3}$ (ambient temperature values).

The construction and instrumentation of a concentric-channel-test-section present a number of difficulties. In a SPTL, the go and return streams are separated by the dielectric annulus (figure 1.1) which is several centimeters thick. Instead, we chose the construction shown in figure 1.5 wherein the go and return streams are separated by a web which gives a controlled thermal resistance between the two streams. Although geometrically different than a SPTL, the characteristic dimensionless cool down parameters are similar: $b$ $=450$ (at ambient temperature) and $N_{\text {tu }}$ ranges from 10 to 22 .

The $16 \mathrm{~m}$ test section (figures 1.5 and 1.6) was swaged to the two passage shape from a $19 \mathrm{~mm} \times .5 \mathrm{~mm}$ wall, type 304 stainless steel cylindrical tubing. The two passages, $6.4 \mathrm{~mm}$ and $4.8 \mathrm{~mm} \mathrm{ID}$, are separated by a $9 \mathrm{~mm} \times 1 \mathrm{~mm}$ web which has a continuous seam weld for hermetic separation of the channels. A $0.05 \mathrm{~mm}$ electro deposited layer of copper enhances the thermal conductance between the passages. For compactness, the test section is wound in a $37 \mathrm{~cm}$ diameter coil (Figure 1.6). Thermal insulation is provided by a high vacuum environment, gold plating, 10 layers of aluminized $\mathrm{film}$, and a radiation shield which may be controlled down to $90 \mathrm{~K}$.

Helium gas is supplied to the test section via a counterflow heat exchanger, a $\mathrm{LN}_{2}$ bath, a second-counter flow heat exchanger, and a LHe bath. The valve arrangement permits either single stream cool-down or warm-ups, as well as counter flow cool-down. For the experiments in which the final temperature was $77 \mathrm{~K}$, liquid nitrogen is used in place of the liquid helium shown in figure 1.5. Single-ended cool-down experiments are run by connecting the go stream discharge directly to the return stream inlet.

Fast thermal response of the go stream and return stream inlets is assured by close coupling the go stream control valve and return stream liquid reservoir to the test section with thin-walled stainless steel tubing. Typical response times of the inlet conditions are 2 to 4 percent of the test section cool-down times. Figure 1.7 compares the inlet temperature decay rate chosen for the numerical calculations to the experimental inlet temperature decay rate for three different experiments. As discussed at the end of Section 1.2 we use the dimensionless parameter $\tau^{1} / \mathrm{N}_{\mathrm{tu}}{ }^{2}$ (dimensionless time divided by dimensionless length squared) because use of this parameter provides a common base of comparison for widely varying conditions. The agreement of the experimental inlet temperature decay rates with the decay rate assumed in the numerical calculations is adequate. The exact value is unimportant so long as the inlet temperature decay time is short compared to the cool-down time.

\subsubsection{Instrumentation}

Temperatures are measured with $0.13 \mathrm{~mm}$ diameter gold ( 0.07 at. percent iron) vs. chromel thermocouples referenced to a liquid nitrogen bath. Those for the test section are mounted on the web equidistant from the two flow channels. Differential thermocouples are used to measure the go and return stream temperature differences at each end. Pressures are measured with variable reluctance diaphram transducers operating at ambient temperature. The return stream exit mass flow rate is measured with an ambient temperature thermal-type flow meter. The total uncertainty in the measurements is estimated to be: temperature, $0.5 \mathrm{~K}$; differential temperature, $0.05 \mathrm{~K}$; pressure 0.5 percent; and mass flow rate, 0.5 percent. 


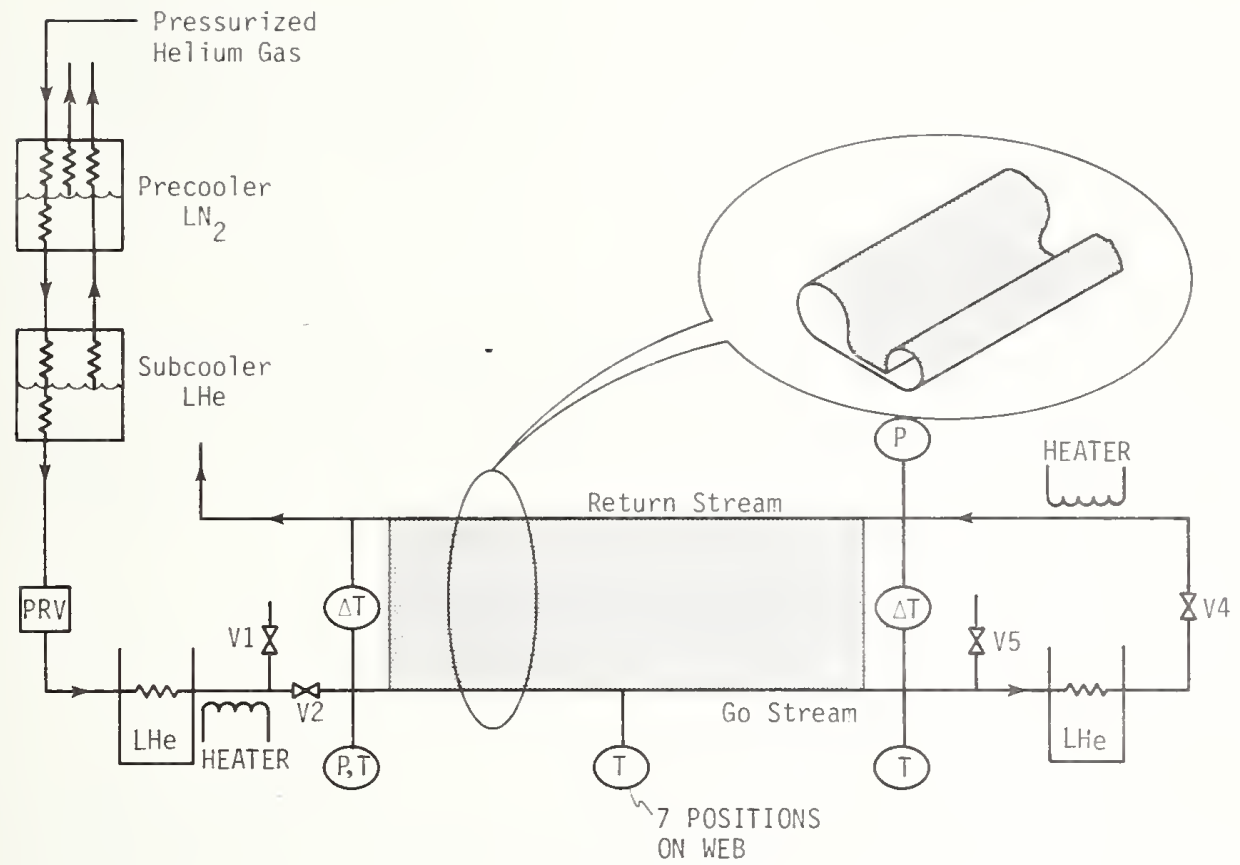

Figure 1.5 Test section and flow schematic for cool-down experiments.

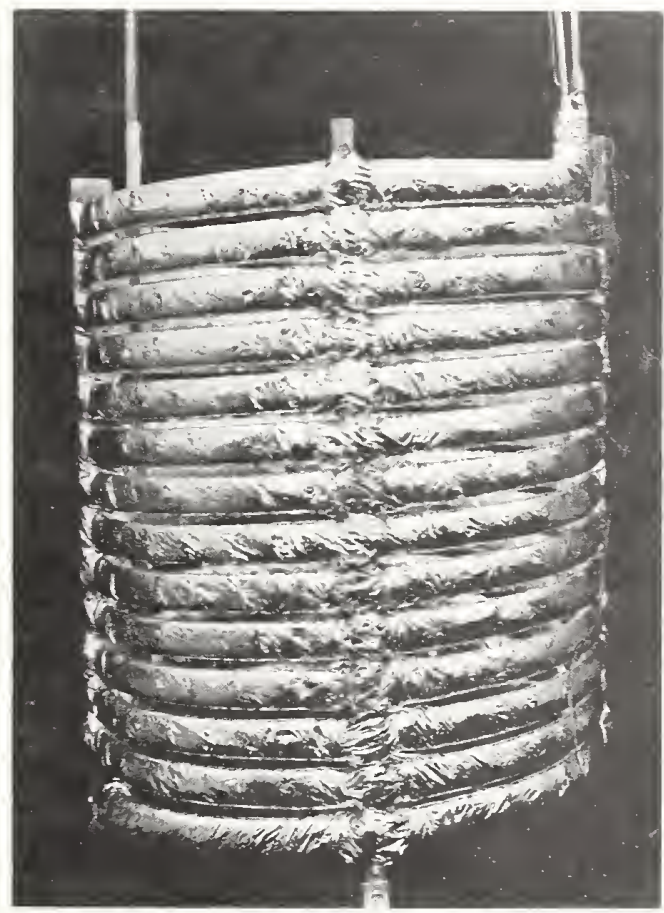

Figure 1.6 Dual passage test section, instrumented and wraped with ten layers of a]uminized film. 


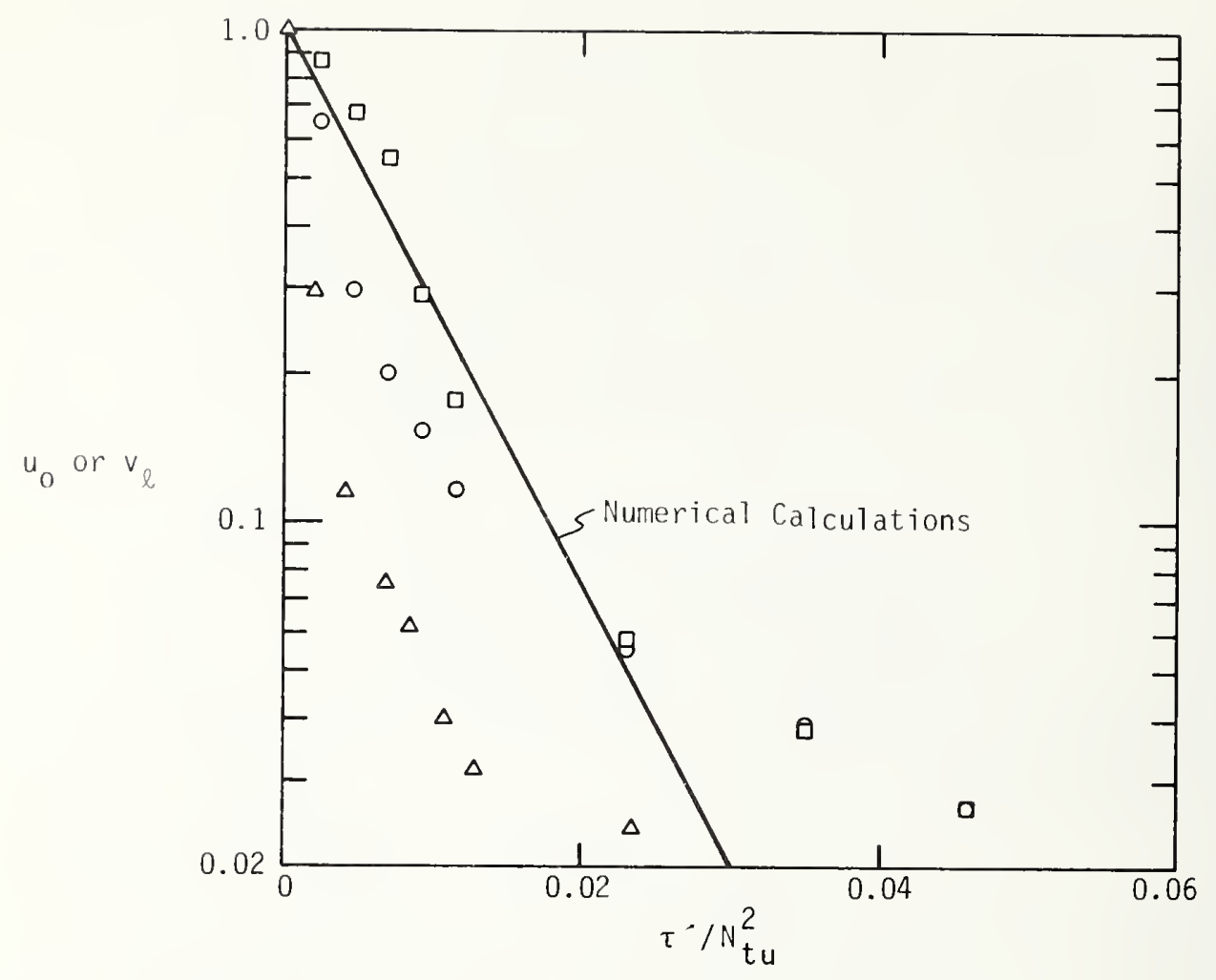

Figure 1.7 Decay of fluid inlet temperature.

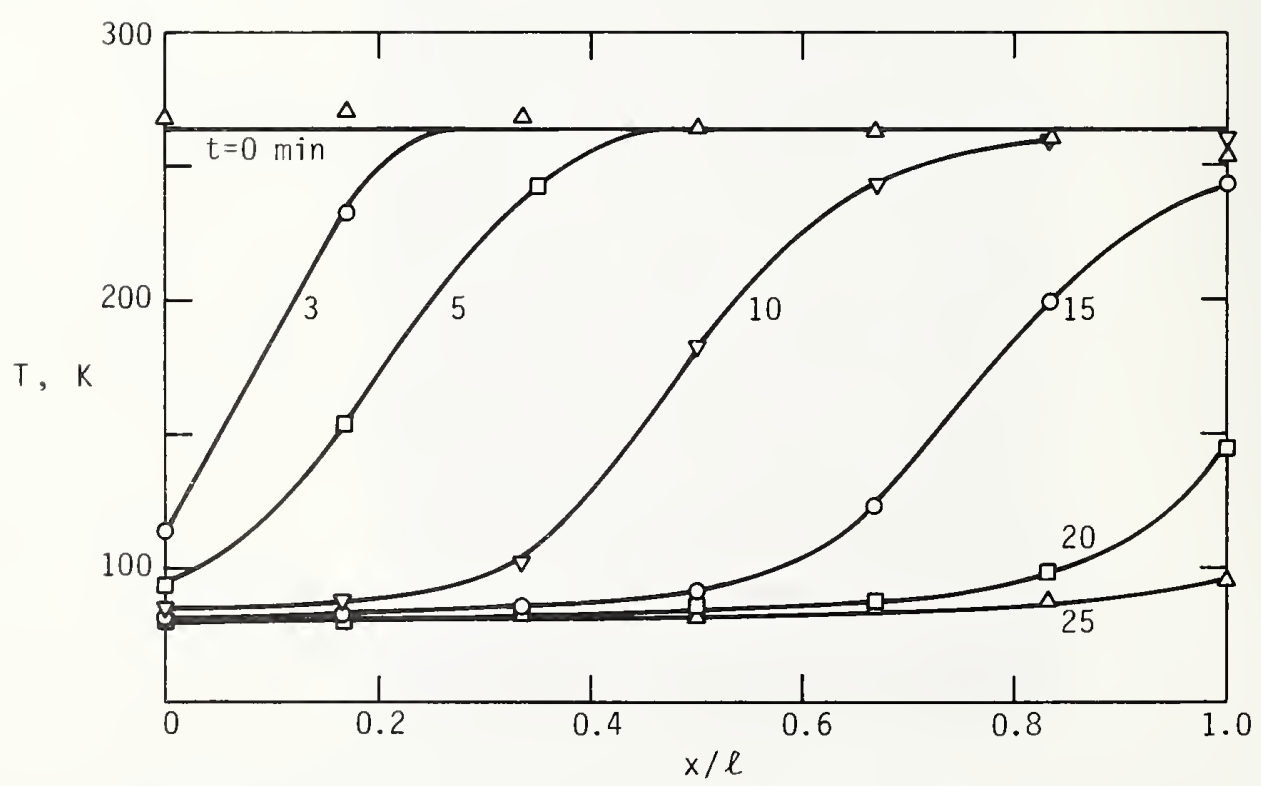

Figure 1.8 Single stream cool-down experiment for evaluation of the test section heat capacity. The curves are to guide the eye through the experimental data. 
Data are collected with a mini computer which gives "real time" conversion of al] instrument channels to physical parameters $(P, T, m)$.

\subsubsection{Procedure}

The study requires three types of experiments. In adition to the counterflow cooldown and warm-up runs, we also measure the test section heat capacity and $\mathrm{N}_{\text {tu }}$.

The test section heat capacity is determined from single stream cool-down experiments using the expression:

$$
(\overline{\rho A C}) l=\frac{1}{\left(T_{i}-T_{f}\right)} \int_{0}^{t}\left(T_{\text {in }}-T_{\text {out }}\right) m C_{p} d t
$$

The experiment begins with the test section at an initial uniform temperature $T_{j}$. Single stream cool-down is initiated by opening V2 (figure 1.5) and closing V1 with V4 closed and V5 open. Figure 1.8 shows the results of such an experiment. The integral in (1.33) is evaluated up to the time when $T_{\text {in }}{ }^{-T_{\text {out }}}$ falls to 4 or 5 percent of its maximum value, i.e., until the cool-down wave has essentially passed through the test section. The contribution of heat leak to the error in heat capacity is estimated to be less than five percent.

The thermal coupling between the go and return streams is determined from the steady state operation of the test section as a counter-flow heat exchanger, i.e., the go stream inlet is held at a constant temperature near ambient, and the return stream inlet is held at $76 \mathrm{~K}$ or $4 \mathrm{~K}$. The $\mathrm{N}_{\text {tu }}$ and UPl are then determined from the heat exchanger effectiveness:

$$
N_{\text {tu }}=\frac{U P \ell}{n C_{p}}=\frac{\varepsilon}{1-\varepsilon}
$$

Figure 1.9 shows the measured test section $N_{\text {tu }}$ as a function of $1 / \mathrm{m}$. The time required to achieve steady-state is approximately equal to the cool down time for the cool down experiments.

The heat leak to the test section during the cool-down experiments is evaluated by solving equation (1.23) for Q. Thus the heat leak is the difference between the rate of refrigeration and the rate of cooling. Figure 1.10 gives the heat leak evaluated by this method for three typical experiments. The complex time dependence of the heat leak results from the experimental arrangement. Although the test section and radiation shield are cooled down together, the temperature of the test section varies in both position and time. Consequently, the radiation shield temperature matches the test section temperature at only a single position or pair of positions, and the heat leak varies with both time and position. 


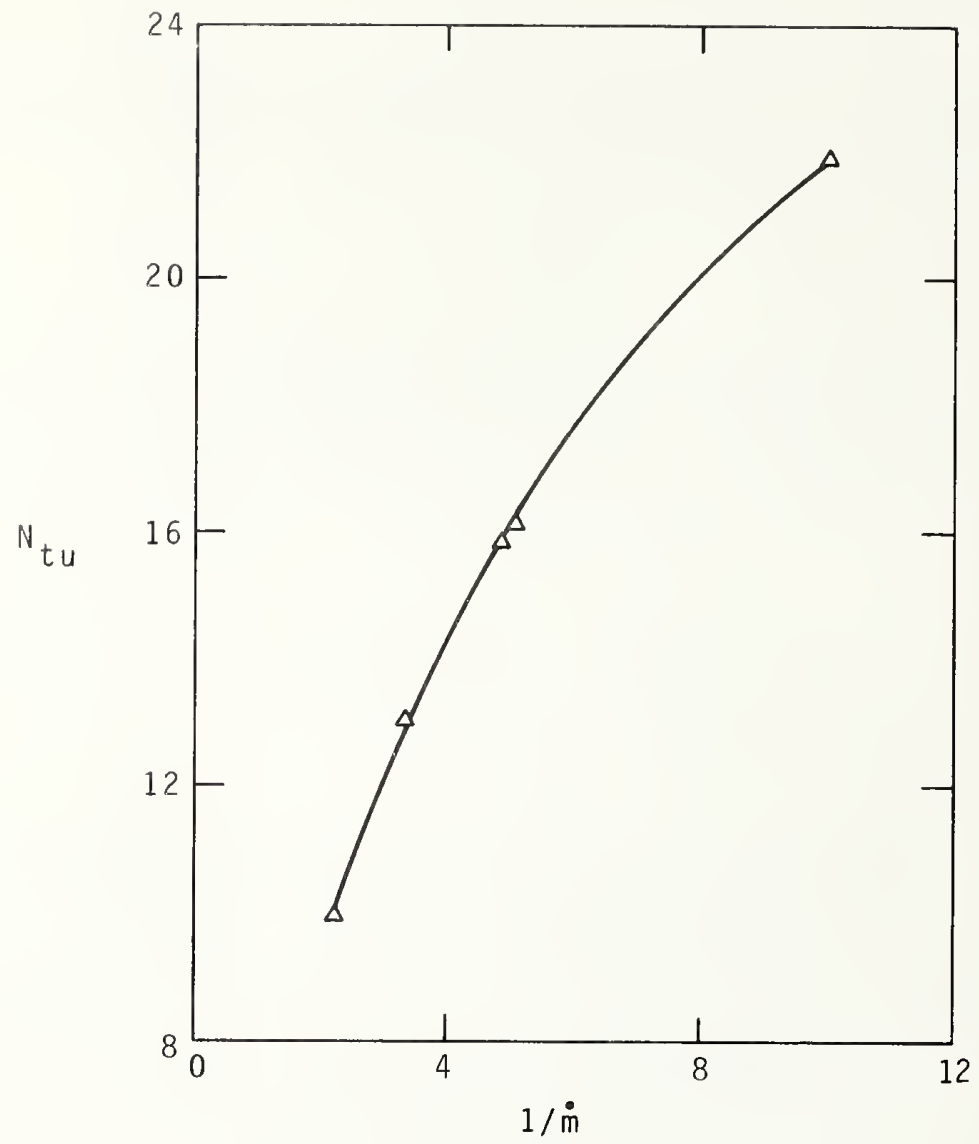

Figure 1.9 Test section $N_{\text {tu }}$ vs. $1 /$ m as determined from steady state counter flow experiments. The curve is to guide the eye through the experimental data.

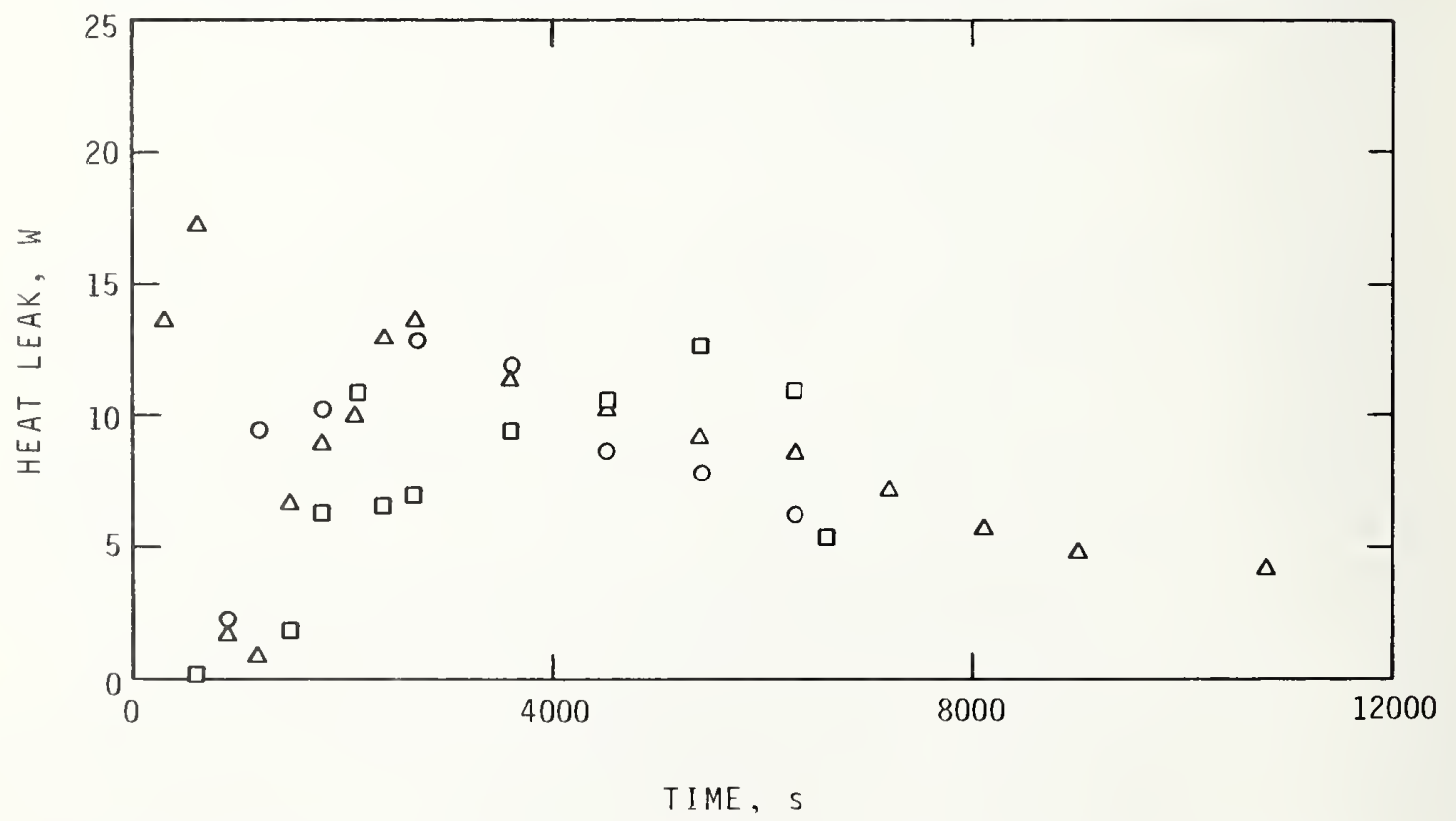

Figure 1.10 Measured heat leak during three typical cool-down experiments. 


\subsection{Results and Discussion}

Table 1 summarizes the experiments: Abortion of two liquid helium temperature runs was caused by the plugging of the lower heat exchanger with solid hydrogen - the result of $100 \mathrm{ppm} \mathrm{H}_{2}$ in the helium gas supply. Replacement of the gas supply eliminated this problem.

In interpreting the experimental results and comparing them to the analysis, we should keep in mind the strong temperature dependence of the test section heat capacity, figure 1.11. This change in heat capacity, coupled with the variation of the helium density, changes $b$ (the heat capacity ratio) by a factor of about $2(10)^{4}$ between 300 and $4 \mathrm{k}$. In spite of these strongly tempērature-dependent properties, however, the agreement of the experiment with the analysis is quite good when average property values are used.

The response of the wall temperature to a near step change in coolant inlet temperature is shown in figures 1.12 through 1.14. The slight asymmetry in figures 1.12 and 1.13 is due to a larger time constant for the return stream inlet temperature compared to that for the go stream inlet temperature. Single-ended cool-down (figure 1.14) gives, as expected, temperature profiles similar to those for a half-length of the double-ended case. For cool-down to helium temperatures (figure 1.13 and 1.14) the curvature near the cool ends is reduced, or becomes slightly concave, compared to figure 1.12 , because of the strong temperature dependence of the wall heat capacity at low temperature.

By using the normalized wall temperature ratio $\mathrm{w} / \mathrm{w}_{\ell}$, we may compare the analytical (equation 1.14), numerical, and experimental wall temperature profiles, figure 1.15 during the second stage of cool-down. The experimental results are for cool-down to $77 \mathrm{~K}$, so the wall heat capacity varies by a factor of about 2 in the experiment, whereas the numerical and analytical results assume a constant heat capacity. For $w_{\ell}<.75$, the three results essentially coincide, and we may expect the sinusoidal approximation to accurately describe the temperature profile during most of the cool-down if the temperature dependence of the heat capacity is not too large.

As discussed in Section 1.2, the key to the analysis is to obtain the near-end temperature difference between the go and return streams, $v_{0}-u_{0}$, since this temperature difference determines the rate of refrigeration, and hence, the cool-down rate. We may compare the analytical, numerical, and experimental values of $v_{0}-u_{0}$ by noting that $u_{0} \equiv 0$ and rearranging 1.17 to give:

$$
\frac{v_{0} L}{u_{\ell}}=\pi
$$

Using this parameter, we may compare values of $v_{0}$ for different values of $L$ and $u_{\ell}$. Figure 1.15 shows that equation (1.35) gives a reasonable approximation of both the numerical and experimental results. Because the experimental values of $v_{0}$ fall about five percent below equations (1.17) and (1.35), the experimental cool-down times should be expected to be about five percent greater than predicted by the sinusoidal approximation.

Experimental cooling curves in dimensional time and temperature are given in figures 1.16 through 1.18. The temperature is the maximum temperature in the 1 ine (position $x / \ell=1$ 
Table 1.--Summary of Experiments

EXP. NO.

TEMPERATURE

(K)

FLOW

$(\mathrm{g} / \mathrm{s})$

\section{COMMENTS}

Counterflow Steady State

$\begin{array}{lll}1 / 29 & 180-76 & .2 \\ 2 / 12 & 274-77 & .2 \\ 2 / 12 & 257-77 & .1 \\ 3 / 16 & 277-87 & .3 \\ 4 / 9 & 280-4.2 & .2 \\ 4 / 20 & 270-4 & .2 \\ 4 / 25 & 279-78 & .2 \\ 5 / 1 & 275-4 & .2 \\ 6 / 27 & 277-76 & .45\end{array}$

$\mathrm{N}_{\text {tu }}=16.1$

$N_{\text {tu }}=16.1$

$\mathrm{N}_{\text {tu }}=21.9$

$\mathrm{N}_{\text {tu }}=13.0$

temperature control problem

temperature control problem

$\mathrm{N}_{\text {tu }}=15.9$

$N_{\text {tu }}=18.2$

$\mathrm{N}_{\text {tu }}=10.0$

Single Stream-Cool Down

$\begin{array}{lll}1 / 26 & 180-79 & .2 \\ 2 / 13 & 251-83 & .2 \\ 3 / 2 & 265-79 & .3 \\ 3 / 16 & 271-15 & .2\end{array}$

$(\rho A C)_{w \ell}=1.514(10)^{3} \mathrm{~J} / \mathrm{K}$ $(\rho A C)_{W \ell}=1.657(10)^{3}$

$(\rho A C)_{W \ell}=1.647(10)^{3}$

$(\rho A C)_{W \ell}=1.250(10)^{3}$

Counter Flow-Cool Down - Both Ends Cooled

$\begin{array}{lll}1 / 26 & 179-76 & .2 \\ 2 / 9 & 274-76 & .2 \\ 2 / 14 & 255-76 & .1 \\ 3 / 1 & 278-76 & .3 \\ 3 / 7 & 278-6 & .2 \\ 3 / 14 & 278-6 & .2 \\ 4 / 3 & 274-7 & .2 \\ 6 / 28 & 281-75 & .45\end{array}$

Counter Flow-Cool Down - One End Cooled

$5 / 8$

$5 / 9$

$270-6 \quad .2$

$5 / 14$

$269-77$

.2

$5 / 29$

$273-76$

.3

$278-75$

.45

aborted helium run- $\mathrm{H}_{2}$ contamination

Counter Flow Warm-Up - One End Warmed

\begin{tabular}{|c|c|}
\hline $5 / 8$ & $22-277$ \\
\hline $5 / 15$ & $118-273$ \\
\hline $5 / 29$ & $82-278$ \\
\hline
\end{tabular}




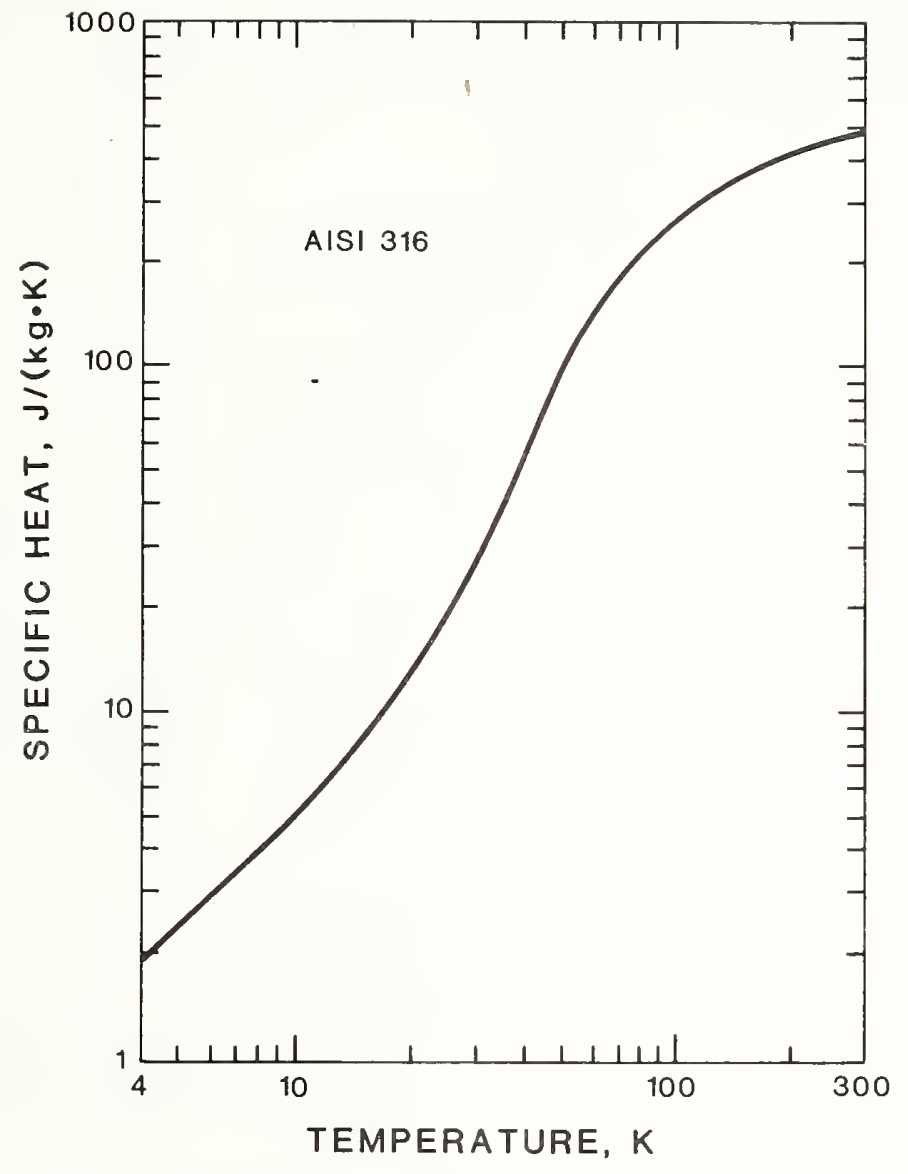

Figure 1.11 Specific heat of stainless steel.

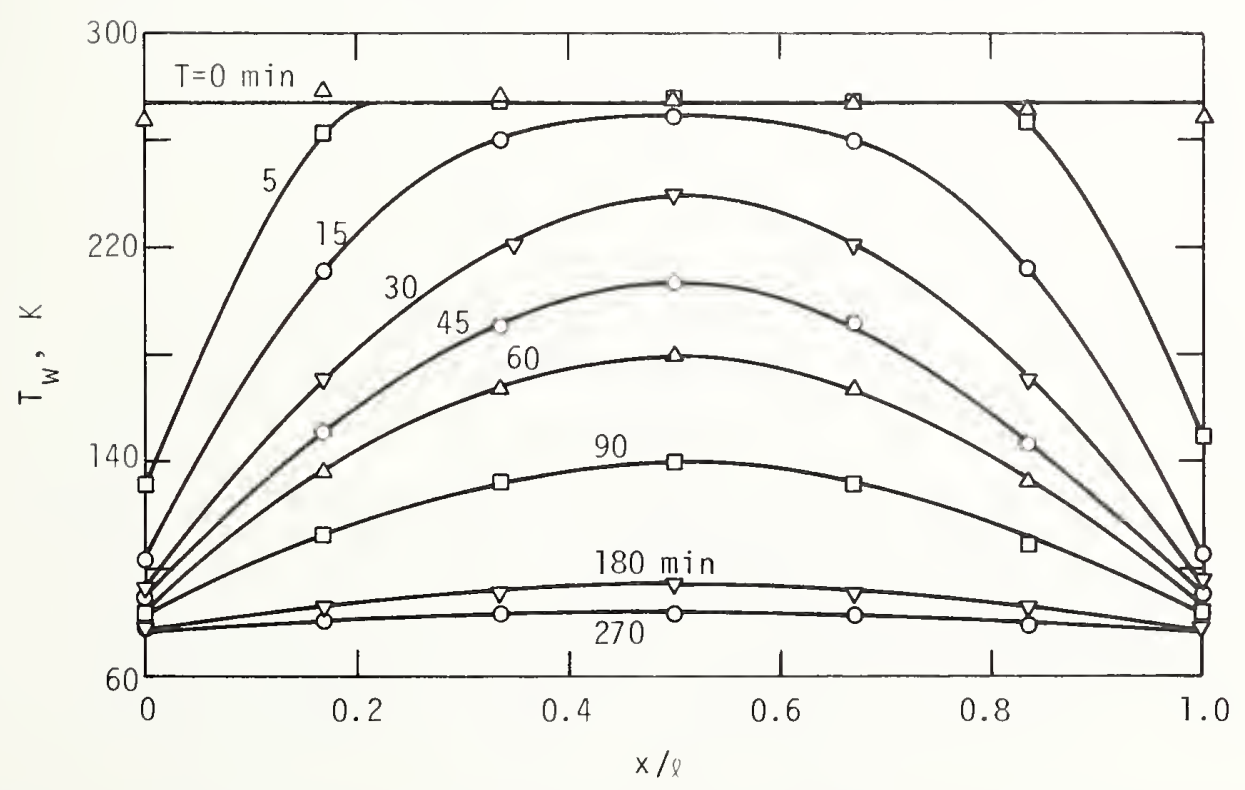

Figure 1.12 Test section temperature profile during cool-down to $77 \mathrm{~K}$ with both ends cooled, experimental results: $p=10 \mathrm{bar}, \dot{\mathrm{m}}=0.2 \mathrm{~g} / \mathrm{s}, \mathrm{N}_{\mathrm{tu}}=16.1$, UPQ $=16.6 \mathrm{~W} / \mathrm{s}$, $(\rho A C)_{w}=1657 \mathrm{~J} / \mathrm{K}$. The curves are to guide the eye through the experimental data. 


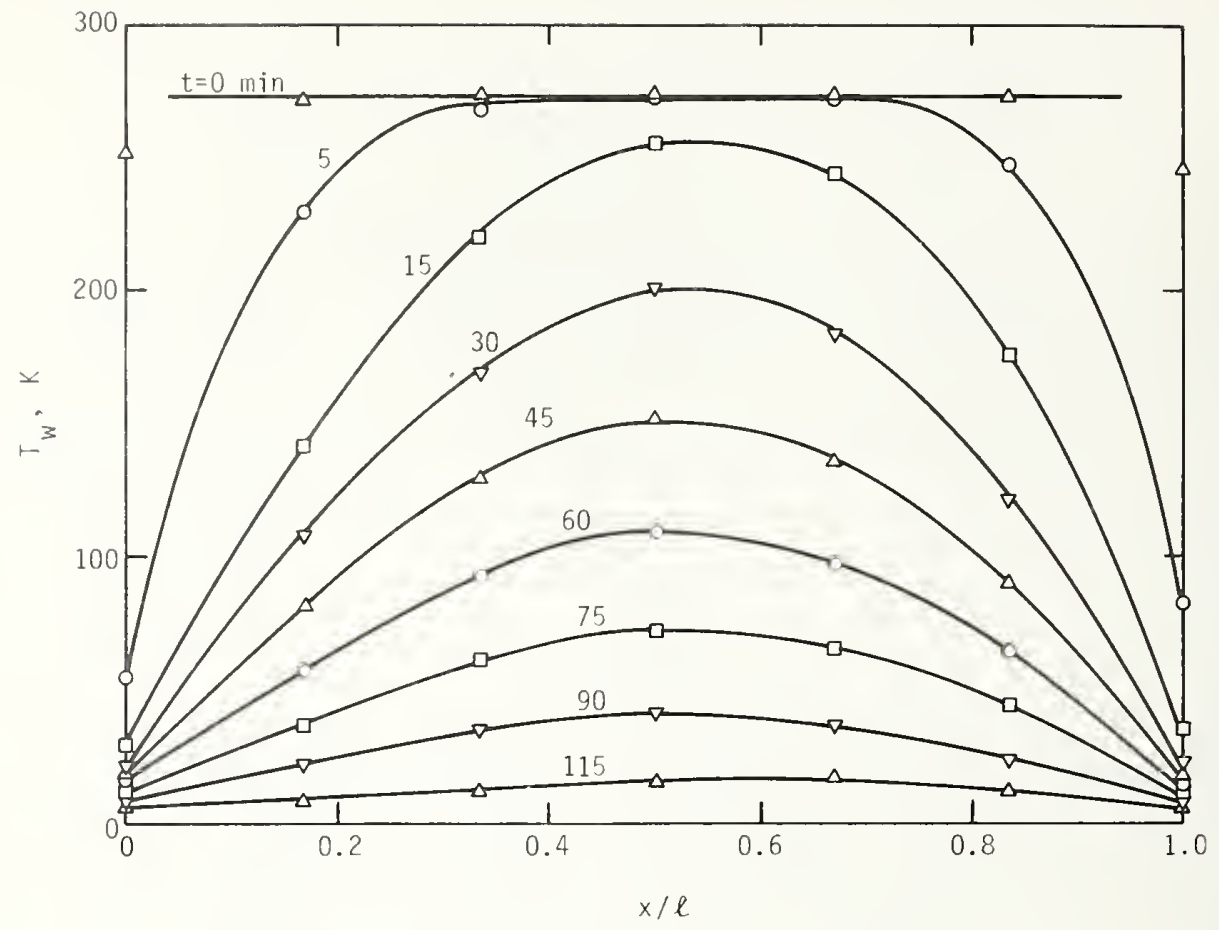

Figure 1.13 Test section temperature profile during cool-down to $7 \mathrm{~K}$ with both ends cooled, experimental results: $p=10 \mathrm{bar}, \dot{m}=0.2 \mathrm{~g} / \mathrm{s}, \mathrm{N}_{\mathrm{tu}}=18.2$, UPl $=19.3 \mathrm{~W} / \mathrm{s}$, $(\rho A C)_{W}=1250 \mathrm{~J} / \mathrm{K}$. The curves are to guide the eye through the experimental data.

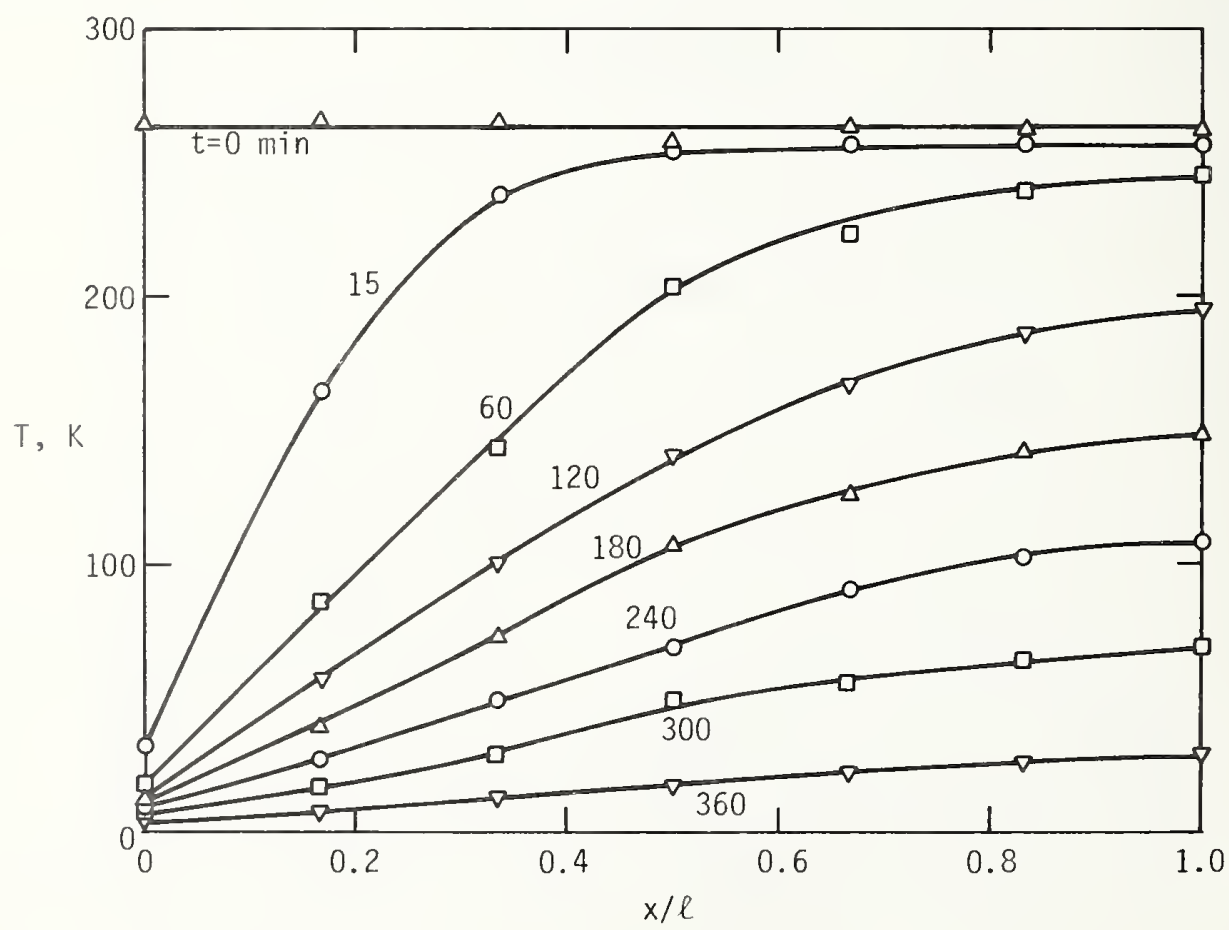

Figure 1.14 Test section temperature profile during cool-down to $6 \mathrm{~K}$ with one end cooled, experimental results: $p=10 \mathrm{bar}, \dot{\mathrm{m}}=.2 \mathrm{~g} / \mathrm{s}, \mathrm{N}_{\mathrm{tu}}=18.2, \mathrm{UPl}=19.3 \mathrm{w} / \mathrm{s}$, $(\rho A C)_{W}=1250 \mathrm{~J} / \mathrm{K}$. The curves are to guide the eye through the experimental data. 


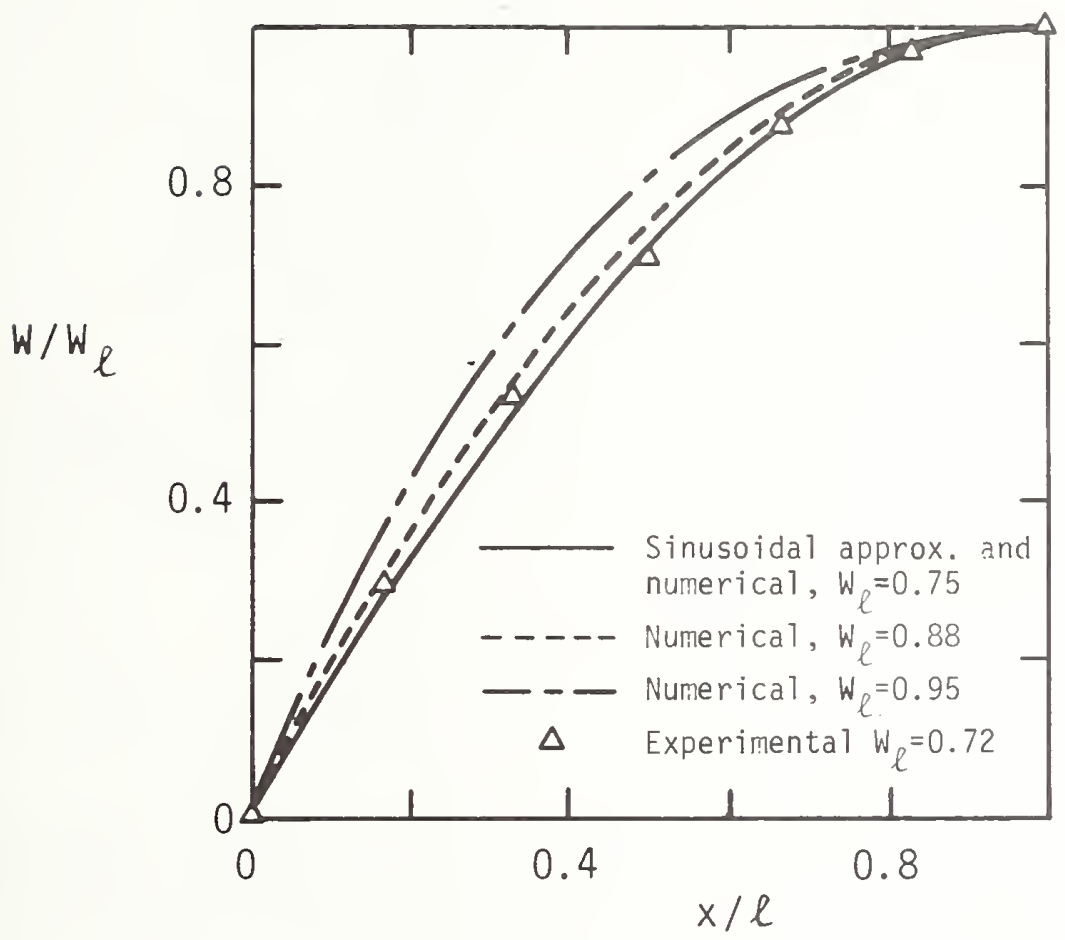

Figure 1.15 Normalized temperatue profile - comparison of experimental, analytical and numerical (constant property) results.

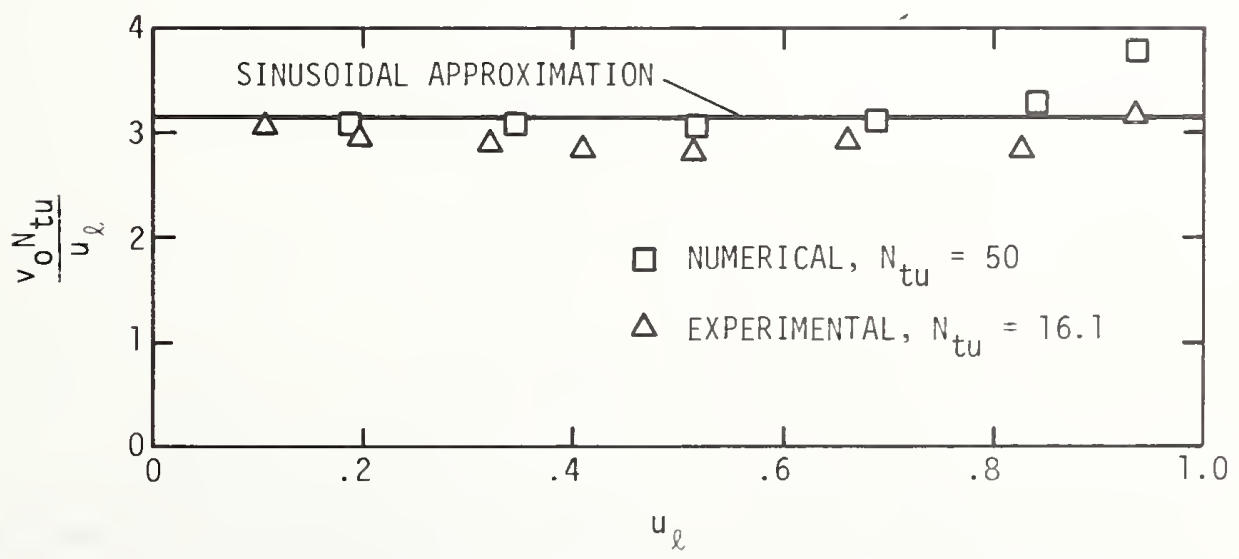

Figure 1.16 Dimensionless inlet temperature difference - comparison of experimental, analytical and numerical (constant property) results (double ended cool-down). 


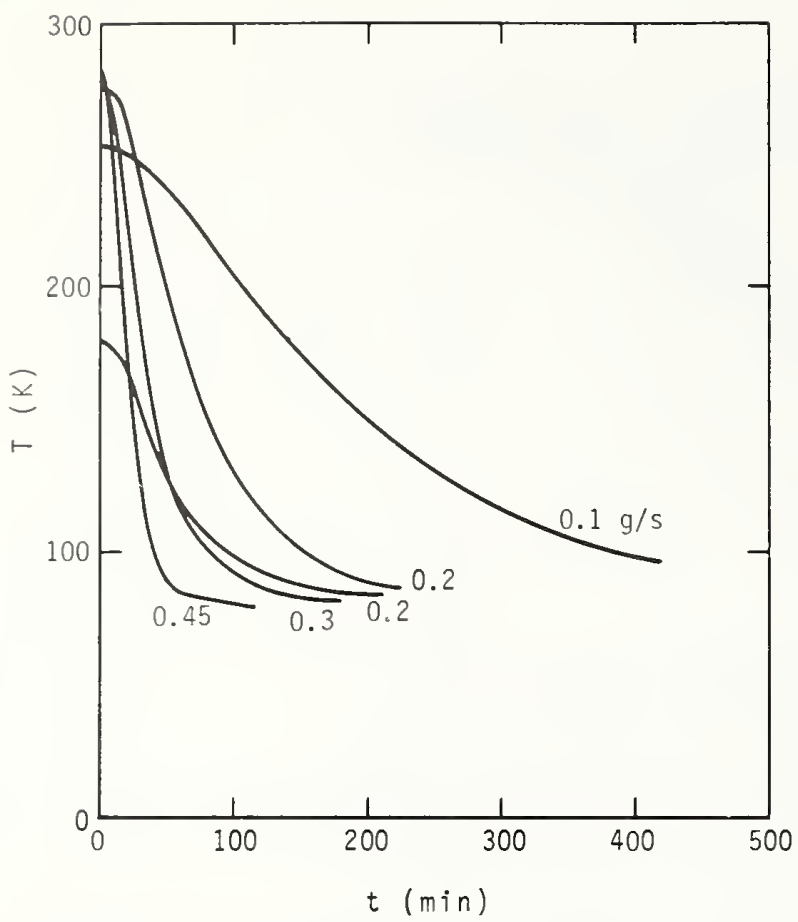

Figure 1.17 Experimental cooling curves for cooldown to $76 \mathrm{~K}$ - both ends cooled. The temperature is at the mid-point $(x / \ell=0.5)$ of the test section.

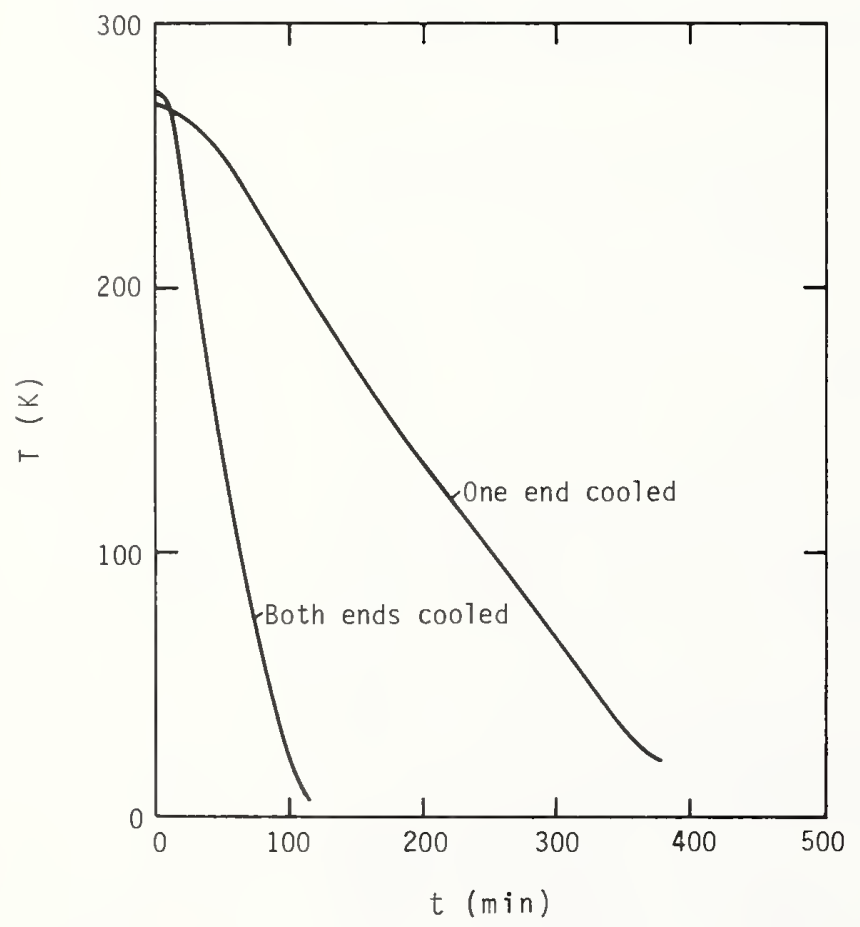

Figure 1.19 Experimental cooling curves for cooldown to $6 \mathrm{~K}$. The temperature is at the mid-point $(x / \ell=0.5)$ of the test section with both ends cooled and at the far end $(x / l=$ $1.0)$ with one end cooled. For both cases $\mathrm{m}=0.2 \mathrm{~g} / \mathrm{s}$.

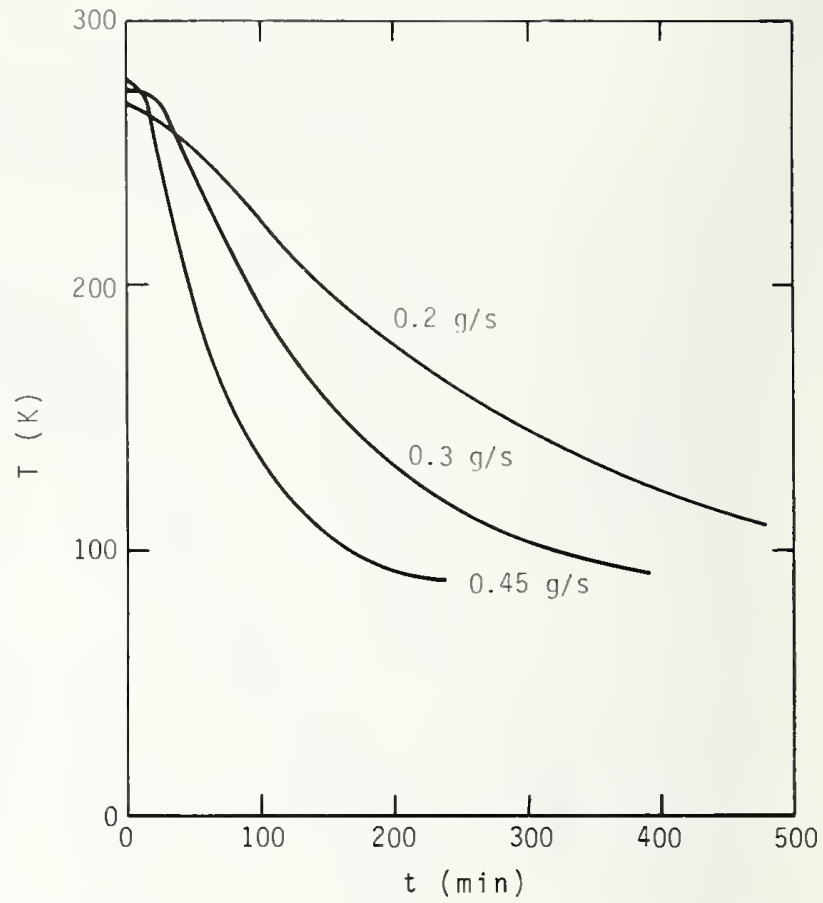

Figure 1.18 Experimental cooling curves for cooldown to $76 \mathrm{~K}$ - one end cooled. The temperature is at the far end $(x / l=1.0)$ of the test section.

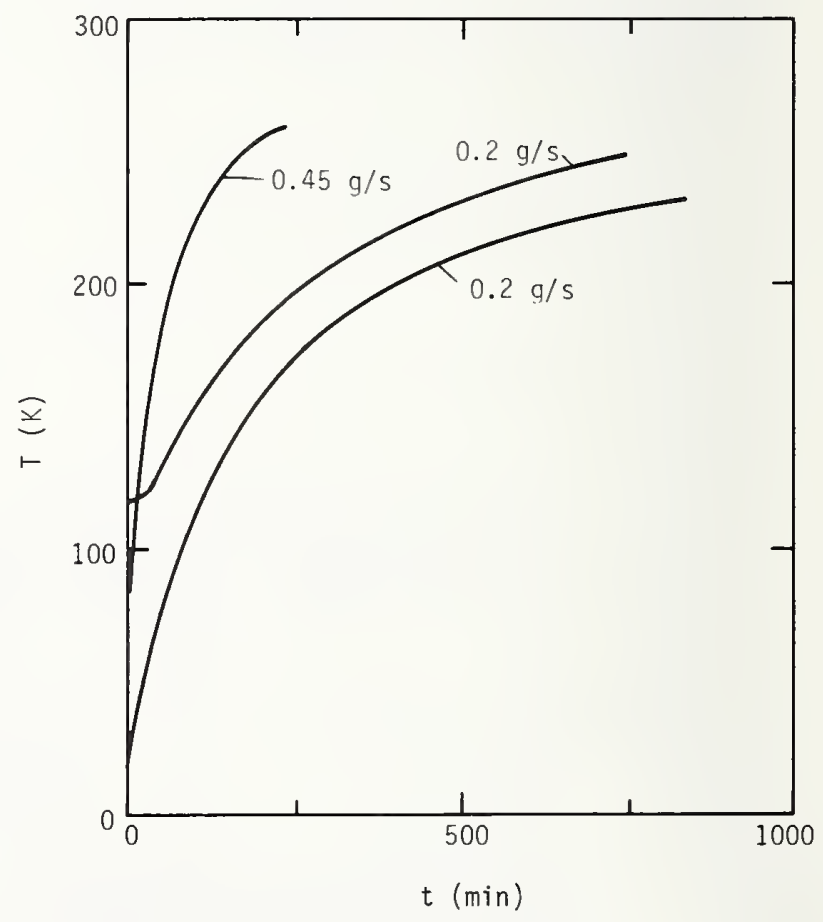

Figure 1.20 Experimental warming curves for warm-up from 22, 82, and $118 \mathrm{~K}$ with one end warmed. The temperature is at the far end $(x / l=1.0)$ of the test section. 
for one end cooled or position $x / \ell=0.5$ for both ends cooled). The curves for cool-down to helium temperature are more nearly linear than exponential because of the rapid decay in the wall heat capacity at low temperatures.

Experimental warm-up curves are given in figure 1.20 for single-ended warming. For constant properties, warm-up is simply the inverse of cool-down.

The analysis suggests the use of $\tau^{1} / \mathrm{N}_{\text {tu }}^{2}$ as a dimensionless correlating parameter for the cool-down curves. Then according to equation (1.26) or (1.30) the normalized wall temperature w will exhibit only a weak dependence $\left(\left[1+\frac{1.4}{N_{\text {tu }}}\right]\right.$ for doubled ended cooling) on $\mathrm{N}_{t u}$ for large $\mathrm{N}_{t u}$. Figure 1.21 compares the analytical and numerical results for zero heat leak in this fashion. When adjusted for $\mathrm{b}$ and $\mathrm{N}_{t u} \rightarrow \infty$, the numerical and analytical results agree to better than one percent. Considering the approximate nature of the analysis, this is probably fortuitous.

The dependence of the cool down parameter $\tau^{\prime} / \mathrm{N}_{\mathrm{tu}}^{2}$ on $1 / \mathrm{N}_{\mathrm{tu}}$ is shown in figure 1.22 , and it appears that the sinusoidal approximation underestimates this dependence. For $\mathrm{N}_{t u}>5$, $\tau^{\prime} / \mathrm{N}_{\mathrm{tu}}^{2} \sim\left(1+\frac{2.19}{\mathrm{~N}_{\mathrm{tu}}}\right)$ more closely describes the numerical results (both ends cooled).

The dependence of $\tau^{1} / N_{t u}^{2}$ on the heat capacity ratio $b$ is shown in figure 1.23 . In this case the analysis, $\tau^{\prime} / N_{t u} \sim\left(1+\frac{2}{b}\right)$, agrees with the numerical results within the accuracy of the calculations. This should be expected since $\left(1+\frac{2}{b}\right)$ is the total dimensionless heat capacity for the system described by equations (1.4) through (1.6), i.e., $\left(1+\frac{2}{b}\right)$ is the dimensionless sum of the wall heat capacity plus the go and return stream heat capacities. Thus, for this simple system, the cool-down time is proportional to the total heat capacity of the walls and fluid, but independent of its distribution.

On the basis of figures 1.21 and 1.22 , we may modify the analytical results to give a $\tau^{\prime} / \mathrm{N}_{\mathrm{tu}}^{2} \sim\left(1+\frac{2.19}{\mathrm{~N}_{\mathrm{tu}}}\right)$ dependence. Equations (1.26), (1.29), and (1.30) then become:

$$
\begin{gathered}
u_{\ell}=\left[1-\frac{Q L}{\pi m C_{p}\left(T_{i}-T_{f}\right)_{0}}\right] \exp \left[-\frac{\pi^{2} \tau_{2}}{2 L^{2}\left(1+\frac{\pi^{2}}{4 L}\left(1+\frac{b}{2}\right)\right.}\right]+\frac{Q L}{\pi m C_{p}\left(T_{i}-T_{f}\right)} \\
\tau_{c d}^{\prime}=1.048 N_{t u}^{2}\left(1+\frac{1.10}{N_{t u}}\right)\left(1+\frac{2}{b}\right)
\end{gathered}
$$

for single ended cool down, and

$$
\tau_{c d}^{\prime}=0.262 \mathrm{~N}_{t u}^{2}\left(1+\frac{2.19}{N_{t u}}\right)\left(1+\frac{2}{b}\right)
$$

for doubled-ended cool-down (90 percent cool down for both cases). Equations (1.26a), $1.29 \mathrm{a})$, and (1.30a) represent the numerical constant property and mass flow results to within one percent for $\mathrm{N}_{t u} \geq 10$ and to within about four percent for $5<\mathrm{N}_{t u}<10$. 


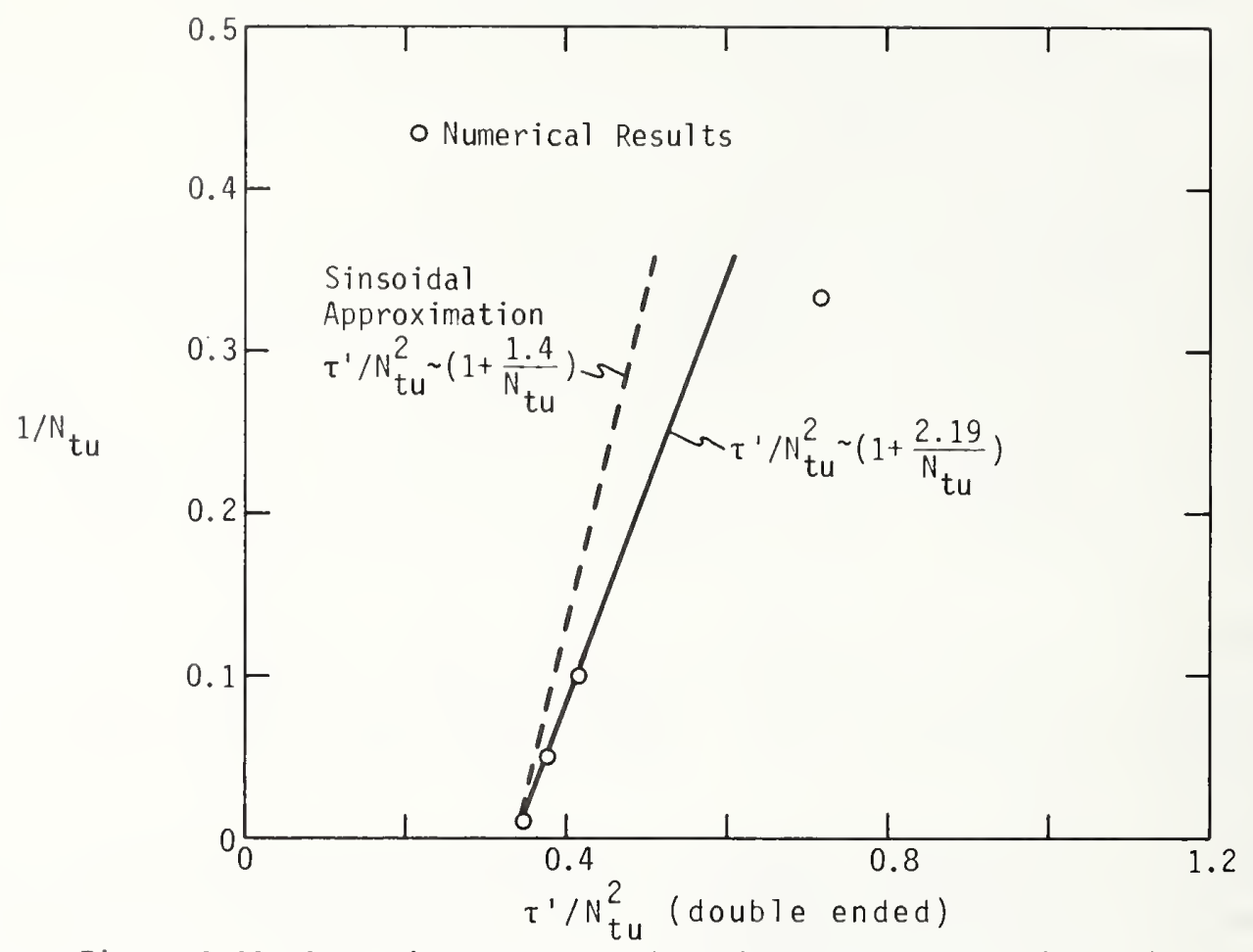

Figure 1.21 Analytical and numerical (constant property) cooling curves in terms of of dimensionless parameters.

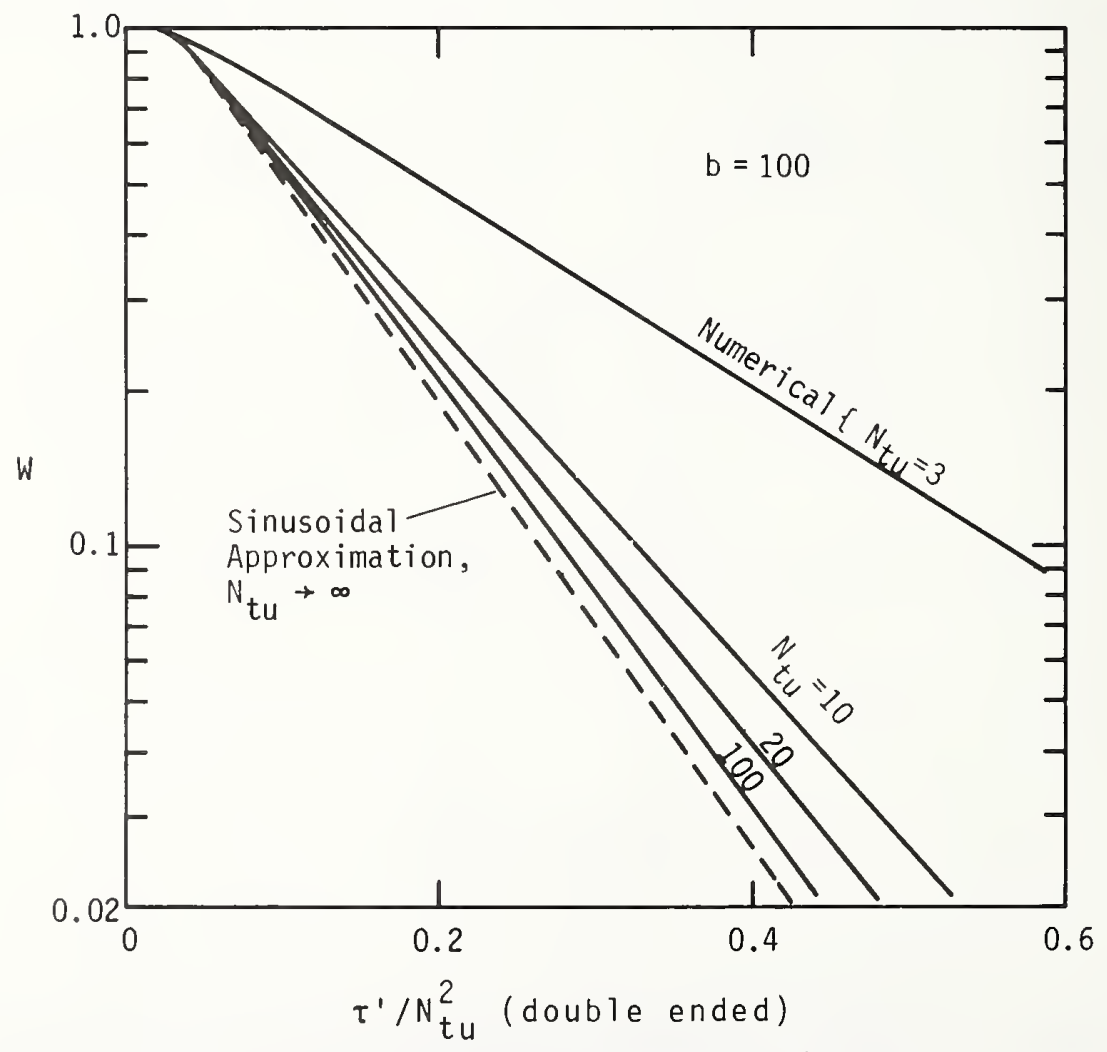

Figure 1.22 Dependence of the cool-down parameter $\tau^{\prime} / \mathrm{N}_{\mathrm{tu}}^{2}$ on $1 / \mathrm{N}_{\mathrm{tu}}$. The parameter $\tau^{\prime} / N_{t u}^{2}$ is evaluated at $w=0.05$. 


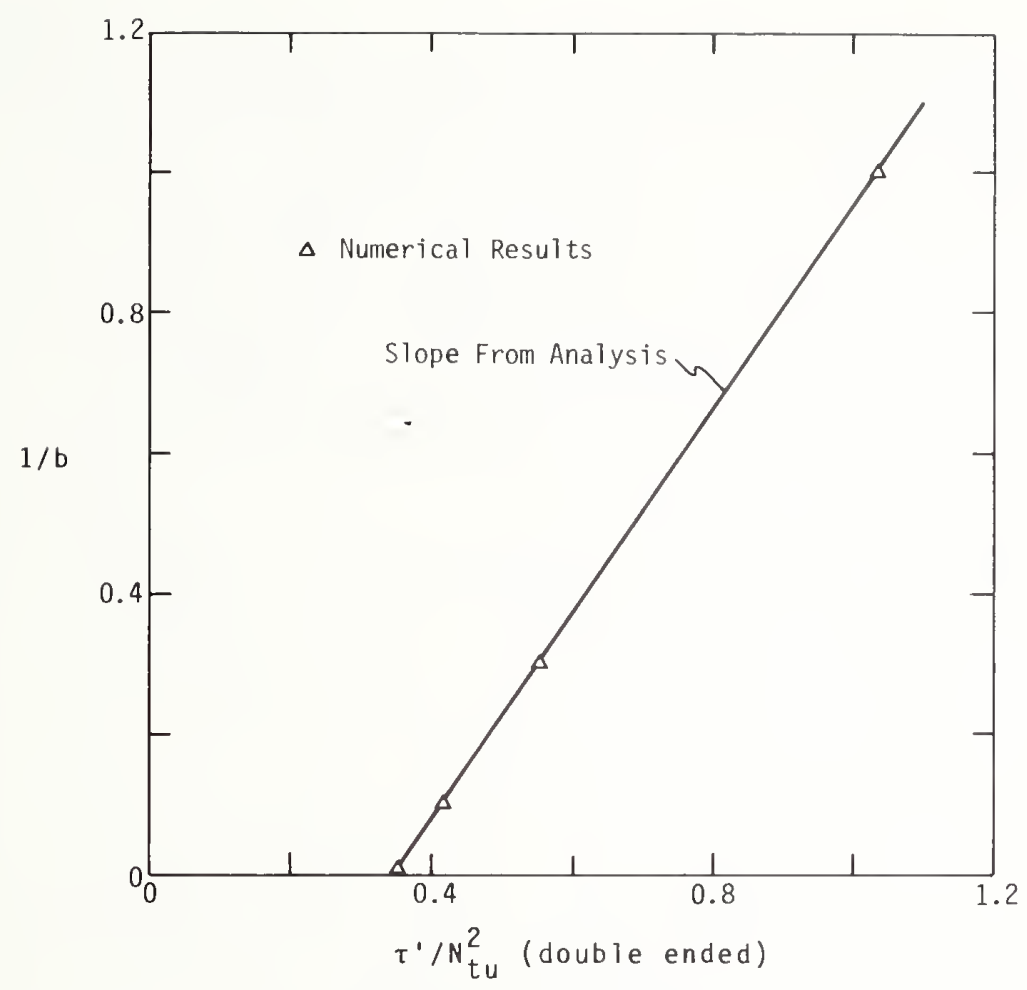

Figure 1.23 Dependence of the cool-down parameter $\tau^{\prime} / N_{t u}^{2}$ on the heat capacity ratio b. The parameter $\tau^{1} / \mathrm{N}_{\text {tu }}^{2}$ is evaluated at $\mathrm{w}=0.05$.

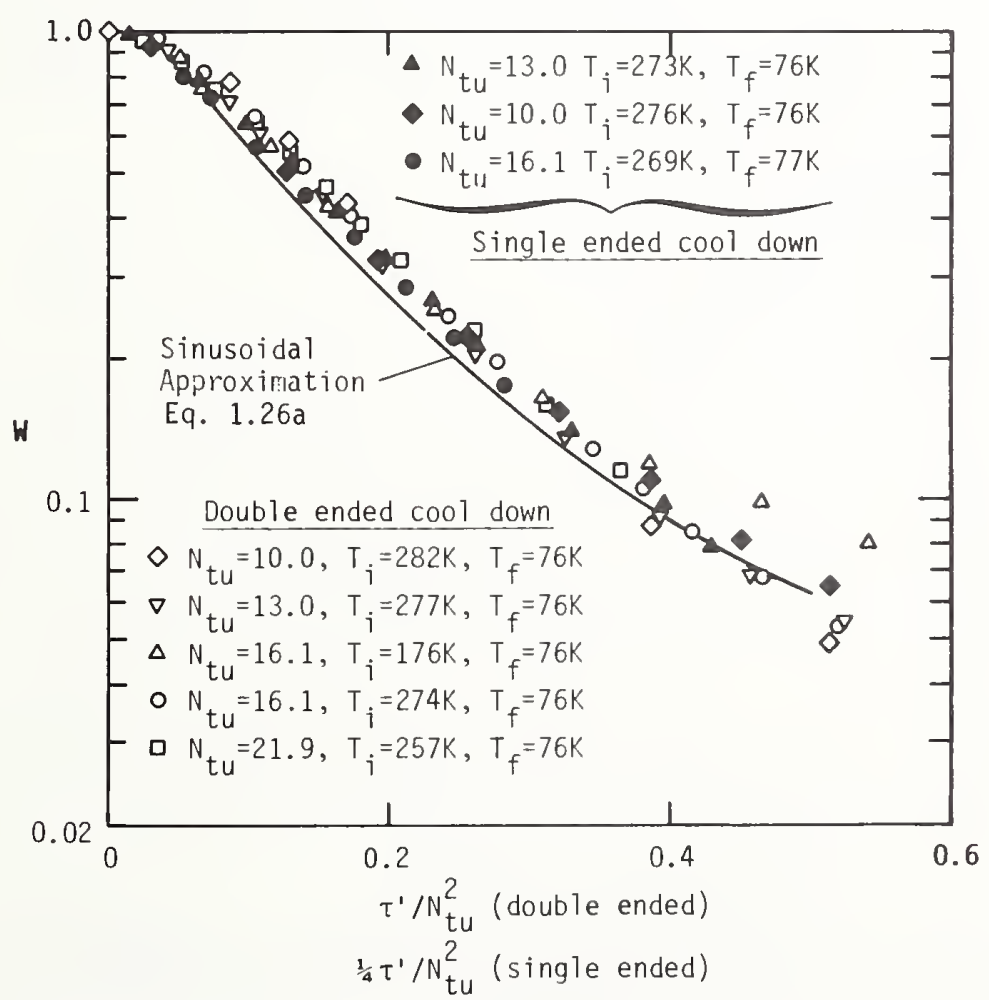

Figure 1.24 Comparison of the experimental and modified analytical (equation 1.22a) cooling curves for cool down to $76 \mathrm{~K}$. The results are given in dimensiontess parameters. 


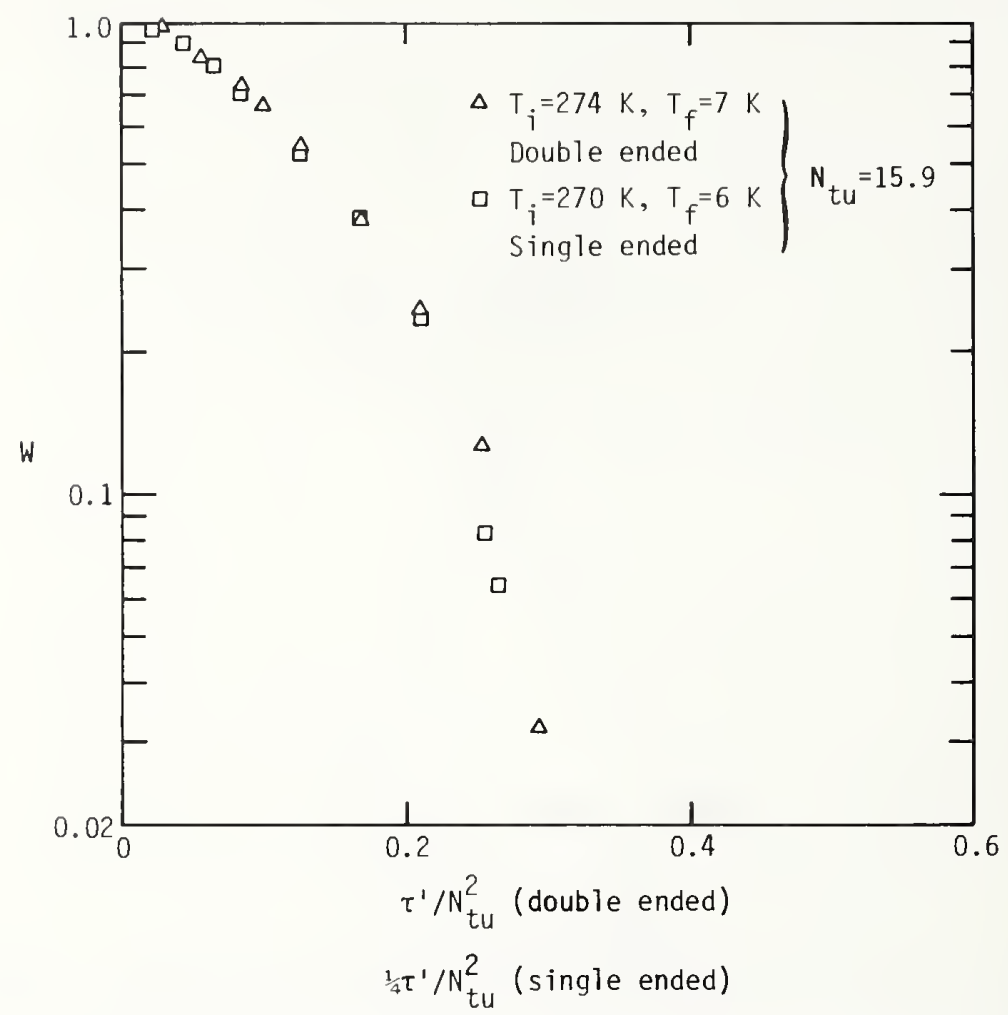

Figure 1.25 Experimental cooling curves in dimensionless parameters for cool-down to $6 \mathrm{~K}$. The normalized temperature $w$ is given at $x / \ell=0.5$ for both ends cooled and at $x / \ell=1.0$ for one end cooled.

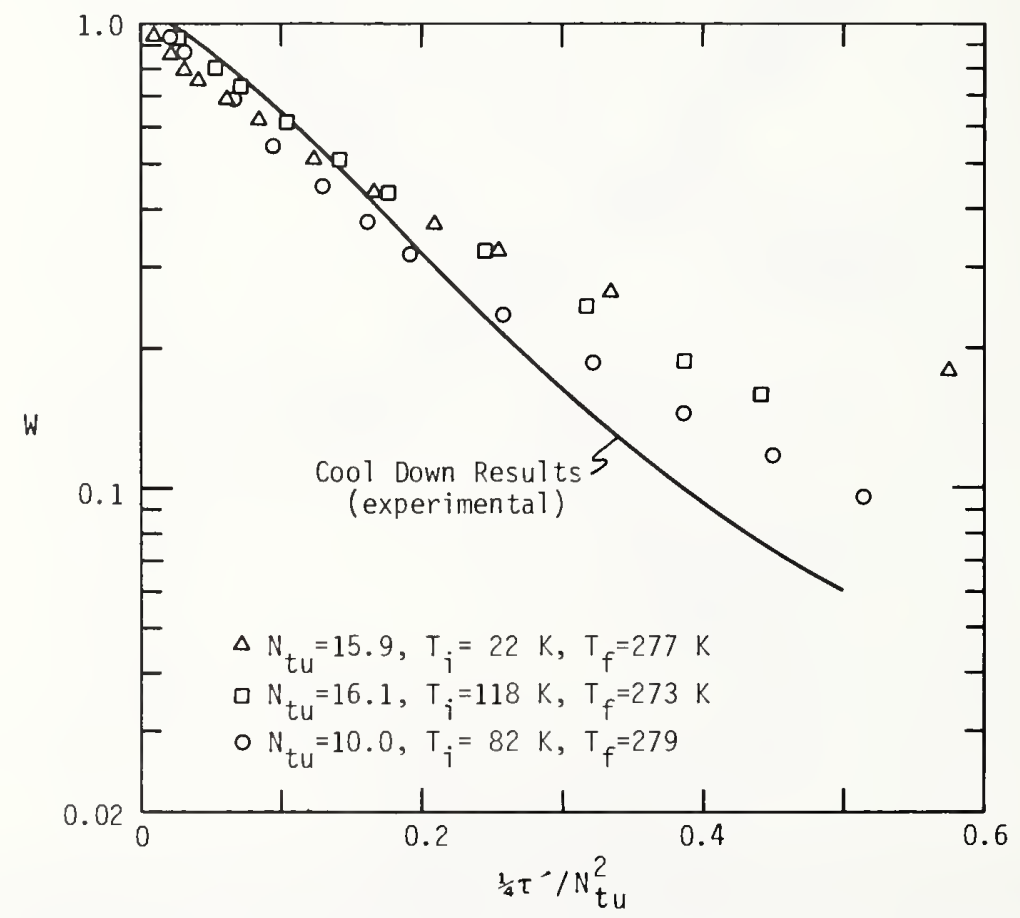

Figure 1.26 Experimental warming curves in dimensionless parameters. 
A comparison of (equation 1.26a) with the $\mathrm{LN}_{2}$ temperature cooling experiments is given in figure 1.24. Note that the parameter $\tau^{1} / N_{\text {tu }}^{2}$ coalesces the experimental data to a single curve, even though the dimensional cool-down times (figure 1.17 and 1.18) differ by more than a factor of 10 . To generate the curve, equation (1.26a) was evaluated for $N_{\text {tu }}$ $=15$ and $Q L / m C p\left(T_{i}-T_{f}\right)=0.05$, values typical of the experiments. There are several differences between experiment and analysis. In the experiment, the test section heat capacity varies with temperature. The heat leak varies both with time during an individual experiment and varies from experiment to experiment as wel1. Considering these differences between experiment and analysis, the agreement of the experiment with the analysis is better than expected.

Figure 1.25 presents the helium temperature cooling curves (figure 1.18) as a function of the cool-down parameter $\tau^{1} / N_{t u}^{2}$. As with the liquid nitrogen temperature experiments, this formulation coalesces the data to a single curve. The convex shape of the curve is due to the large variation in the test section heat capacity with temperature. Complete cool down is achieved at $\tau^{\prime} / N_{\text {tu }}^{2} \approx 0.3$ (double ended cooling).

Comparison of the warm up experiments with the cool-down experiments (figure 1.26) shows, as expected, that warm up is essentially the inverse of cool-down. Initially, warm-up proceeds somewhat faster because of the lower initial heat capacity. The effect of heat leak is much larger in the warm-up experiments since the final stage of the warmup occurs at ambient temperature where radiation heat transfer effects are much larger. In the warm-up of a real SPTL, the heat leak will always be positive (into the line) so that heat leak will aid the warm-up. In these warm-up experiments, the heat leak is negative and consequently slows down the warm-up.

1.5 Detailed Computer Program for the Calculation of Cool-Down - Comparison with Experimental Results

Previous to the work reported in the sections thru 1.4, one of us (MCJ) developed a more detailed computer program for the calculation of flow and heat transfer transients in channels in which single phase (supercritical) helium is a coolant. This program differs from the numerical solution of equations 1.4 thru 1.7 in that it considers energy, momentum, and continuity for each channel rather than just energy, and in that variable thermal properties are considered for both the cable and the coolant. The main features of the program are:

i) Time-dependent fluid behavior is described by a transformed set of three partial differential equations of conservation with dependent variables pressure $P$, enthalphy $H$, and velocity $U$. These variables represent cross-sectional averages, the flow being treated one-dimensionally.

ii) Fluid properties and other thermodynamic variables such as temperature are represented by polynomials with $\mathrm{P}$ and $\mathrm{H}$ as arguments. The use of polynomials permits fast computation with acceptable error. These polynomials are contained in a properties subroutine for continuous up-dating to current local conditions. 
iii) Linear heat transfer to the channel wall is allowed and the temperature of the channel wall is described by the transient heat conduction equation for one-dimensional heat flow.

iv) The resulting set of 8 partial differential equations is solved with appropriate boundary and initial conditions by an available software package based on finite element collocation.

Further details can be found in reference [1].

The computer program has been used to make predictive calculations on the cool-down of superconducting power transmission lines (SPTL's) and for the study of transients in hollow superconductors. Now that experimental results are available for cool-down, it seemed wise to validate the computer program by comparison of computed with experimental results. This work is now partially complete and here we report the results of a comparison with an experiment in which a conduit with two thermally coupled streams in counter flow was cooled with supercritical helium to liquid nitrogen temperature. The discussion following refers to the run of $3 / 1 / 79$ in which a mass flow rate of $0.3 \mathrm{~g} / \mathrm{s}$ was fed in at each end of the test section.

The comparison we have made shows first of all that perhaps the least well-known quantity is the time dependent heat leak. The experiments described in this report (see figure 1.10) show that this is a complex function since it first increases and then decreases with time due to experimental conditions discussed in Section 1.4. It was therefore necessary to fit the heat leak function to the experimental results. It was found that for all runs a single crude approximation of the form

$$
Q_{\text {leak }}=a t e^{-b t}+c\left(1-e^{-d t}\right)
$$

could be used, where $Q_{1 e a k}$ is a lumped heat leak and a,b,c, and d are empirical constants. Results for the mid-point temperature computed as a function of time using the above heat leak function are shown in figure 1.27. In the dashed curve, the actual measured mass of the two-stream channel was used. In all other respects this was a calculation from first principles and while the error is acceptable for engineering purposes it indicates an imprecise knowledge of the thermal capacity of the two-stream channel or the heat transfer resistance between the two streams, or both. Now the actual thermal capacity is known experimentally from single-stream cool-down experiments. In that determination (and in the cool-down computation) the heat capacity data from [11] was used and it was then found that the effective mass of the test section was $4.603 \mathrm{~kg}$. In separate steady-state, it was determined that the product of overall heat transfer coefficient and heat transfer area (UA) was $20.31 \mathrm{~W} / \mathrm{K}$. These figures compare with the measured mass of $4.095 \mathrm{~kg}$ and a calculated UA of $19.54 \mathrm{~W} / \mathrm{K}$ used in the computation. We therefore ran the computation again with the larger figures. The result for mid-point temperatures is the solid curve in figure 1.27. The agreement with experiment is now seen to be almost exact.

A comparison of computed and measured temperature profiles at two different times during cool-down is shown in figure 1.28. Again the agreement is almost exact. 


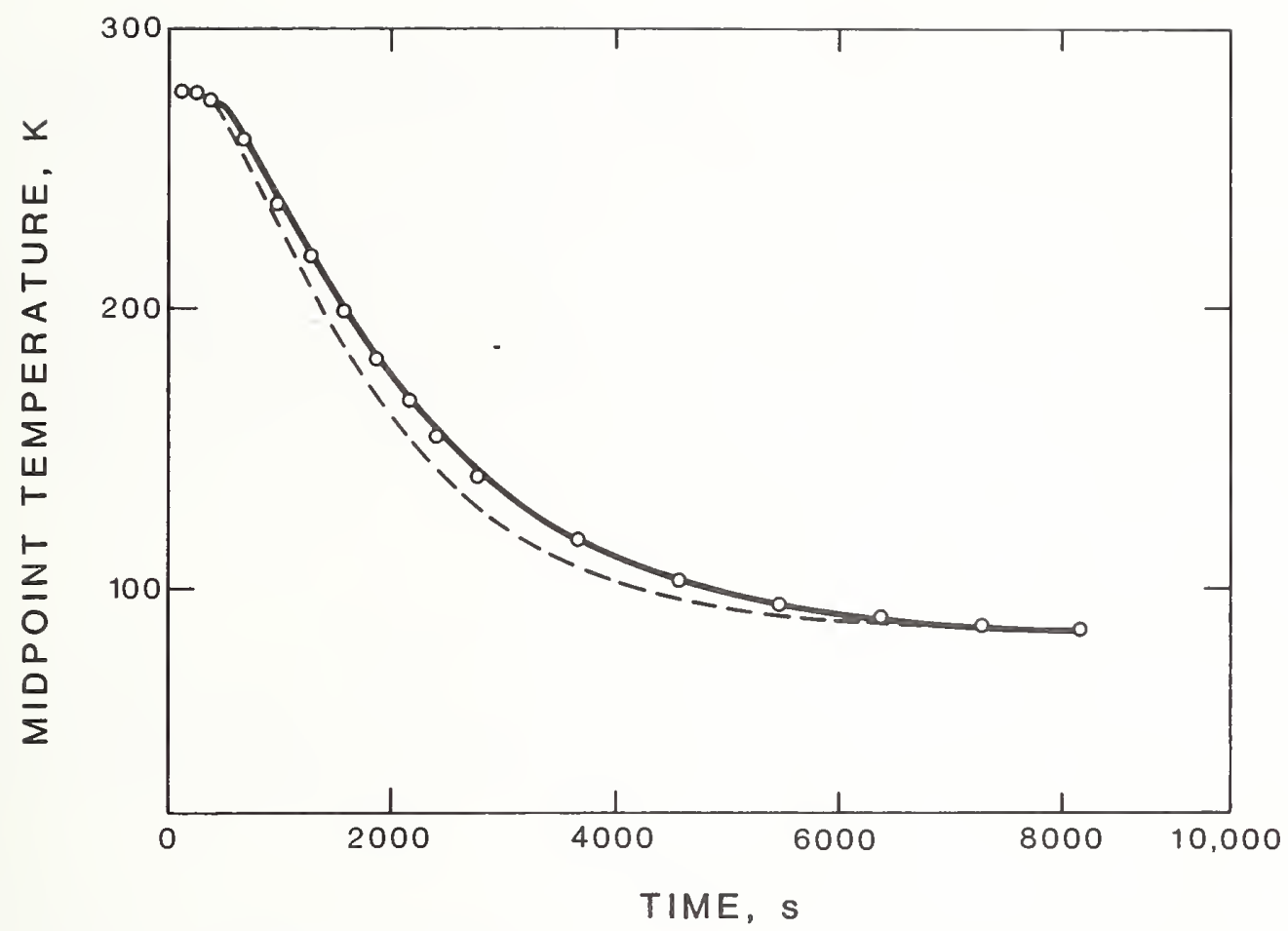

Figure 1.27 Comparison of computed mid-point temperature with experimental cool-down results. o, experimental;---computed (measured test section mass);--computed (effective test section mass).

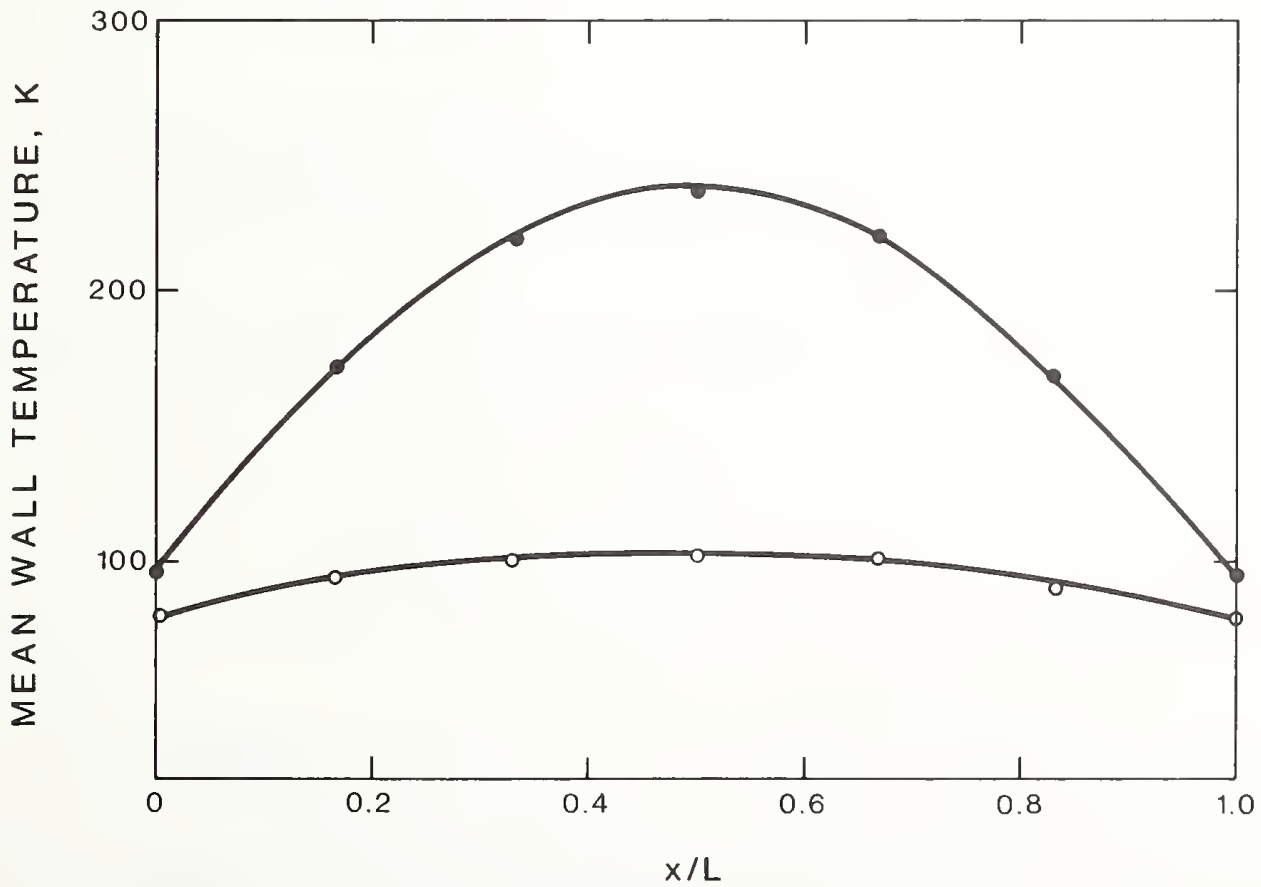

Figure 1.28 Comparison of computed with experimental temperature profiles. Experimental results, - 960s, o 4560s. Computed curves are for 1000 s and 4500s respectively. 
With the comparison at SPTL operating temperature yet to be completed, we conclude tentatively that the computer program is capable of excellent prediction provided the heat leak function, the effective mass, and the heat transfer resistance are accurately known. The latter two quantities can apparently be estimated from first principles - at least for the simple experimental simulation - with acceptable accuracy. Because of its relatively high value in the laboratory experiments, the heat leak function is more critical and in this instance, it was necessary to rely on the experimentally determined function. In the case of cool-down calculations for full-scale SPTL's, the relative size of the heat leak is much smaller and the results are not particularly sensitive to the heat leak function.

\subsection{Summary}

We have investigated the two stream counterflow method of SPTL cool-down by a combined analytical, numerical, and experimental approach. The experiments were conducted with well-controlled boundary conditions and constant mass flow rate for ease of comparison with the analytical and numerical methods.

Counter flow cool-down progresses in two stages. During the first, and shorter, stage a constant amplitude temperature wave develops until it extends the full length of the line, figure 1.3. During the second stage the amplitude of this wave decays exponentially to zero, figure 1.4. The rate of decay is proportional to the temperature difference between the go and return streams (i.e., to the rate of refrigeration) which in turn is proportional to the thermal resistance between the go and return streams, i.e.

$$
t_{c d} \sim U\left(\frac{\ell}{n}\right)^{2}
$$

for large $\mathrm{N}_{\text {tu. }}$. Thus for perfect heat transfer between the two streams $(U \rightarrow \infty)$ the cool-down time goes to infinity. Clearly, poor thermal contact between the go and return streams is required for short cool-down times.

The flow rate in a full-scale transmission line will usually be limited by the available pressure drop, in which case analysis gives

$$
t_{c d} \sim \frac{U_{\ell}{ }^{3}}{\bar{p} \Delta p} .
$$

The more detailed results of the analysis are given by equations $1.26 a, 1.29 a$ and 1. 30a.

We conclude by noting that the analytical results give a reasonable prediction of the cool-down time for the constant mass flow rate case when average property values are used. The detailed numerical model reproduces the experimental results for cool-down to $80 \mathrm{~K}$ so that we may expect that it will also give accurate estimates for cool-down to SPTL operating conditions for a variety of boundary conditions. 


\subsection{Nomenclature}

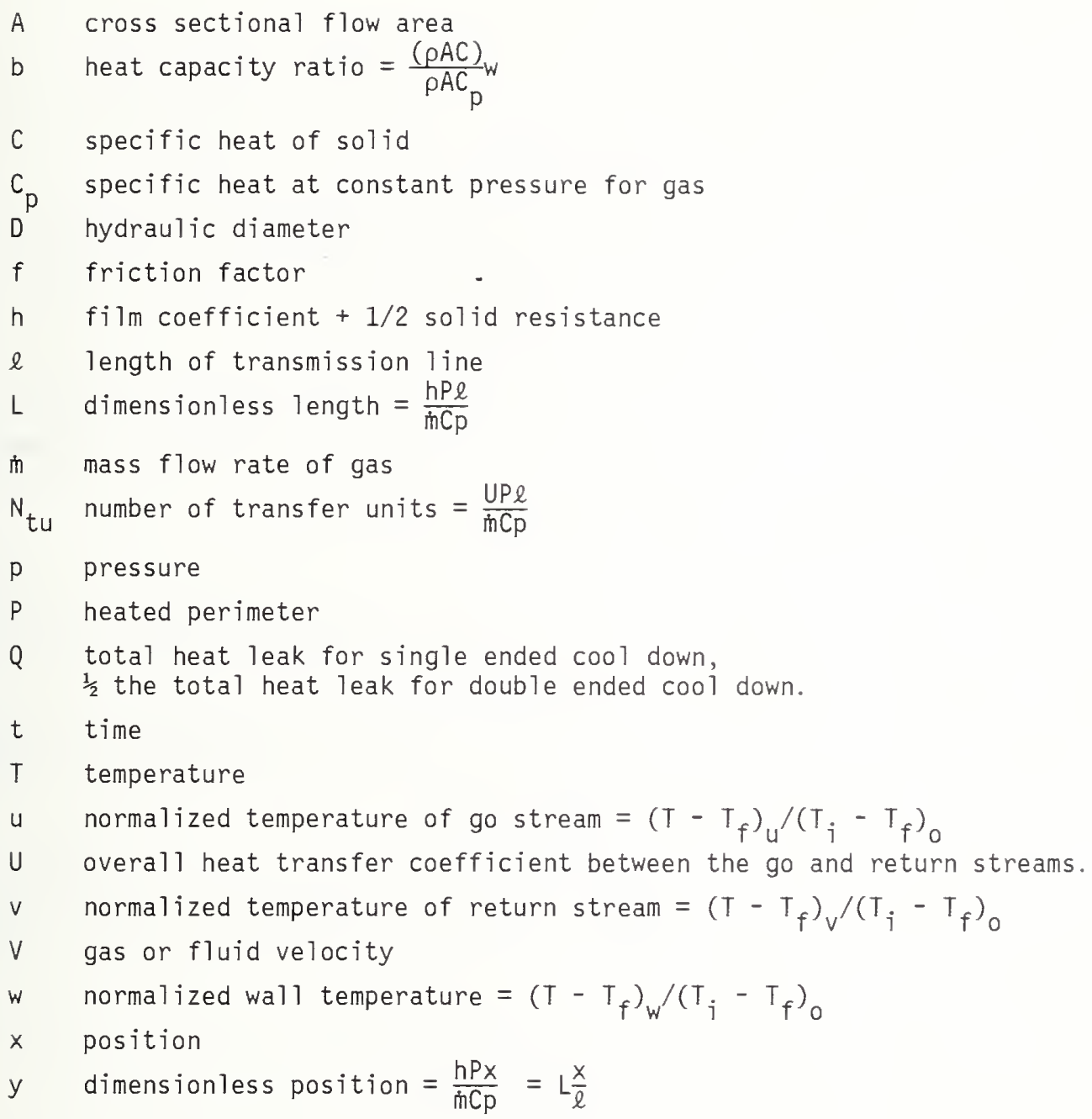

Greek

$\varepsilon \quad$ heat exchanger effectiveness

$\lambda$ dimensionless position of wave front during the first phase of cool down.

$\rho$ density (gas if unsubscripted)

$\tau \quad$ dimensionless time $=\frac{h P}{(\rho A C)_{W}} t$

$\tau^{\prime} \quad$ dimensionless time $=\frac{U P}{(\rho A C)_{W}} t$

Subscripts

cd cool down

i initial condition

in inlet

$f$ final condition for zero heat input

\& $\quad x=$ position

o $\quad x=0$ position out outlet

u go stream

$\checkmark$ return stream

w wall

1 first phase of cool down

2 second phase of cool down 
[1] Jones, M. C., Cool down of superconducting power transmission lines with single phase helium, Cryogenics, 20, pp 139-145 (1980).

[2] Dean, J.W., and Jensen, J. E., Supercritical helium refrigerator for superconducting power transmission cable studies, Advances in Cryogenic Engineering, Ed. K. D. Timmerhaus, 21, pp 197-204 (Plenum Press, New York, 1976).

[3] Wilkinson, K. J.R., Prospect of employing conductors at low temperature in power cables and in power transformers, Proc. I.E.E., 113, No. 9, pp 1509-1521 (September $1966)$.

[4] Garwin, R. L., and Matison, J., Superconducting lines for the transmission of large amounts of electric power over great distances, Proc. I.E.E.E., 55. No. 4, pp 538-548 (Apri1 1976).

[5] Norris, W. T., and Swift, D. A., Developments augur design of superconducting cables, Electric World, 168, No. 4, pp 50-53 (July 24, 1967).

[6] Fleming, R. B., Cooling on electric cable by means of counter-flow fluid streams, Report No. 67-C-419, General Electric Research and Development Center, Schenectady, New York (October 1967).

[7] Edney, K., Fox, M., and Gilbert, G., Longitudinal temperature distribution in low temperature cables with counter-flow cooling, cryogenics, 7 , pp 355-358 (1967).

[8] Morgan, G. H., and Jensen, J. E., Counter-flow cooling of a transmission line by supercritical helium, Cryogenics, 17, pp 259-267 (1977).

[9] Madsen, N. K., and Sincovec, R. F., Numerical methods for differential systems, Ed. L. Lapidus and W. E. Schiesser, pp 229-242 (Academic Press, Inc., New York, 1976).

[10] Eckert, E. R. G., and Drake, Jr., R. M., Heat and mass transfer, p 485 (McGraw - Hi11 1959).

[11] Collings, E. W., Jelinek, F. J., Ho, J. C., and Mathew, M. P., Advances in Cryogenic Engineering, 22, p 159 (Plenum Press, New York, 1977). 
1.9 Appendix - Cool-down time for constant pressure drop boundary condition

Starting with the general expression for pressure drop in a tube,

$$
d p=-\frac{32 f}{\pi^{2} D^{5}} \cdot \frac{\dot{m}^{2}}{\rho} \cdot d x
$$

and assuming an ideal gas equation of state,

$$
\rho=\frac{P}{R T}
$$

gives

$$
d p=-\frac{32 f R}{\pi^{2} D^{5}} \cdot \frac{T m^{2}}{p} \cdot d x
$$

where $T=T(x)$ and $m=m(t)$.

The sinusoidal temperature distribution assumed in equation 1.13 may also be written as

$$
T(x)=\left(T_{\ell}-T_{0}\right) \sin \frac{\pi}{2} \frac{x}{\ell}+T_{0}
$$

Substituting $1.3 \mathrm{a}$ into $1.2 \mathrm{a}$ and integrating over the length of the channel gives

$$
\begin{aligned}
\dot{m}^{2}=\frac{\bar{p} \Delta p}{\ell} \cdot \frac{1}{\mathrm{C}\left[\frac{2}{\pi}\left(T_{\ell}-T_{0}\right)+T_{0}\right]} \\
\bar{p}=\frac{P_{\ell}+P_{0}}{2} \\
\Delta P=P_{0}-P_{\ell} \\
C=\frac{32 f R}{\pi^{2} D^{5}}
\end{aligned}
$$

where

To obatin the cool-down time for constant pressure drop in the go-stream, we return to equation 1.12, the first law of thermodynamics for the transmission line:

$$
\dot{m} C_{p} v_{0} d t=-(\rho A C)_{w}\left(1+\frac{2}{b}\right) \int_{0}^{e}[w(x, t+d t)-w(x, t)] d x .
$$


The normalized temperature difference between the go and return streams, $v_{0}$, is given by equation 1.17 as

$$
v_{0}=\frac{\pi}{L} u_{\ell}
$$

or, noting that

$$
\begin{aligned}
L & =\frac{h P \ell}{\dot{m} C p} \\
v_{0} & =\frac{\pi m C p}{h P}
\end{aligned}
$$

Substituting $1.6 \mathrm{a}$ into $1.5 \mathrm{a}$, replacing $\dot{\mathrm{m}}^{2}$ with $1.4 \mathrm{a}$ and evaluating the integral on the right hand side of $1.5 \mathrm{a}$ gives

$$
\frac{\pi^{2} C p^{2}}{h P} \cdot \frac{\bar{P} \Delta P}{\ell^{3}} \cdot \frac{u_{\ell}}{C\left[2 / \pi\left(T_{\ell}-T_{0}\right)+T_{0}\right]} d t=-d u_{\ell}(\rho A C)_{w}\left(1+\frac{2}{b}\right)\left(1+\frac{\pi}{2 L}\right)
$$

Noting that

$$
\frac{2}{\pi}\left(T_{\ell}-T_{0}\right)+T_{0}=\left(T_{i}-T_{0}\right)\left[\frac{2 u_{\ell}}{\pi}+\frac{T_{0}}{T_{j}-T_{f}}\right]
$$

equation 1.7 a becomes

$$
\left(\frac{2}{\pi}+\frac{a}{u_{\ell}}\right) d u_{\ell}=-B \frac{\bar{P} \Delta P}{\ell^{3}} d t
$$

where

$$
\begin{gathered}
a=\frac{T_{0}}{T_{i}-T_{0}} \\
B=\frac{\pi^{4} C P^{2} D^{5}}{64(\rho A C)_{W}\left(1+\frac{2}{b}\right)\left(1+\frac{\pi}{2}\right) h P f R\left(T_{i}-T_{0}\right)}
\end{gathered}
$$

If we neglect the time dependence of $L$, ie assume that $L$ is large, then we may integrate 1.9 a to give

$$
\frac{2}{\pi}\left(u_{\ell}+1\right)+a \log \left(u_{\ell}\right)-B\left(\frac{\bar{P} \Delta P}{\ell^{3}}\right) t
$$

for the initial condition of $u_{\ell}=1$ at $t=0$. 


\subsection{CABLE PERMEABILITY}

(P. R. Ludtke and D. E. Daney)

In case of a rupture in the lead sheath of the cable, it is important to know how much leakage from the pressurized (15 bar) cable might occur. Our measurements of the cable permeability were intended to define the magnitude of the problem rather than to give a precise value for the leak rate at the anticipated operating conditions.

The apparatus and the cable are the same ones that were used previously for thermal cycling of a BNL model cable [1]. . Figure 2.1 is a cut back view of the cable. As shown in figure 2.2, five symmetrically-spaced gas taps in the cable's lead sheath are connected to individual wet test gas flow meters. The taps are formed by soldering (Wood's metal solder) $4.8 \mathrm{~mm}$ ID tubes into holes cut in the lead sheath. Thus, the experiment measures the leak rate through the composite between the pressurized bronze core of the cable and the $4.8 \mathrm{~mm}$ diameter holes in the lead sheath spaced at $70 \mathrm{~cm}$ intervals. The effect of end leakage (between the core and the lead sheath) is given by the difference between the flow rates of the center tap and the end taps. The ambient pressure is .82 bar, and the pressure difference across the cable is the gauge pressure. Helium gas was used in all tests.

Figures 2.3 through 2.5 give the measured cable leak rate at ambient temperature and at $76 \mathrm{~K}$. Some shift in the ambient leak rate occurred even though the cable had previously been thermally cycled 20 times.

In order to estimate the leak rate at operating conditions ( $P=15$ bar and $T=8 \mathrm{~K}$ ), we use the expression:

$$
G \sim \sqrt{\frac{\rho \Delta P}{\mu}}
$$

and obtain a leak rate of about $15 \mathrm{~g} / \mathrm{s}$ per hole - extremly high. Here $\mathrm{G}$ is mass flux, $\rho$ density, $\Delta P$ pressure difference, and $\mu$ viscosity.

From these measurements we conclude that any significant rupture of the lead sheath will lead to an unacceptably high leak rate from the pressurized core. The high permeability of the composite within the lead sheath also suggests that some fluid convection in this layer may accompany forced flow inside the bronze core since the composite layer will experience the same axial pressure gradient.* As a result, the thermal conductance across the wrapped dielectric may be very much higher than anticipated. Because this conductance is critical to the performance of the SPTL, we strongly recommend that the radial thermal conductance of a cable be measured under the expected operated conditions, i.e., with supercritical helium flowing through the core.

\footnotetext{
*Natural convection effects in wrapped dielectrics have been measured separately by Thullen and Hajjar (F. G. Hajjar, Thermal Conductivity of Selected Dielectric Materials in Liquid Nitrogen, paper AIAA-80-0089, AIAA 18th Aerospace sciences meeting, January 14-16, 1980, Pasadena, California).
} 


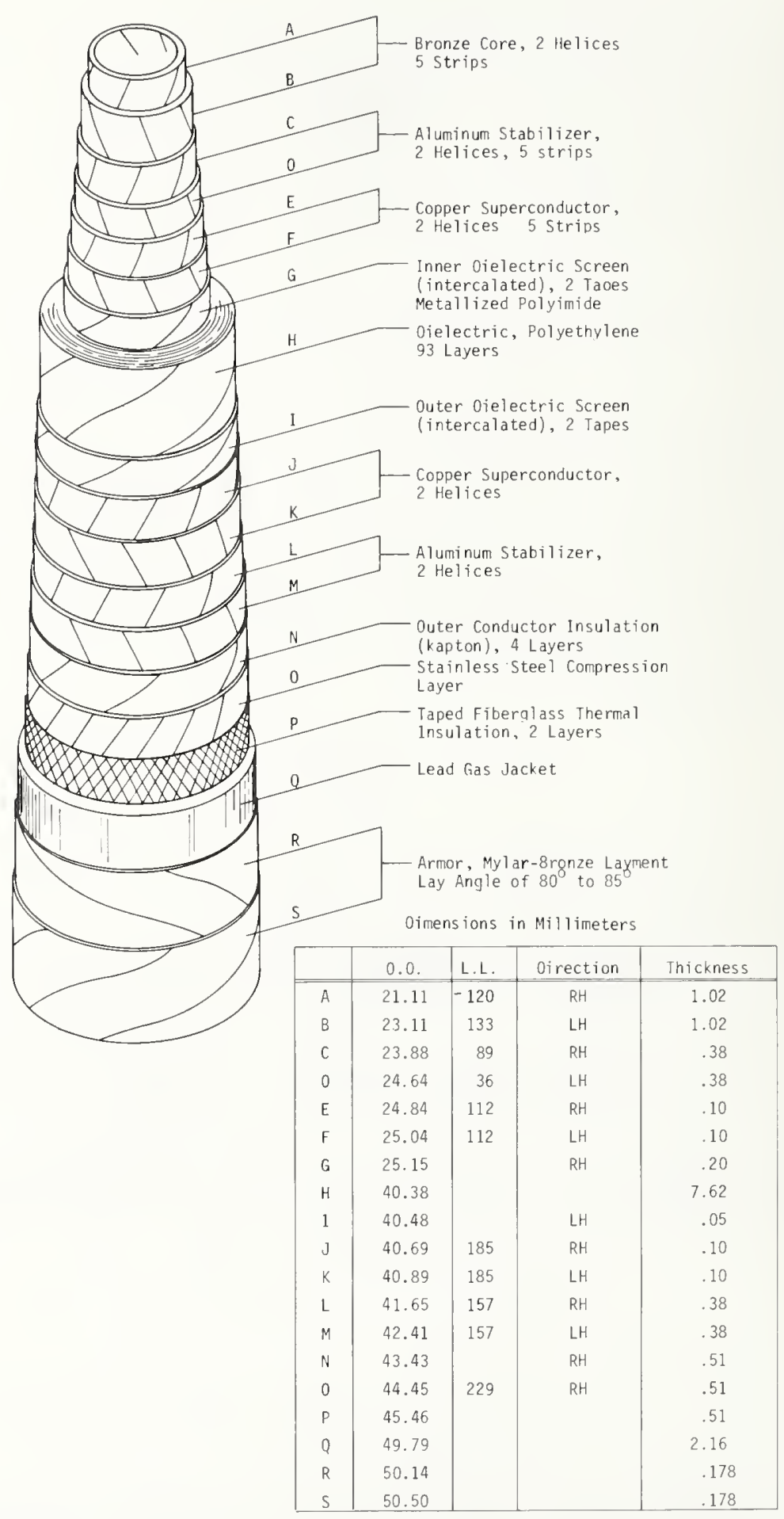

Figure 2.1 Cable cross section, cut back view 


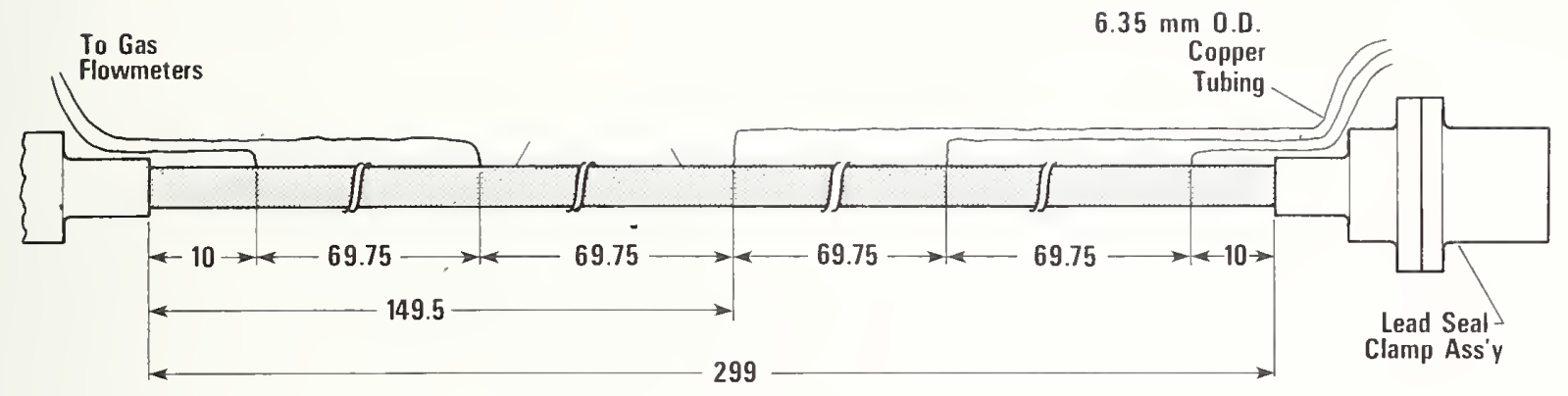

Figure 2.2 Cable permeability test arrangement.

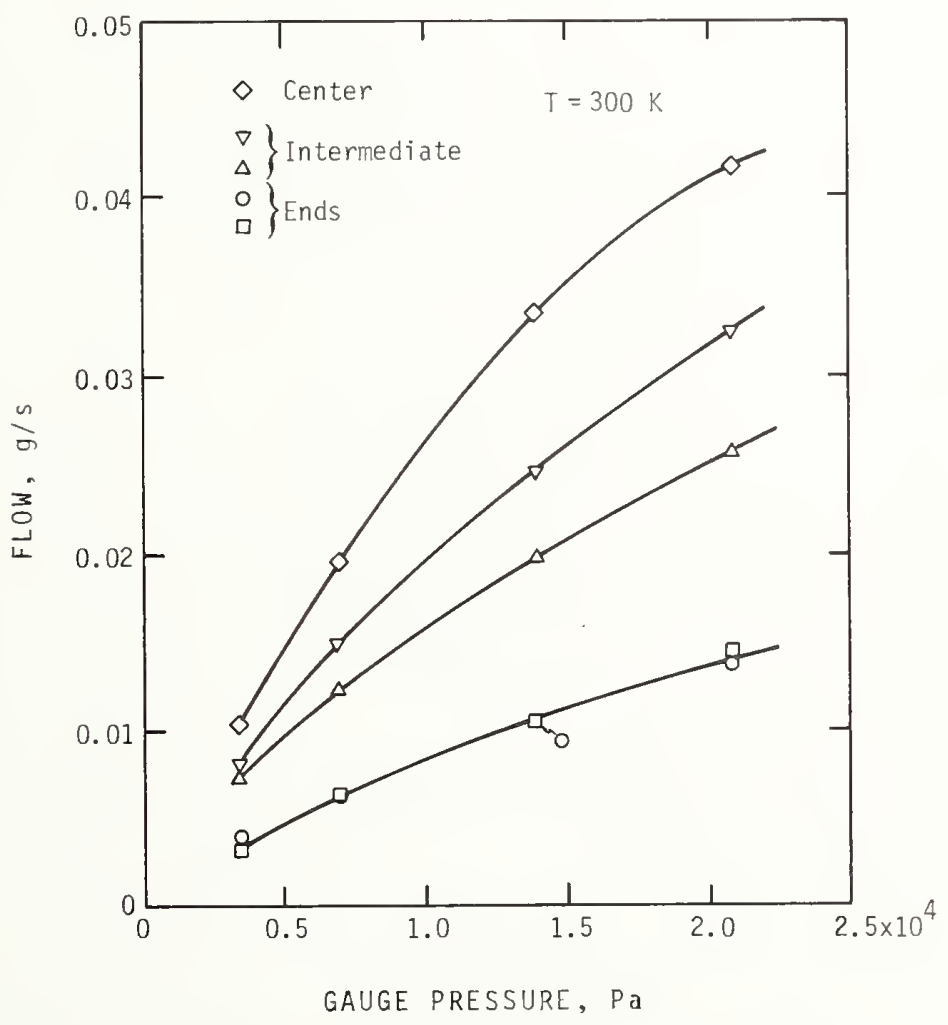

Figure 2.3 Cable leak rate before cool-down. 


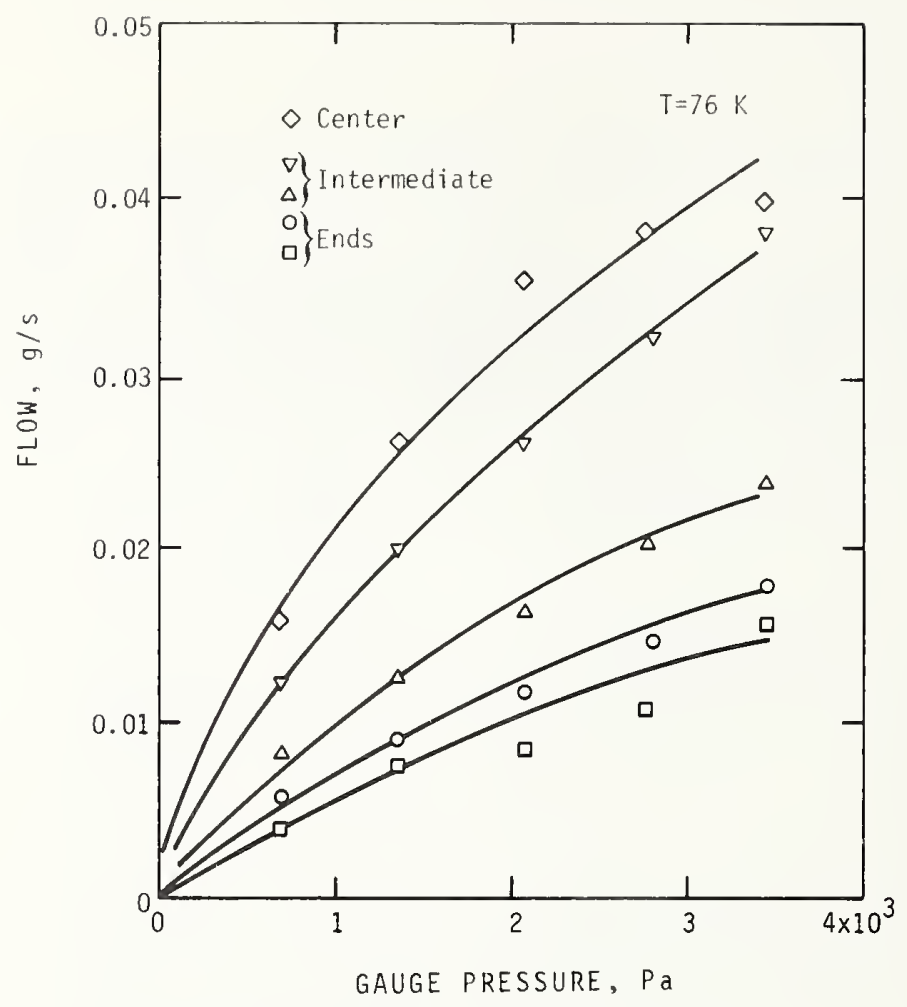

Figure 2.4 Cable leak rate at $76 \mathrm{~K}$.

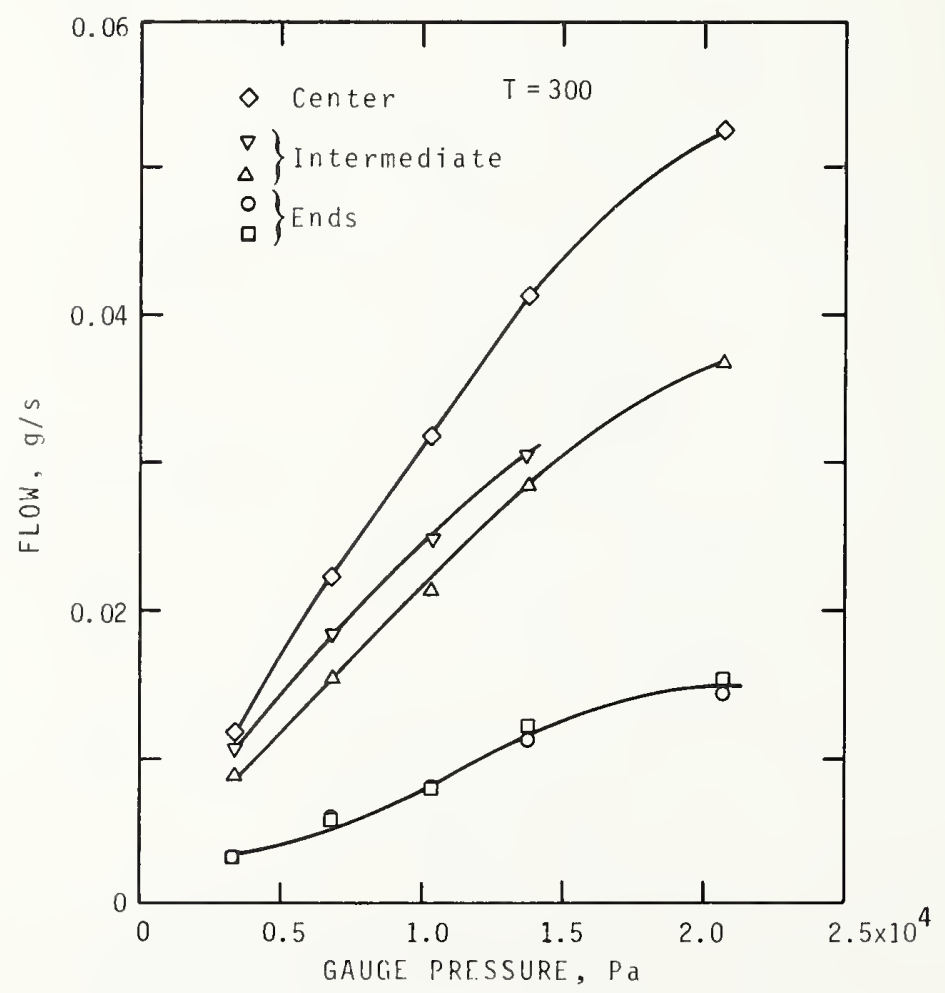

Figure 2.5 Cable leak rate after cool-down. 


\subsection{EVALUATION OF THERMAL FLUX METERS}

$$
\text { (P. R. Ludtke) }
$$

\subsection{Introduction}

Integrity of the insulating vacuum in the transmission line thermal enclosure is essential to the successful operation of the line. The standard practice for determining the integrity of a multilayer insulated cryostat is to measure the insulating vacuum directly. The required penetration of the vacuum space as well as the vacuum gauge itself, however, introduce an additional risk of a vacuum leak. For this reason, it is highly desirable to determine the integrity of the thermal insulation by some non-intrusive means.

Thermal flux meters, which are the subject of this study, have been proposed for this purpose. Not only are these meters non-intrusive because they are mounted on the outside of the enclosure wall, but they also provide the enclosure heat flux directly.

Successful field application of heat flux meters requires detailed study of a number of factors such as meter sensitivity and effects of moisture and other soil conditions. Most important, however, are the variations in the soil heat flux which might mask the rather low enclosure heat leak - approximately $30 \mu \mathrm{W} / \mathrm{cm}^{2}$. These variations in the soil heat flux have three basic periods; the diurnal variation, variations of a few days or weeks due to weather patterns, and the seasonal (yearly) variation. Since the amplitude of the variation in soil temperature is diminished by the factor

$$
\exp \left(-\sqrt{\pi / \alpha \tau_{0}} \quad \chi\right)
$$

the effect of the seasonal variation will be far larger than the diurnal variation. In the above, $\alpha$, is the thermal diffusivity of the soil, $\tau_{0}$ is the period and $x$ is the depth. Preliminary concern was centered on the diurnal

variation, and analysis indicated a signal to noise ratio of over 5,000 if the sensors are buried at a depth of $1.5^{\circ}$ meters. The results so far indicate that the effect of variable soil heat flux can largely be eliminated by taking the algebraic sum of the signals mounted $180^{\circ}$ from each other.

During this reporting period, laboratory testing of the heat sensors was completed, and field testing was initiated.

\subsection{Experimental}

The experimental study proceeded in two stages. First, the sensitivity of four pairs of commercial heat flux sensors were evaluated in the laboratory. Then, the sensors were evaluated under field conditions, i.e., buried and subjected to diurnal and longer term variations of the soil temperature and heat flux. 
The four pairs of heat sensors from different manufacturers are mounted on a $51 \mathrm{~cm}$ (20-inch) 0.D. $\times 61 \mathrm{~cm}$ (24-inch) long steel pipe which simulates the cryogenic envelope. Table 3.1 summarizes the properties of the meters. Six of the meters have flat surfaces, and the other two have surfaces contoured to fit the outer surface of the pipe. Copper adapters with one side flat and the other side curved were machined from high purity copper. The adapters were designed such that the curved surface area was equal to the flat surface area of the heat flow meters. A moderately high-thermal-conductivity epoxy was used to bond the adapters and meters to the steel pipe. Sensors from each pair were mounted $180^{\circ}$ from each other on a circumferential centerline equidistant from each end of the pipe. The outer surface of the pipe was divided by four quadrant lines parallel to the pipe's axis. Two sensors were placed near each quadrant line; the edge of each sensor was $2 \mathrm{~cm}$ from the quadrant line.

Early in the program, four sandwich-type meters delaminated. The copper or aluminum surface plates, which are bonded to the inner plastic core, separated and three of the four meters were replaced by manufacturers C \& D prior to testing. Later in the program, the fourth sensor malfunctioned 28 days into the field test. Meters $A$ and $B$ are of one piece plastic construction, and appear to be much better sealed for an underground application where moisture is of concern. All of the meters have a monitoring thermocouple within the meter body.

Uniform heat flux is generated by a heater mounted on the inside surface of the pipe. It is fabricated from 60 series-connected segments of stainless steel shim stock $.05 \mathrm{~mm}$ (.002-inch) $\times 25.4 \mathrm{~mm}(1-i n c h) \times 60 \mathrm{~cm}$ (23 3.4-inch), bonded by RTV silicone to $.13 \mathrm{~mm}$ (.005-inch) polyimide film electrical insulation.

Table 3.1--Heat-Flow Meter Specifications

\begin{tabular}{|c|c|c|c|c|c|}
\hline Brand & $\begin{array}{l}\text { Size } \\
(\mathrm{cm})\end{array}$ & $\begin{array}{l}\text { Contoured } \\
\text { Surface }\end{array}$ & $\begin{array}{c}\text { Manufacturer's } \\
\text { Sensitivity }\end{array}$ & $\begin{array}{l}\text { Type of } \\
\text { Construction }\end{array}$ & $\begin{array}{l}\text { Type of } \\
\text { Sensor }\end{array}$ \\
\hline & & & $\frac{\text { watts }}{\mathrm{cm}^{2}-\mathrm{mv}}$ & & \\
\hline
\end{tabular}

\begin{tabular}{|c|c|c|c|c|c|}
\hline A & $11.4 \times 11.4 \times .48$ & NO & 300 & $\begin{array}{l}\text { Integral, } \\
\text { Epoxy Glass }\end{array}$ & Thermopile \\
\hline B & $5.08 \times 15.2 \times .64$ & YES & 135 & $\begin{array}{l}\text { Integral, } \\
\text { Dially1 } \\
\text { Phthalate }\end{array}$ & Thermopile \\
\hline C & $15.2 \times 15.2 \times .47$ & NO & 113 & $\begin{array}{l}\text { Sandwich, } \\
\text { Copper- } \\
\text { Polyimide }\end{array}$ & $\begin{array}{l}\text { Solid State } \\
\text { Thermopile }\end{array}$ \\
\hline D & $5.08 \times 5.08 \times .25$ & NO & 160 & $\begin{array}{l}\text { Sandwich, } \\
\text { Aluminum- } \\
\text { Phenolic }\end{array}$ & $\begin{array}{l}\text { Solid State } \\
\text { Thermopile }\end{array}$ \\
\hline
\end{tabular}


Potential taps at the heater ends are used for measuring the electric power input. The effects of end losses are minimized by mounting the heat-flux sensors at the axial center of the pipe. A photo of the heater strips inside the pipe section is shown in figure 3.1. The inside of the pipe was then filled with pour-type polyurethane foam, and the ends were hermetically sealed with fiberglass caps. A thin coat of RTV silicone coating was applied to the sensors with laminar construction for an additional hermetic seal. Photos of the complete pipe section assembly, with heat-flow meters, adapter plates, and fiberglass end caps is shown in figure 3.2 .

The laboratory tests were conducted in an isothermal environment provided by the arrangement in figure 3.3. The temperature of the copper thermal shield is controlled to $\pm .01^{\circ} \mathrm{C}$ by water circulated from the temperature controlled bath. Additional stability is provided by the outer layer of perlite and styrofoam insulation.

\subsubsection{In-situ Calibration}

Most of the measurements were made with air in the annulus surrounding the pipe. Because the field tests were to be made with the pipe buried in sand, a few laboratory tests were also made with the annulus filled with sand. Somewhat to our surprise, we observed moderate shifts in the calibrations in going from air to sand.

The expected heat flux to a typical cryogenic enclosure was assumed to be that for the BNL-LILCO plan $3 B$ - about $28 \mu \mathrm{w} / \mathrm{cm}^{2}$. Accordingly the meters were tested at $9,18,28$, 53, 114, and $969 \mu \mathrm{W} / \mathrm{cm}^{2}$. After the pipe appeared to reach equilibrium at a given power level, measurements were continued for 4 to 8 days to obtain equilibrium data. The emf from each heat-flow meter is recorded daily during the equilibrium period and from these data points, the arithmetic means, the sample standard deviation, and the coefficient of variation are calculated. Table 3.2 shows data from a typical calibration test, and figure 3.4 is a plot of the coefficients of variation for the first eight calibration tests, with air surrounding the meters. The highest heat flux of $969 \mu$ watts $/ \mathrm{cm}^{2}$ has an extremely low coefficient of variation, and all the meters show a fairly consistent coefficient of 1 to $3 \%$.

The temperature dependence of the meter calibration was determined at a power level of $28 \mu \mathrm{W} / \mathrm{cm}^{2}$ and temperatures of 4,15 , and $26^{\circ} \mathrm{C}$--the temperature range anticipated during the field test. The results of these tests, which are given in table 3.3 , indicate a slight dependence, the sign of which varies with the meter type. A typical manufacturer's correction curve is given in figure 3.5. It indicates that the temperature correction factor is negligible for small deviations from the calibration temperature.

The results of the air and sand calibration are given in figures 3.6 through 3.9. In al1 cases the meter response is quite linear, but the zero bias is somewhat larger with sand. The difference between the air and sand calibration, summarized in table 3.4, is rather puzzling--both because it occurs at al1, and because it is in different directions for different meters.

Several factors could be responsible, such as meter construction, adapter plate design, and pressure or moisture sensitivity. Meters A and B, which exhibit a decrease in 


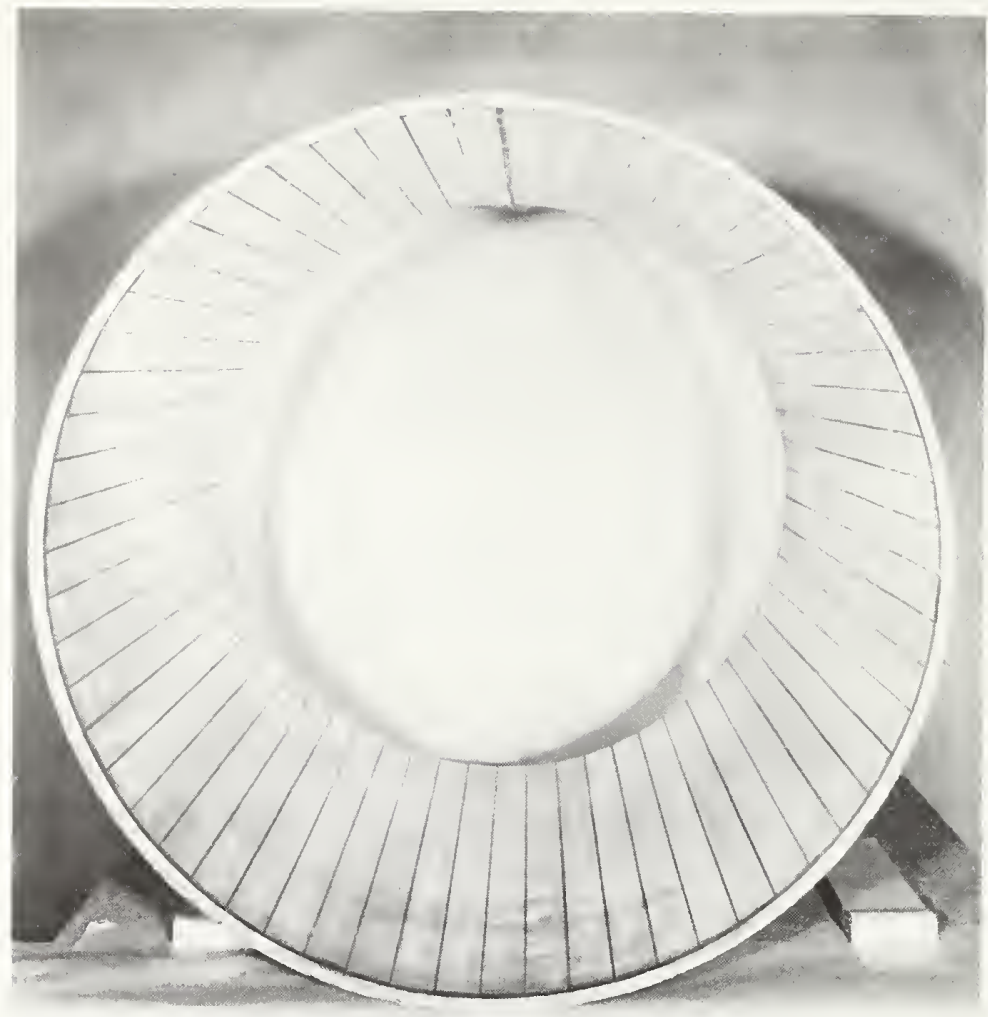

Figure 3.1--Heater mounted on inside of diameter of pipe.

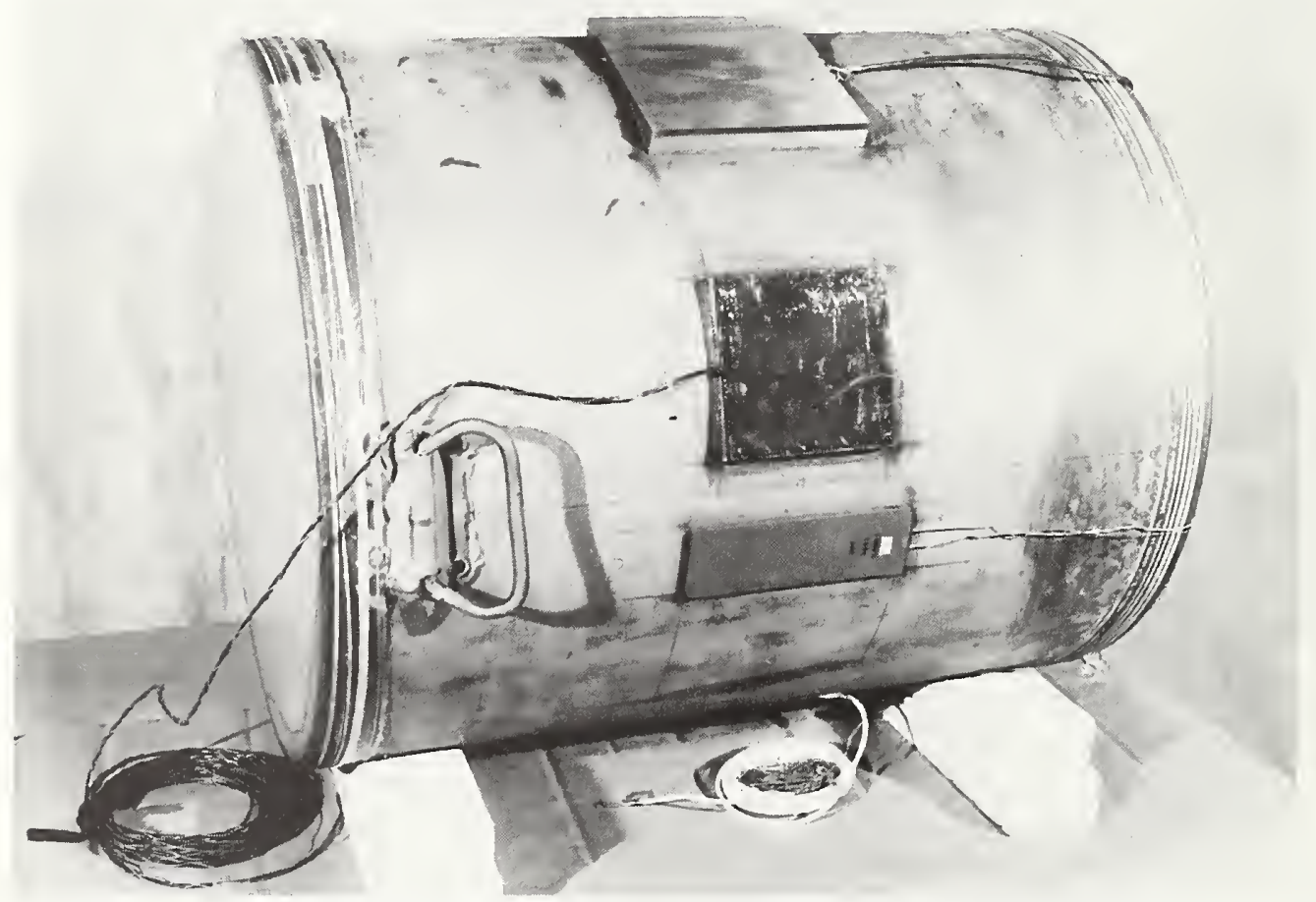

Figure 3.2--Heat flux mounted on pipe and ready for testing. 


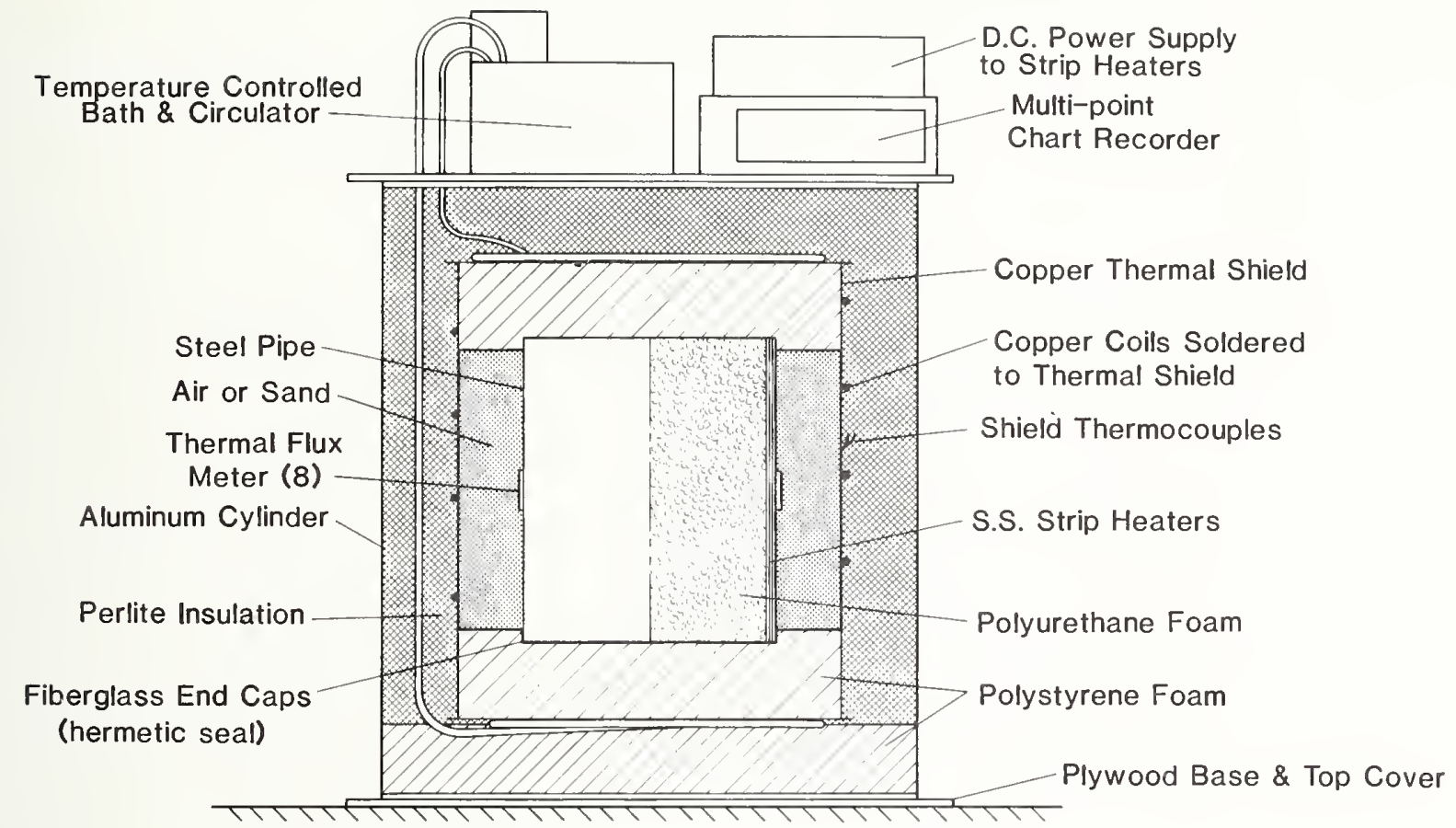

Figure 3.3 Heat sensor laboratory test apparatus.

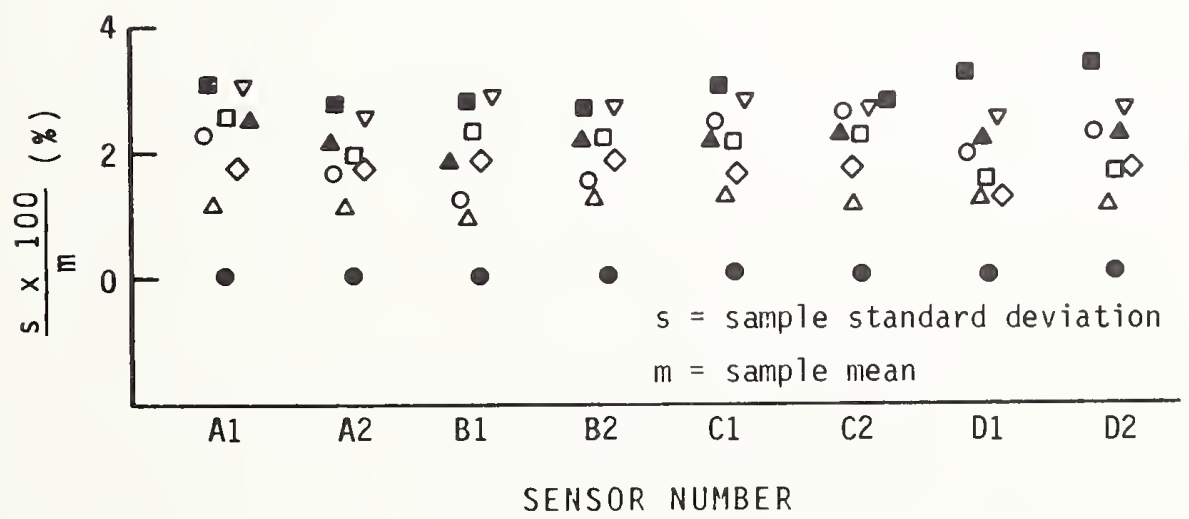

Figure 3.4 Coefficient of variation for laboratory evaluation of heat flux meters. Different symbols are for different heat fluxes. 
Table 3.2--Calibration Test No. 3

$$
\text { (Heat Flux }=28.5 \mu \text { Watts } / \mathrm{cm}^{2} \text { ) }
$$

\begin{tabular}{|c|c|c|c|c|c|c|c|c|c|c|c|c|c|c|c|}
\hline & & & & & & & & & & & & & \multicolumn{3}{|c|}{ Data $\rightarrow 24-168$ Hrs. } \\
\hline Date & $6-2$ & $6-3$ & $6-4$ & $6-4$ & $6-5$ & $6-5$ & $6-6$ & $6-6$ & $6-7$ & $6-7$ & $6-8$ & $6-9$ & & Standard & Coefficient \\
\hline Cumulative & $11 \mathrm{am}$ & $11 \mathrm{am}$ & $9 a m$ & $4 \mathrm{pm}$ & $8 a m$ & $5 \mathrm{pm}$ & $8 a m$ & $3 \mathrm{pm}$ & $9 a m$ & $4 \mathrm{pm}$ & $4 \mathrm{pm}$ & $11 \mathrm{am}$ & Mean & Deviation & of Variation \\
\hline Hours & 0 & 24 & 46 & 53 & 69 & 78 & 93 & 100 & 118 & 125 & 149 & 168 & $(\mathrm{~m})$ & (s) & $\frac{5 \times 100}{\mathrm{~m}}$ \\
\hline Sensor & & $\rightarrow$ & & & & Heat- & Flow Me & ter emf & $\left(\mu V_{0}\right) t$ & & & & $\mu$ volts & $\mu$ volts & \\
\hline$A-1$ & 176 & 96 & 96 & 95 & 101 & 96 & 100 & 98.5 & 100 & 100 & 101 & 102 & 98.68 & 2.49 & 2.52 \\
\hline$A-2$ & 183 & 101 & 101 & 100 & 106 & 100.5 & 104 & 103 & 104 & 103 & 104 & 105 & 102.86 & 1.98 & 1.92 \\
\hline B-1 & 550 & 306 & 307 & 301 & 319 & 304 & 314 & 312.5 & 320 & 317 & 321 & 320 & 312.86 & 7.25 & 2.32 \\
\hline$B-2$ & 555 & 308 & 309 & 303 & 322 & 304 & 317.5 & 314 & 320 & 316 & 321 & 320 & 314.05 & 6.95 & 2.21 \\
\hline$c-1$ & 487 & 272 & 275 & 270 & 282 & 270 & 277.5 & 277 & 280 & 277 & 282.5 & 277 & 276.36 & 4.32 & 1.56 \\
\hline$c-2$ & 539 & 301 & 303.5 & 300 & 314 & 300 & 309 & 307 & 310.5 & 309 & 314 & 309 & 307.0 & 5.18 & 1.69 \\
\hline D-1 & 491 & 270 & 270 & 266 & 281 & 266 & 277 & 274 & 279 & 274 & 281 & 281 & 274.45 & 5.82 & 2.12 \\
\hline$D-2$ & 538 & $\begin{aligned} & 295 \\
\rightarrow & \text { Equi }\end{aligned}$ & $\begin{array}{r}295.5 \\
\text { ibrium }\end{array}$ & 289 & 307 & 290 & 302 & 300 & 306 & 303 & 306 & 307 & 300.05 & 6.70 & 2.23 \\
\hline
\end{tabular}


Table 3.3--Meter Dependence on Operating Temperature

\begin{tabular}{|c|c|c|c|}
\hline \multicolumn{4}{|l|}{ Meter } \\
\hline Temperature & $4^{\circ} \mathrm{C}$ & $15^{\circ} \mathrm{C}$ & $26^{\circ} \mathrm{C}$ \\
\hline $\begin{array}{l}\text { Test No. } \\
\text { Heat Flux }\end{array}$ & $\frac{5}{28.8 \frac{\mu W a t t s}{\mathrm{~cm}^{2}}}$ & $\frac{3}{28,4} \frac{\mu \text { Watts }}{\mathrm{cm}^{2}}$ & $\frac{6}{28.4 \frac{\mu W a t t s}{\mathrm{~cm}^{2}}}$ \\
\hline Meter No. & & Meter emf $(\mu \mathrm{V})$ & \\
\hline$A-1$ & 97.17 & 98.68 & 101 \\
\hline$A-2$ & 102.47 & 102.86 & 103.6 \\
\hline$B-1$ & 311.41 & 312.86 & 314.13 \\
\hline$B-2$ & 313.69 & 314.05 & 313.75 \\
\hline$c-1$ & 283.36 & 276.36 & 268.7 \\
\hline$C-2$ & 313.67 & 307.00 & 298.25 \\
\hline $0-1$ & 278.23 & 274.45 & 270.5 \\
\hline$D-2$ & 302.79 & 300.05 & 297.0 \\
\hline
\end{tabular}

Table 3.4--Heat-Flow Meter Sensitivities

\begin{tabular}{|c|c|c|c|}
\hline Sensor & $\begin{array}{l}\text { Manufacturer's } \\
\text { Sensitivity }\end{array}$ & $\begin{array}{l}\text { In-Situ } \\
\text { (Air) }\end{array}$ & $\begin{array}{l}\text { In-Situ } \\
\text { (Sand) }\end{array}$ \\
\hline$A-1$ & $328.3 \frac{\mu W a t t s}{\mathrm{~cm}^{2}-\mathrm{mV}}$ & $323.5 \frac{\mu W a t t s}{\mathrm{~cm}^{2}-\mathrm{mV}}$ & $371.5 \frac{\mu W a t t s}{\mathrm{~cm}^{2}-\mathrm{mV}}$ \\
\hline$A-2$ & $287.3 \quad "$ & $307.7 \quad "$ & $361.7 \quad "$ \\
\hline$B-1$ & 131.5 & 98. & 105.2 \\
\hline$B-2$ & 137.3 & 100.4 & 110.8 \\
\hline$C-1$ & 117.6 & 111.5 & 108.5 \\
\hline$c-2$ & 108.9 & 99.6 & 79.8 \\
\hline$D-1$ & 167.3 & 112.8 & 99.8 \\
\hline$D-2$ & $154.8 \quad$ & $102.4 \quad$ & 92.8 \\
\hline
\end{tabular}




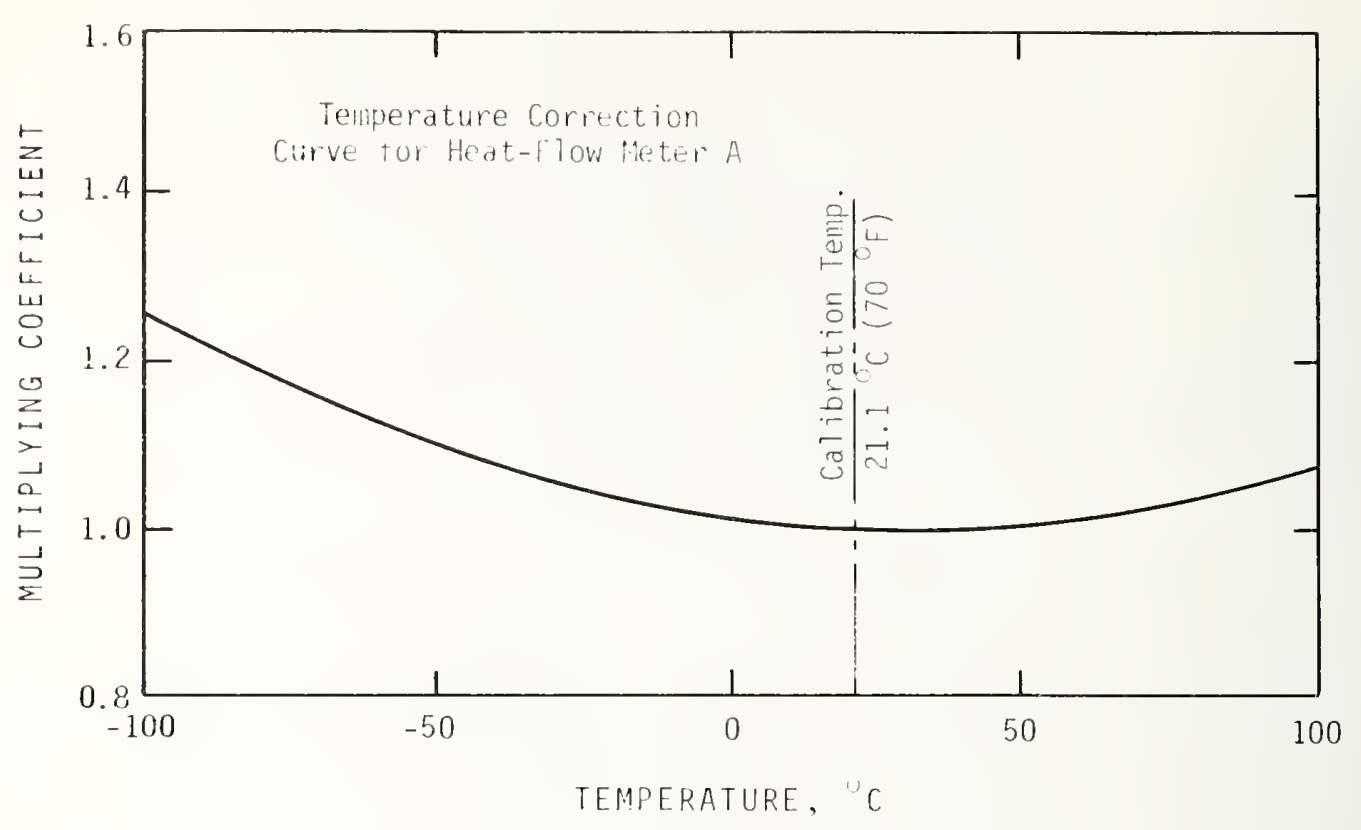

Figure 3.5 Typical heat flux meter temperature correction curve.

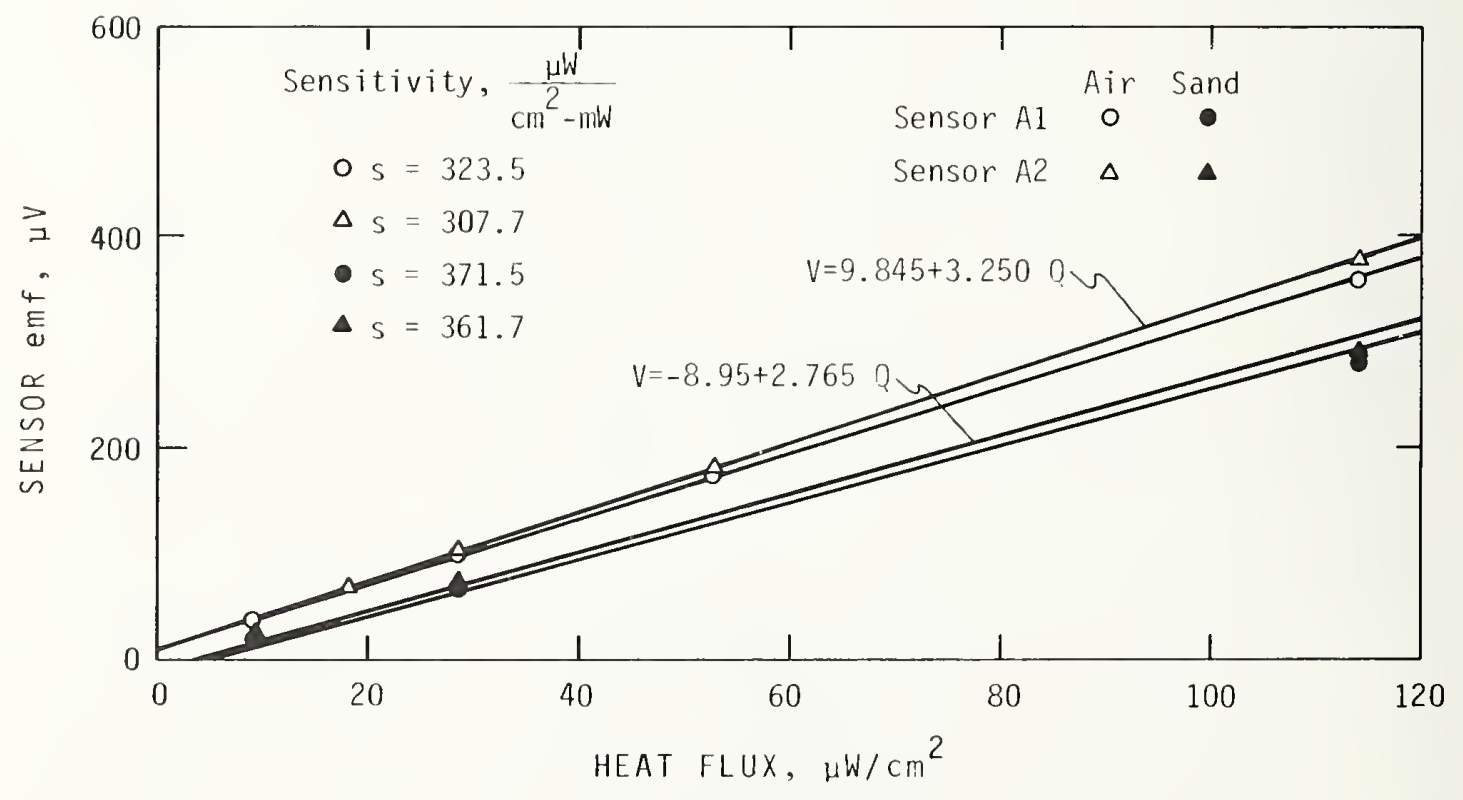

Figure 3.6 Calibration for sensors $A 1$ and $A 2$. 


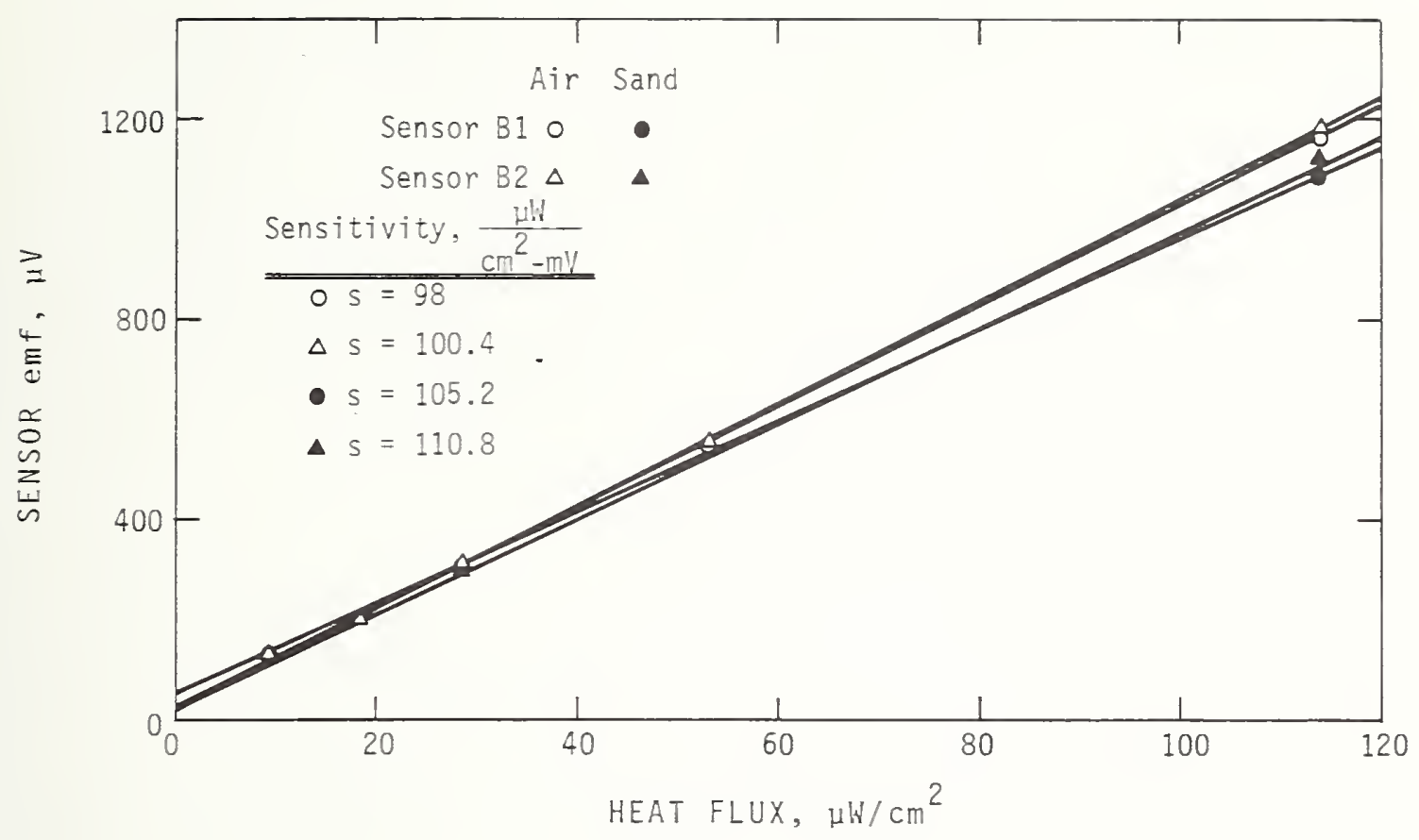

Figure 3.7 Calibration for sensors BI and 82 .

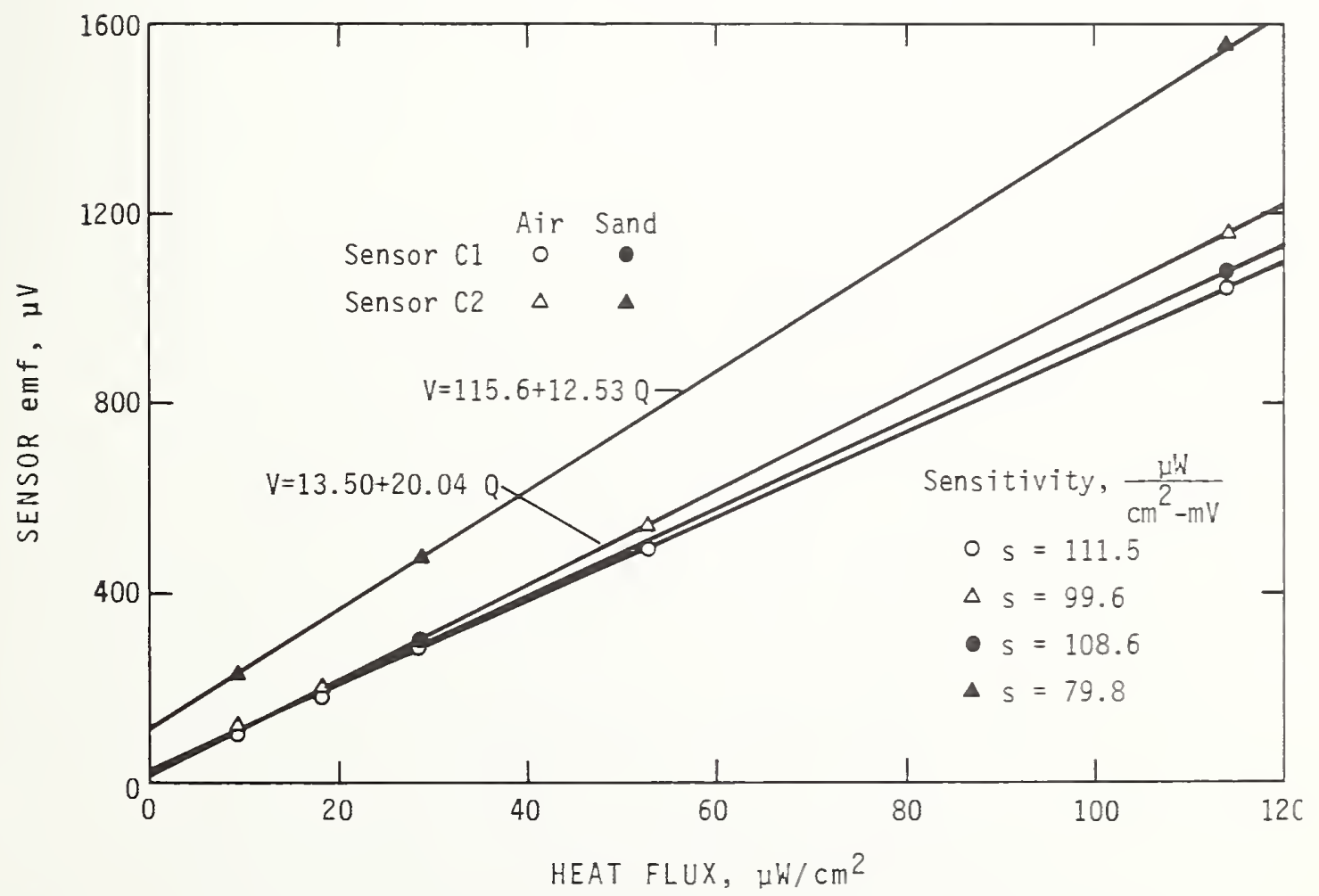

Figure 3.8 Calibration for sensors $\mathrm{C} 1$ and $\mathrm{C} 2$. 


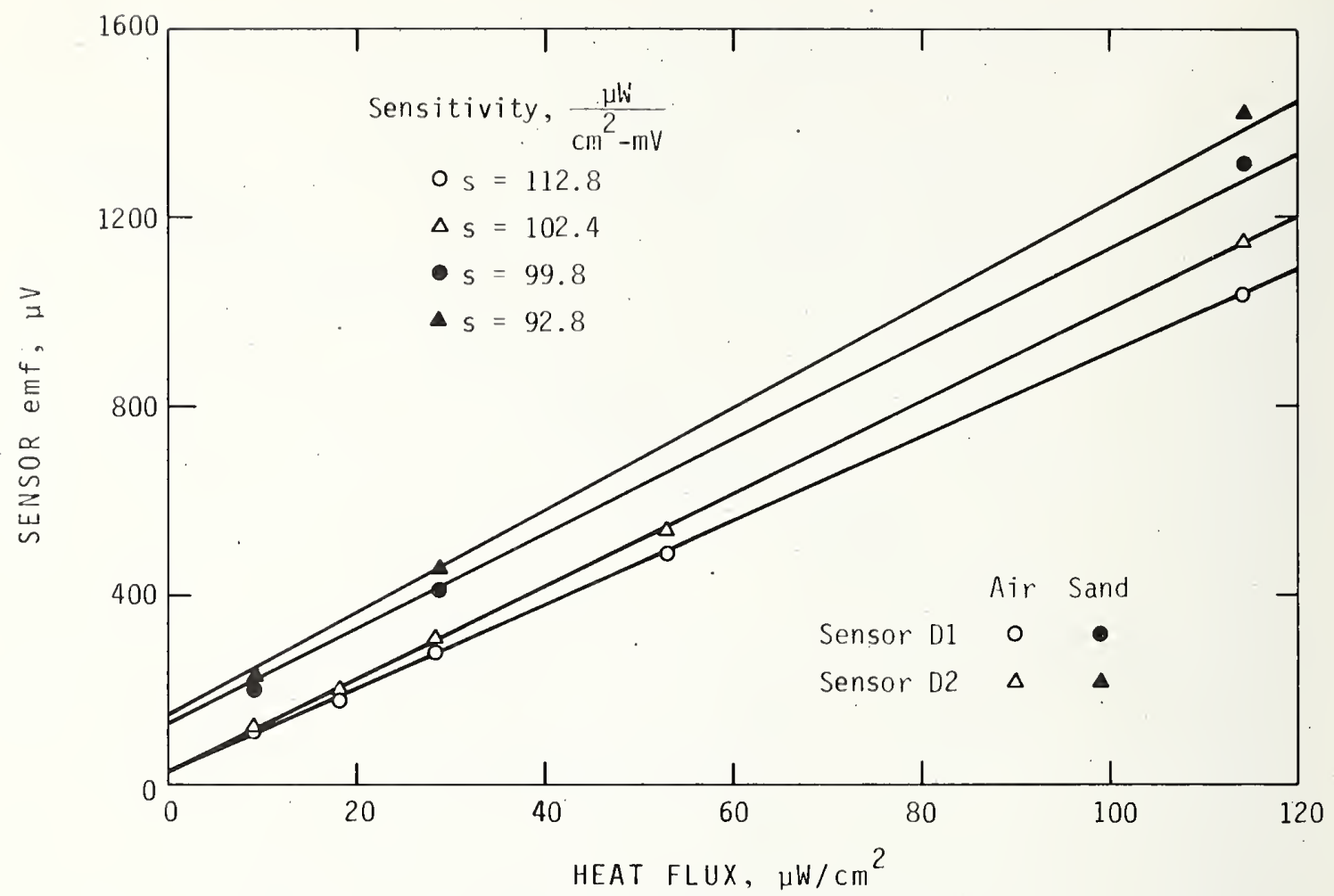

Figure 3.9 Calibration for sensors D1 and D2.

thermocouples

in sand

15 pair shielded

cable to lab recorder
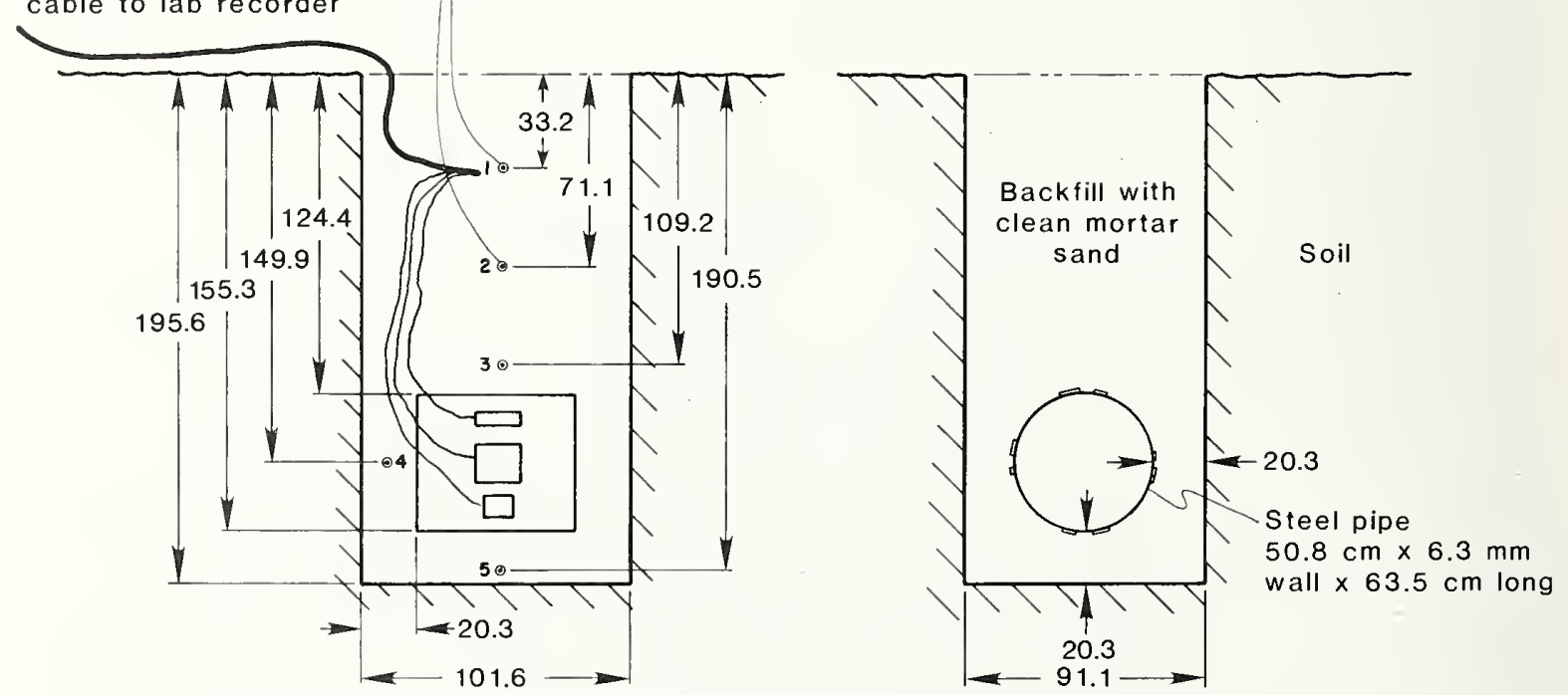

NOTE:

All dimensions in $\mathrm{cm}$.

Figure 3.10 Burial configuration for the pipe-meter assembly. 
sensitivity, are one piece cast plastic, whereas meters $C$ and $D$, which exhibit an increase in sensitivity, are of sandwich construction with metal plates for outer surfaces. Both $C$ and $D$ have solid-state sensor elements. Heat loss through the edges of the adaptor plates of meters $A, C$, and $D$ would cause a sensitivity shift only if the relative loss changes from air to sand.

In summary, there is no simple explanation for the calibration shifts observed, and it is beyond the scope of the program to investigate absolute calibration anomalies of the small sampling of meters tested. More importantly, we should note that the purpose of the laboratory tests. is to provide as-installed calibrations of the sensors for use in the field tests.

\subsubsection{Field Test}

The pipe assembly was buried 7 meters east of the laboratory to a center-1ine depth of 1.5 meters and backfilled with clean, dry mortar sand. As shown in figure 3.10, the pipe axis is horizontal with the sensors located adjacent to the vertical and horizontal axes. Type $E$ thermocouples in the sand back fill measure the thermal gradient of the earth near the pipe. Thirty meters of pair-shielded cable connect the thermocouples and sensors to the instrumentation in the laboratory. The heat-flow meter signals were wired directly into a multi-range, multi-point recorder, and the thermocouple signals were connected to a solid-state ice reference, and then to the multi-point recorder.

Backfilling of the pipe assembly was completed September 17, 1979, and data acquisition began September 17 . To provide a base for comparison, we have studied the zero heating case first. Thus, all the field test data given in this report are for zero power input to the electrical heater. Heat input is scheduled for January 1980.

Twenty-eight days after burial, heat sensor $D 2$ failed with the resistance increasing from 25 kilohms to several megohms.

The variation of the sensor signal with time is given in figures $3.11,3.12$, and 3.13 for zero heater input. The meters are wired such that outward radial heat flux produces a positive emf. The associated earth temperatures are given in figure 3.14 and the vertical temperature difference across the pipe (thermocouples 3 and 5 ) is given in figure 3.15 .

The results clearly demonstrate the effect of the seasonal (Fall) cooling of the earth's crust. The measured soil temperature gradient of $6 \mathrm{k} / \mathrm{m}$ is more than 100 times the geothermal gradient [1]. The soil heat flux, associated with this relatively high soil temperature gradient, is seen by the pipe mounted heat flux meters as illustrated in figure 3.11 through 3.13. This occurs because the thermal conductivity of the pipe wall is much greater (approximately 100 times) than that of the soil. Thus, the soil heat flux enters the bottom of the pipe, is conducted along the pipe wall, and exits the top.

The result of this situation is that a time varying heat flux, which is an order of magnitude greater than that which we wish to detect, is superimposed on the normal pipe heat flux. One way around this problem is to algebraically sum the response of one or more pairs of sensors mounted on opposite sides of the pipe. Since the earth heat flux passes through the opposed sensors in opposite radial directions, the effect is largely 


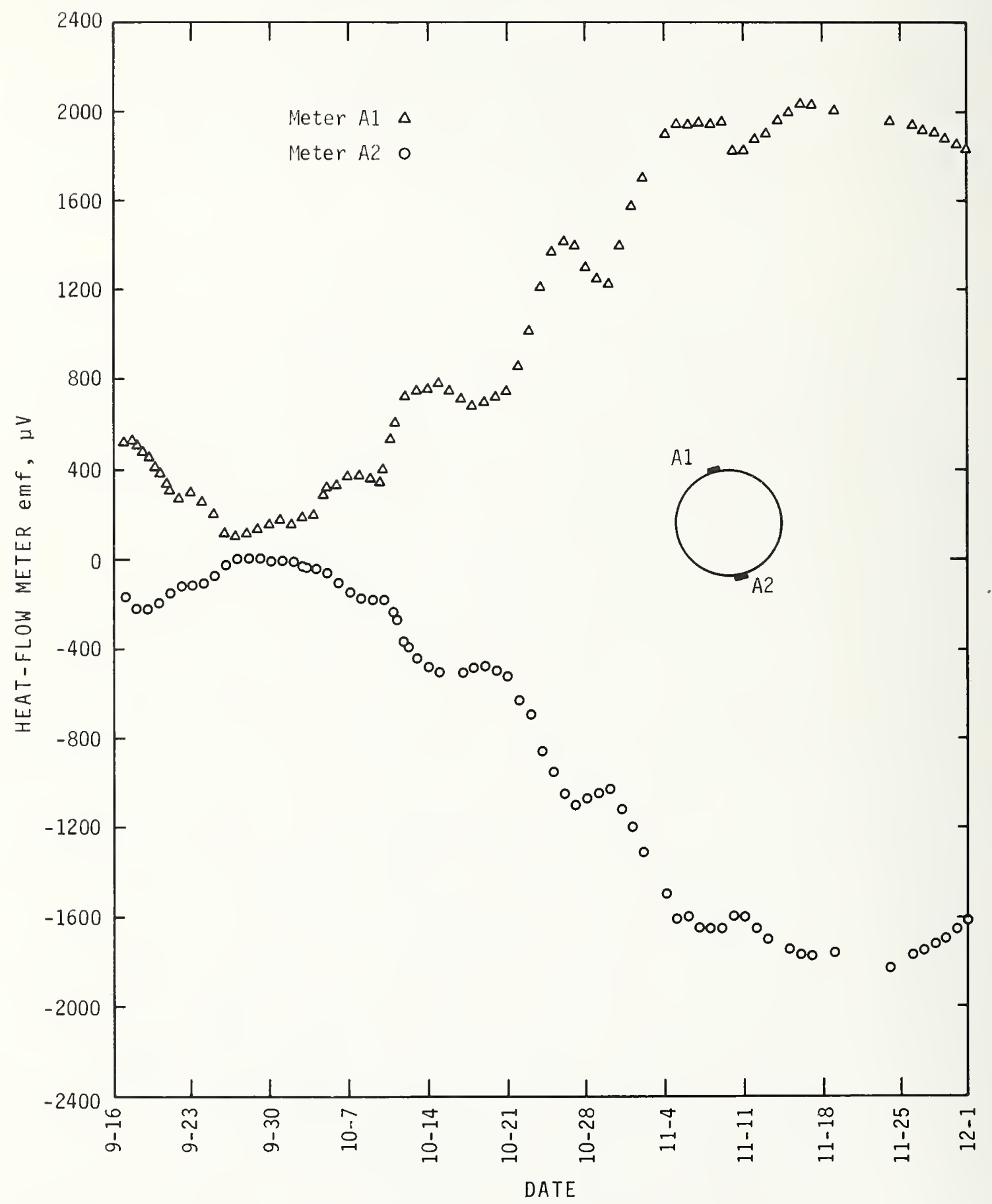

Figure 3.11 Field response of meters $A 1$ and $A 2$. 


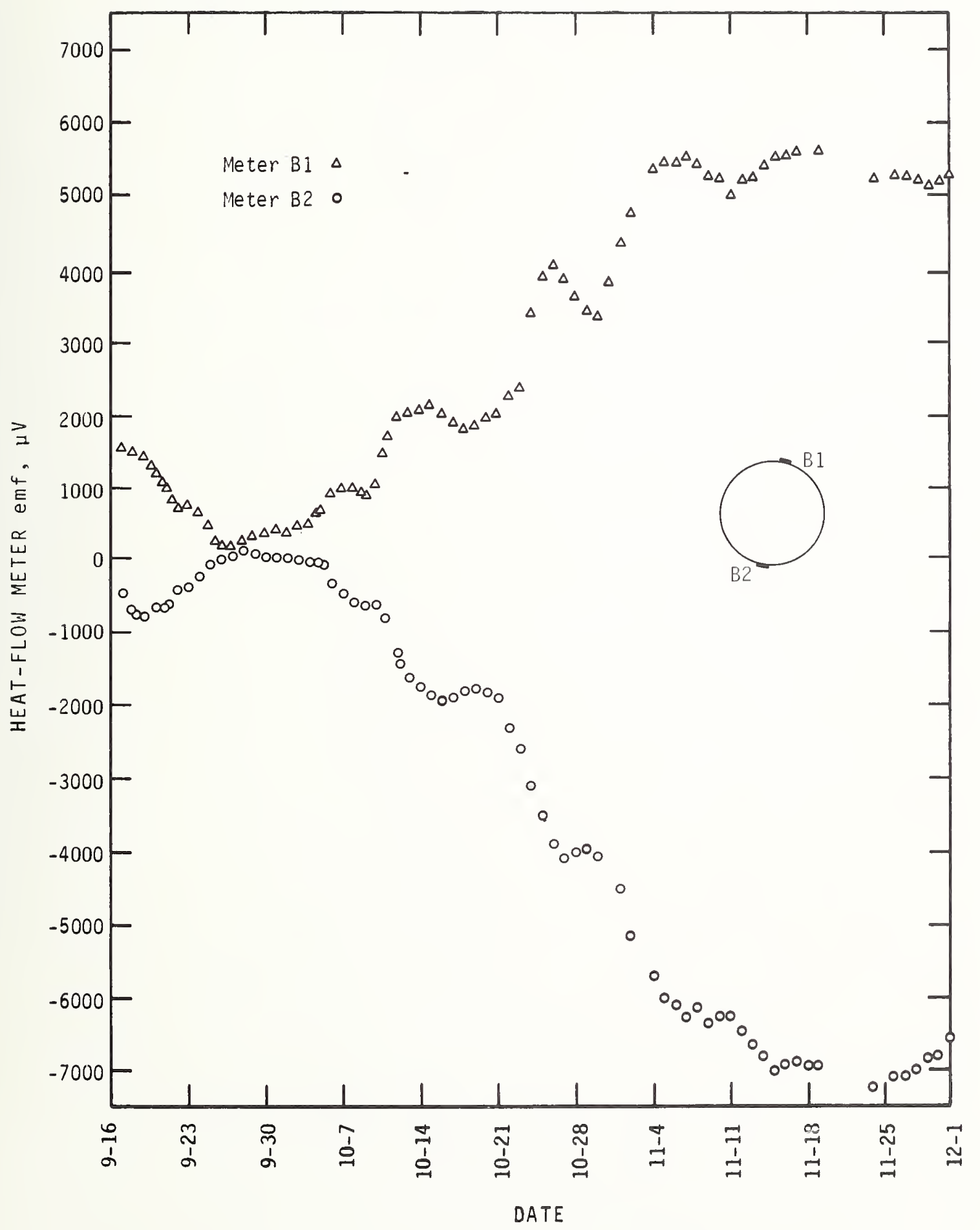

Figure 3.12 Field response of meters $B 1$ and $B 2$. 


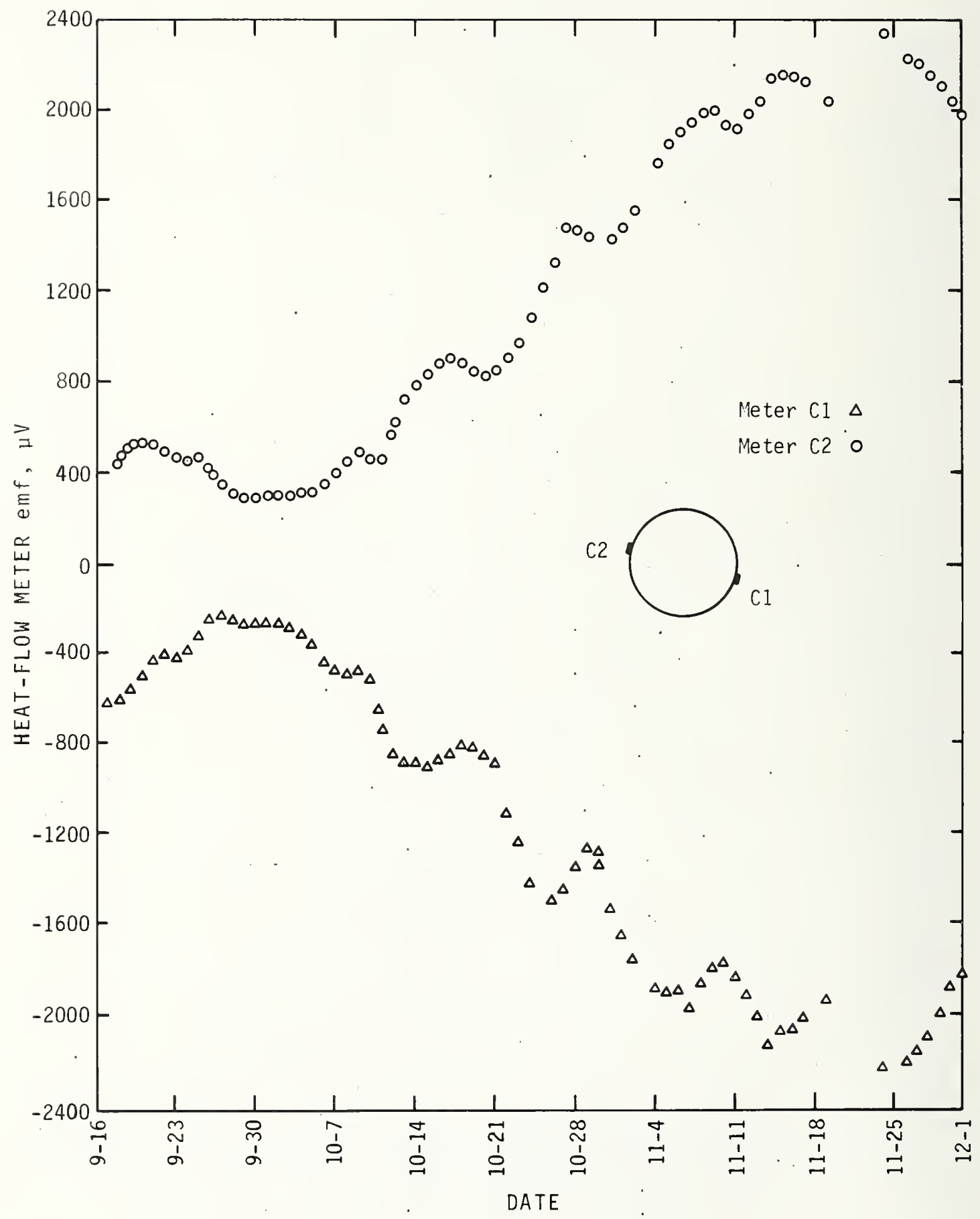

Figure 3.13 Field response of meters $\mathrm{C} 1$ and $\mathrm{C2}$. 


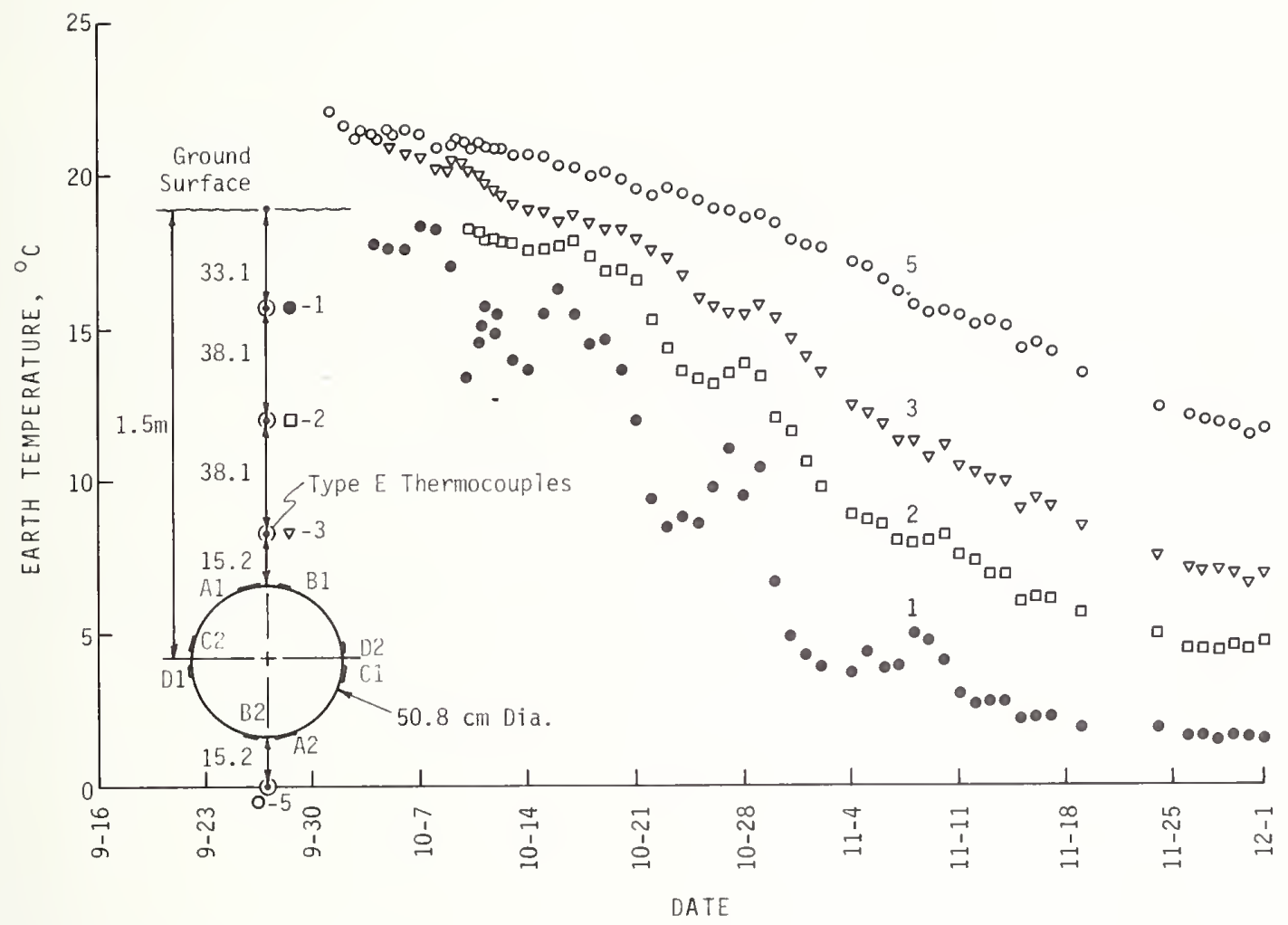

Figure 3.14 Soil temperatures during heat flux meter field evaluation.

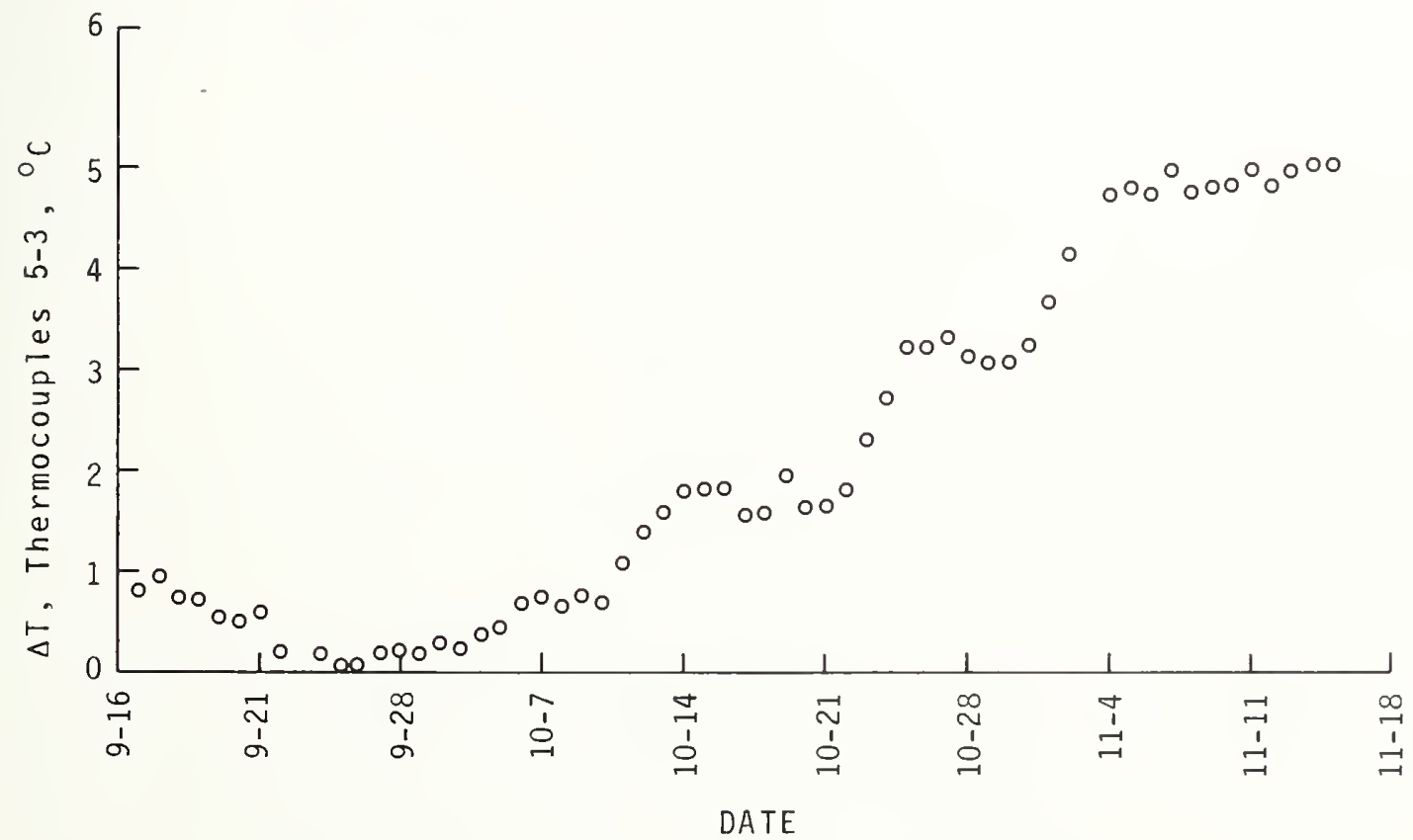

Figure 3.15 Vertical temperature difference across pipe during heat flux meter field evaluation. 
canceled. The preferred orientation for the sensors is on the horizontal axis, since the earth temperature gradients and heat fluxes are much lower in this direction.

Figure 3.16 shows the results of such signal addition for horizontal sensors $\mathrm{Cl}$ and C2. The variation of the sum of the signals is about 20 times less than the variation in the individual signals, and it now appears that we should be able to detect changes in heat flux of one or two times the nominal enclosure value.

[1] H. S. Carslaw and J. C. Jaeger, Conduction of Heat in Solids, Oxford University Press, London, 1959. 


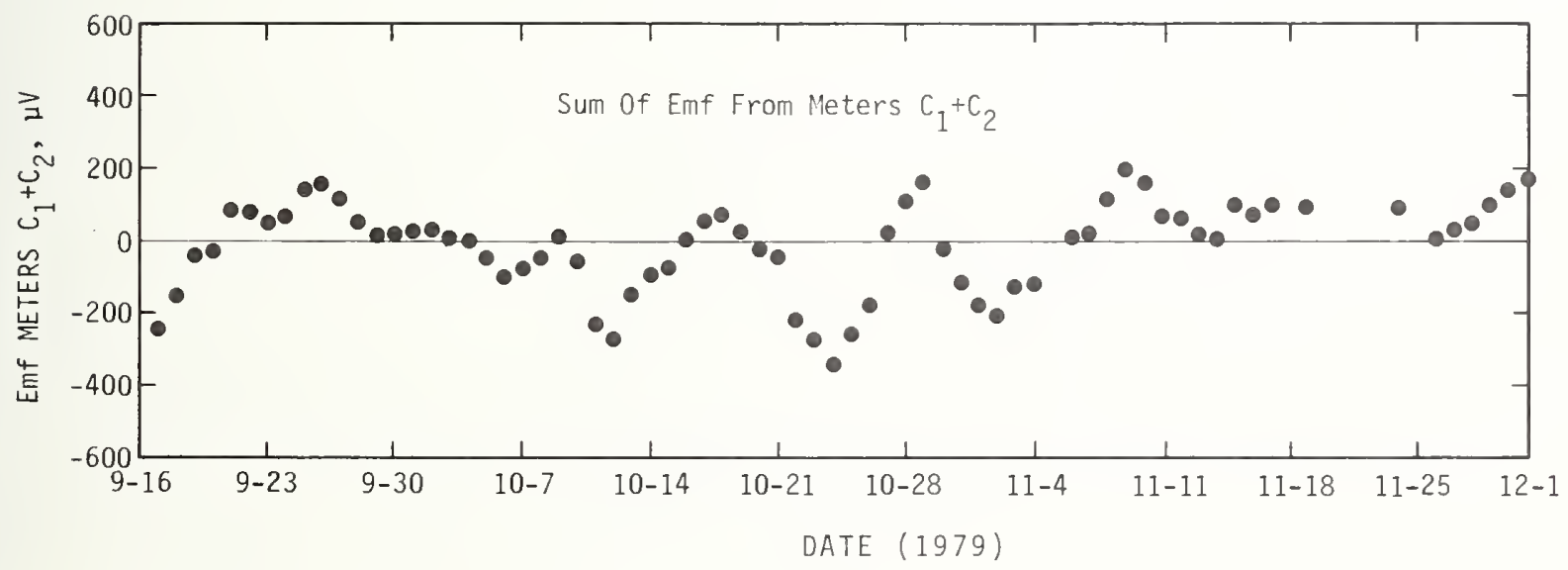

Figure 3.16 Effect of summing signals of horizontally opposed sensors. 
U.S. DEPT. OF COMM.

BIBLIOGRAPHIC DATA SHEET
1. PUBLICATION OR REPORT NO.

NBSIR 80-1637

4. TITLE AND SUBTITLE

Helium Research in Support of Superconducting Power Transmission

\begin{tabular}{c} 
Annual Report \\
(October 1978 - September 1979) \\
\hline
\end{tabular}

7. AUTHOR(S)

D. E. Daney, Editor

9. PERFORMING ORGANIZATION NAME AND ADDRESS

2.Gov't. Accession No. 3 . Feciptents Accession No.

5. Publication Date December 1980

6. Performing Organization Code

8. Performing Organ. Report No.

10. Project/Task/Work Unit No.

NATIONAL BUREAU OF STANDARDS

DEPARTMENT OF COMMERCE

WASHINGTON, DC 20234

11. Contract/Grant No.

433475-AGS

12. SPONSORING ORGANIZATION NAME AND COMPLETE ADDRESS (Street, City, State, ZIP)

Brookhaven National Laboratory

Power Transmission Project

Upton, NY 11973

13. Type of Report \& Period Covered

Annual, 10/78 - 9/79

14. Sponsoring Agency Code

15. SUPPLEMENTARY NOTES

Document describes a computer program; SF-185, FIPS Software Summary, is attached.

16. ABSTRACT (A 200-word or less factual summary of most significant information. If document includes a significant bibliography or literature survey, mention it here.)

During FY 79, the NBS Thermophysical Properties Division program of research for superconducting power transmission line (SPTL) development focused on three tasks:

1) Analytical, numerical, and experimental modeling of counter-flow SPTL cool-down.

2) Measurement of radial permeability of a SPTL cable to gas flow.

3) Experimental evaluation of thermal flux meters as a possible technique for determining enclosure heat leak.

We have completed the first phase of our investigation of SPTL cool-down in which the aim was to develop a fundamental understanding of the counter-flow method of cool-dowil. The excellent agreement of our analytical, numerical, and experimental results gives us confidence that we can accurately model the cool-down of full scale SPTL's.

The cable permeability measurements indicate that any significant rupture of the lead gas barrier of the cable will lead to an unacceptably high leak rate from the pressurized core.

During FY 80 we shall concentrate on developing cool-down strategies for full scale SPTL's using the detailed computer code previously developed at NBS. Field evaluation of thermal flux meters will also continue.

17. KEY WORDS (six to twelve entries; alphabetical order; capitalize only the first letter of the first key word unless a proper name;

cable cool-down, cable permeability, counter-flow cool-down, heat flux meters, liquid helium, permeability of composites, superconducting power transmission.

18. AVAILABILITY

For Official Distribution. Do Hot Release to NTIS

, Order From Sup. of Doc., U.S. Government Printing Office, Wasinington, DC 20402

XX] Unlimited

X Order From National Technical Information Service (NTIS), Springfield, VA. 22161

\begin{tabular}{|l|c|}
\hline $\begin{array}{l}\text { 19. SECURITY CLASS } \\
\text { (THIS REPORT) }\end{array}$ & $\begin{array}{c}\text { 21. NO. OF } \\
\text { PRINTED PAGES } \\
\text { UNCLASSIFIED }\end{array}$ \\
\hline $\begin{array}{l}\text { 20. SECURITY CLASS } \\
\text { (THIS PAGE) }\end{array}$ & 22. PIICE \\
UNCLASSIFIED & $\$ 7.00$ \\
\hline
\end{tabular}




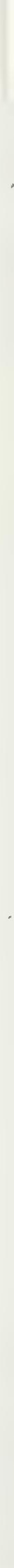




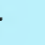


